\title{
UC-NRLF
}

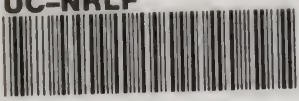

के 89950

$\frac{\infty}{a}$

5 


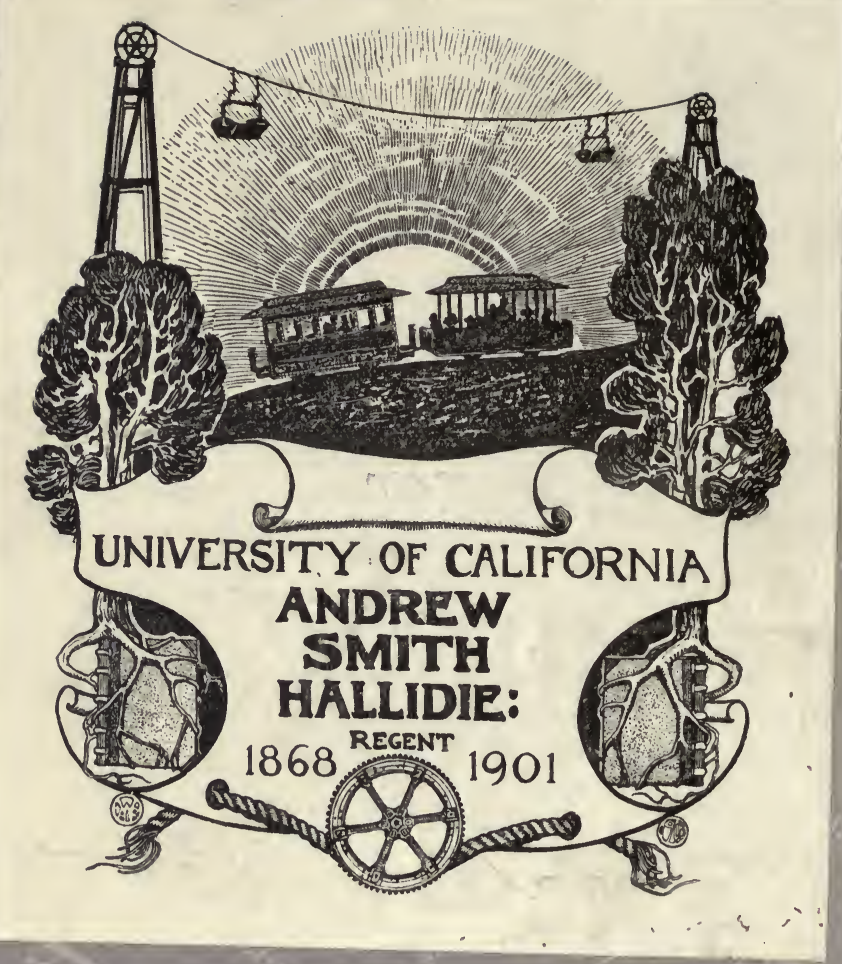




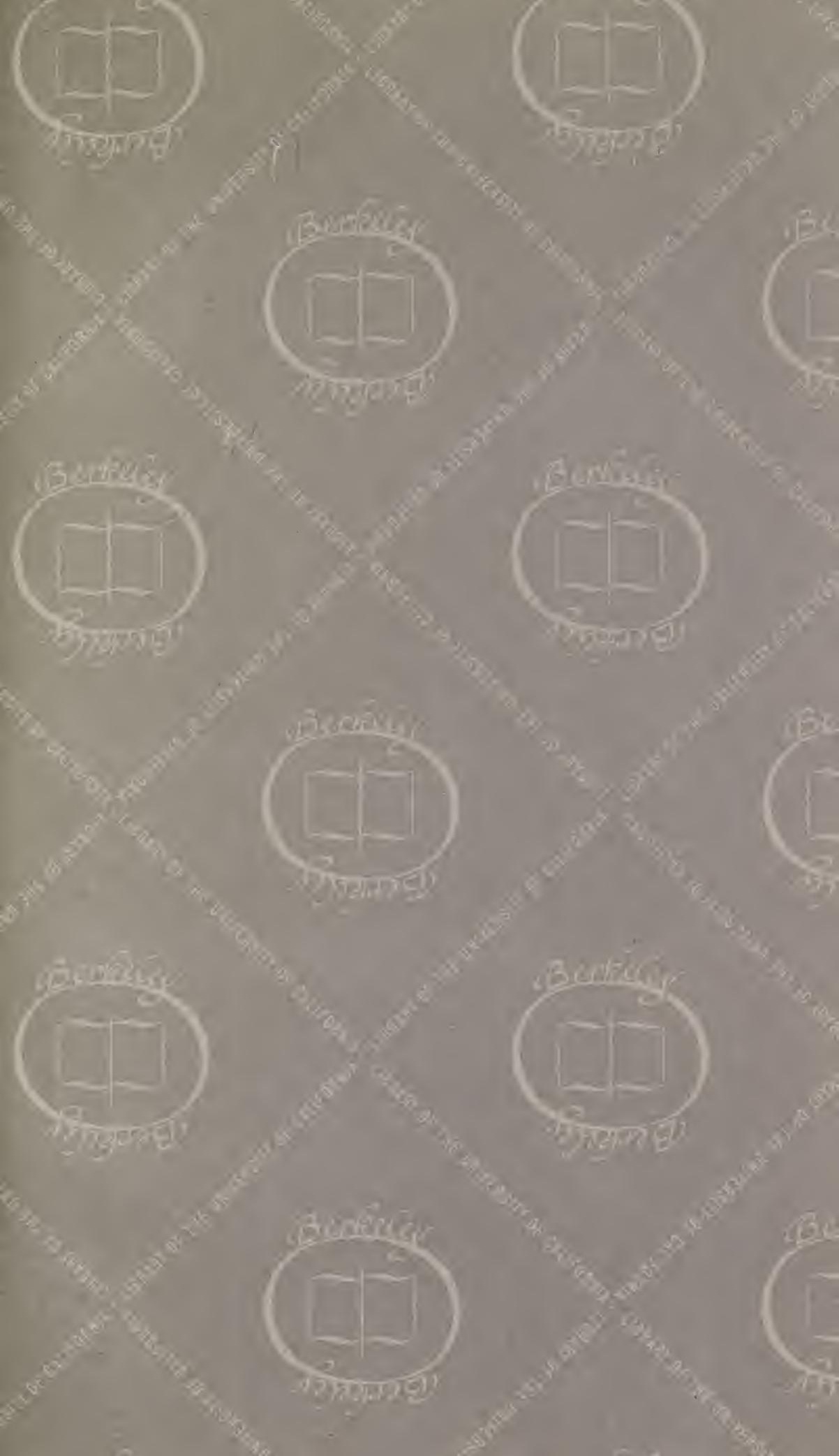




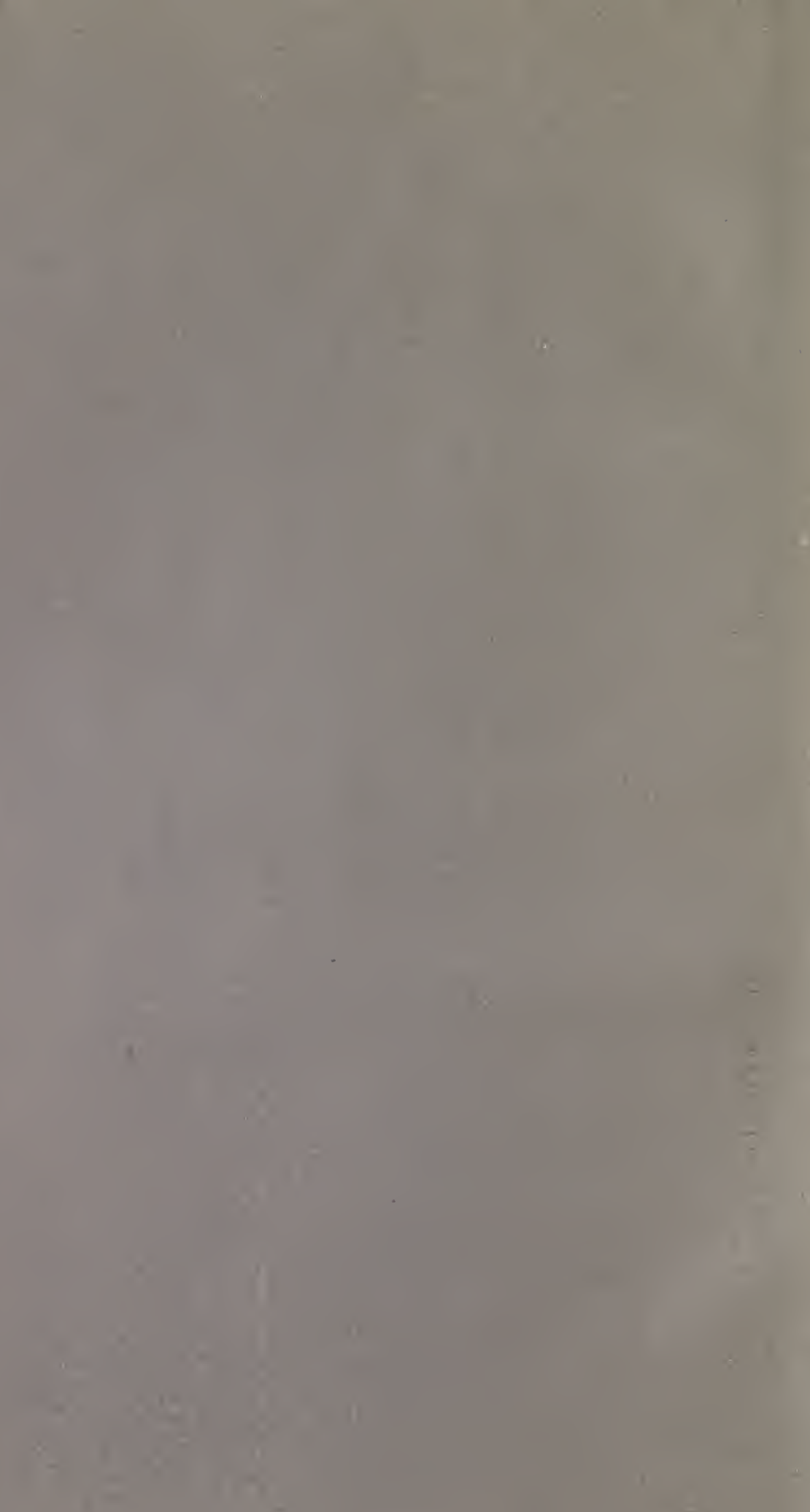




\title{
SCIENCE OF. AGRICULTURE :
}

\author{
COMPRISING
}

A COMMENTARY ON AND COMPARATIVE INVESTIGATION

\section{AGRICULTURAL CHEMISTRY}

\author{
OF THE
}

OF

MR. KIRWAN AंND SIR HUMPHRY DAVY;

THE

\section{CODE OF AGRICULTURE}

of

SIR JOHN SINCLAIR, SIR JOSEPH BANKS, AND OTHER AUTHORS ON THE SUBJECT.

SHEWING,

That there is not only a discrepance in the opinions of those Authors on many of the most important operations of Agriculture ; but that this arises from their inferencés and conclusions being erroneous; and their principles unfounded, or inapplicable; and particularly on the subject of breeding, and the nature, preparation, and application of manures. And also of the rust or black blight in wheat ; of which the true cause, and its preventive are here explained.

Dericated to the 3 ritiob lpublic.

By JOSEPH HAYWARD, AUTHOR OF THE SCIENCE OF HORTICULTURE.

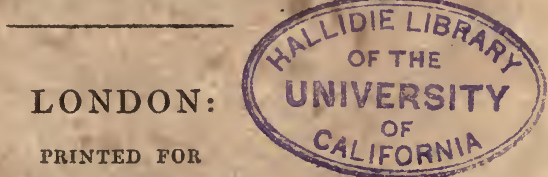

LONGMAN, HURST, REES, ORME, BROWN, AND GREEN, PATERNOSTER-ROW 


$$
\begin{array}{r}
5493 \\
H 4
\end{array}
$$
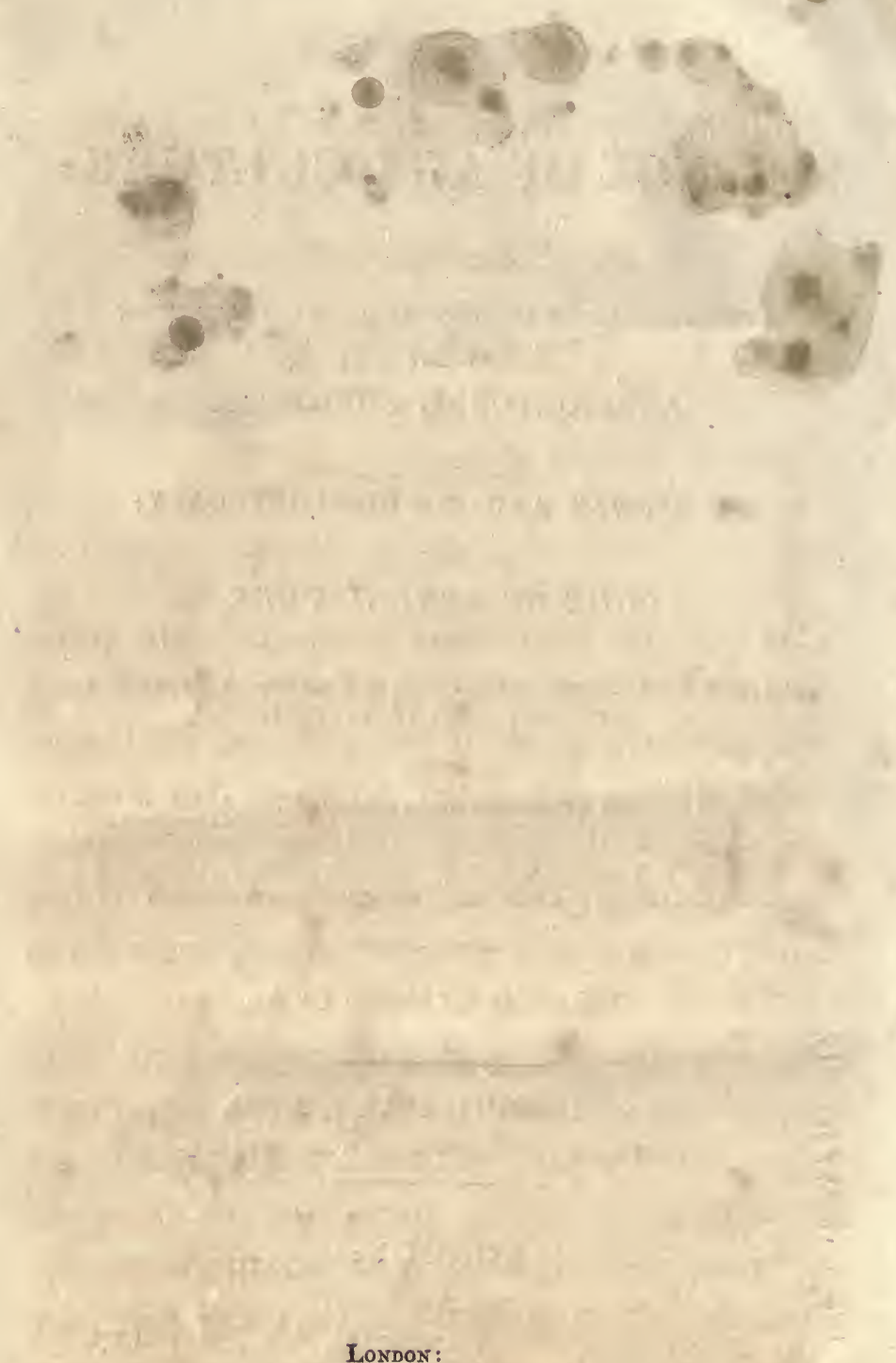

Printed by A. \& R. Spottiswoode, New-Strect-Square. 


\section{ADVERTISEMENT AND}

\section{DEDICATION.}

After the numerous books of late published on the subject of agriculture, and particularly those of Mr. Kirwan, Sir Humphry Davy, Sir John Sinclair, Sir Joseph Bankes, and others, another may appear superfluous; but all who have read those different authors with attention, must have been convinced that however elaborate their works, there is such a discrepancy in their opinions on some of the most important operations of agriculture, as to justify an attempt to bring them to the test of a just investigation and comparison, by tracing their principles in their progress from cause to effect. I am not a professor of chemistry, nor an extensive

A 2 
practical agriculturist, nor the member of any learned society: and as it is the fashion of the times to attach great importance to such authority, some may consider me arrogant, presumptuous, and invidious, in attempting to intrude on the public my commentaries on the works of such established characters : but I disclaim any other intention, than that of ascertaining and establishing just principles, and I cannot hope to induce any one to adopt my notions in preference to others, unless I prove theirs to be wrong. My ideas on the science of horticulture have long been before the public; and the critics remarked on that work, that I was more bold than politic: but what sort of policy must it be to deter an Englishman from appearing as the advocate of truth and science? If they mean that by my boldness in endeavouring to point out what I conceived to be the errors of others, and to rectify that which I had proved to be bad in practice, I lost the patronage of the Horticultural Society of London, they may be correct ; for this, as a 
body, I cértainly could not obtain, although previous to the publication of that work, I privately submitted the same to some of the first public characters, and particularly to Sir Humphry Davy, and to the president and council of the Horticultural Society. Sir Humphry very politely received and acknowledged the perusal of my papers, and with great liberality stated his admission, that to that part of my work which related to the objects of his peculiar study, he found no objection; at the same time excusing himself from giving an opinion on the practical part, by observing, he did not consider himself possessed of sufficient practical knowledge to give it importance; and expressed his intention to commend me to the president of the Horticultural Society: I dedicated my book to the president and society, and repeatedly applied to them for their opinion, and invited them to an investigation of my demonstrations, but which they uniformly refused! Nearly six years have now elapsed, and I have never seen any comment of his or theirs on it: however, 
the public having done me the honour to have purchased the first edition, and good part of the second, assures me it cannot now be suppressed; and whether the improvements I had established, were or were not received and treated as they deserved, time will show. Every man has a right to confide in his own understanding, and if his conscience does not accuse him of having presumed to violate truth, or pluming himself on his fancied powers, to have imposed false and untried theories on the ignorant and credulous, he need not fear others. Fortune may enable pride and arrogance to smother truth and science for a time, but in a land of liberty these must ultimately establish themselves, however humble their immediate patrons. Although the Horticultural Society of London have refused to acknowledge the merit of my arrangement and explanation of scientific principles, they must ultimately adopt them, or be left far in the back ground, and their garden exhibit a glaring instance of a want of candour and liberality in the directors. 
Repeated observation and demonstrative experiments have convinced me, that although Sir Humphry Davy's analysis, and expositions of chemical principles, are correct and clear, in his application of them to agricultural practice, and in his inferences, he is greatly mistaken.

That although Sir John Sinclair, is copious and minute in his description of agricultural operations and practical results, his opinions and deductions are erroneous and inconclusive.

That Sir Joseph Bankes, in his opinion and description of the rust or black blight in wheat, has mistaken the effect for the cause, and thus misled the public in their endeavours to find a remedy.

That Mr. Knight's opinions and expositions, as quoted by Sir John Sinclair and Sir Humphry Davy, are hypothetical and fallacious.

That Bakewell's principles and practice in breeding, condemned by Sir John Sinclair, and neglected by the generality of agriculturists, are founded on true scientific 
principles, and are the most correct and beneficial that can be followed.

That the practice of Jethro Tull and Mr. Curwen is grounded on just scientific principles; although these are not recognised, or not explained by them.

That the methods in general practice, of preparing and applying manure, are erroneous and imperfect.

That by the common mode of making hay, much unnecessary risk and expense are incurred, and the saccharine and nutritive principles lessened and dissipated.

That every county in England may make as good cider as Hereford, Devon, or Somerset; and the apple trees may be trained so as never to be subjected to the injuries of being overloaded with fruit or snow, and without incurring additional expense.

And that the defects I have described: being removed, and the remedies and practices I have explained adopted; 'much' increase, and more certainty in the produce of the land, may be obtained. 
Then, under such convictions, ought I to fear being censured as obtrusive and presuming, in thus offering myself to the public? I know, among the practical agriculturists, it is a prevailing opinion, that no good arises from attending to theorists. To these I will beg leave to observe, that however repeatedly they may have been misled by theory, they cannot be justified in opposing or neglecting science; for whilst ignorant of this, they are mere imitators, and can never be masters of their business. And surely, the nobility and gentry, will not consider a correct knowledge of the relation of effects to their causes, as it regards objects which are not only essential to their happiness, but to their existence, to be beneath their notice?

I trust the British public will not consider me unworthy their attention, because I have no great man, or body of men, to patronise my work. At any rate, when they consider the result of my having opposed the theories of a great man in my former work, they will, perhaps, excuse 
X ADVERTISEMENT AND DEDICATION.

me, in thus wishing to avoid mortification, and of relying upon their candour and liberality, by dedicating this work to them, of whom I have the honour to be one,

And their very faithful,

$$
\text { and humble servant, }
$$

THE AUTHOR. 


\section{O N T E N T S.}

Page

Advertisement and Dedication - _ - - iii

Introduction - - - - $_{-}+-_{-} 1$

General View of the Subject - - - - 5

On Breeding or Raising Vegetables - - $\quad$ - 9

On Breeding and Rearing Animals - - - 21

On Cultivating the Earth - _ _ _ - 61

Arrangement of Chemical Principles - - - 71

On the Roots of Plants - _ - _ _ - 77

On the Use and Office of the Leaves - - - 82

On the Food of Plants - $\quad$ - $\quad$ - $\quad$ - 98

On the Rust or Black Blight in Wheat - - 156

On Fallowing Land and Paring and Burning - 169

On the Composition of Soils and the Agency

of the Earths, \&c. - - - - _ - 189

On the Nature and Application of Lime - - 195

On Haymaking - - - - - - - - 208

On Orchards and Cider - _ _ _ _ - 212 


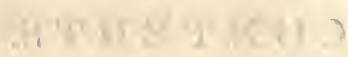

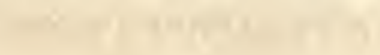

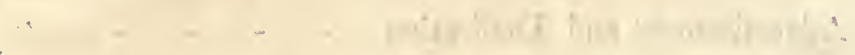

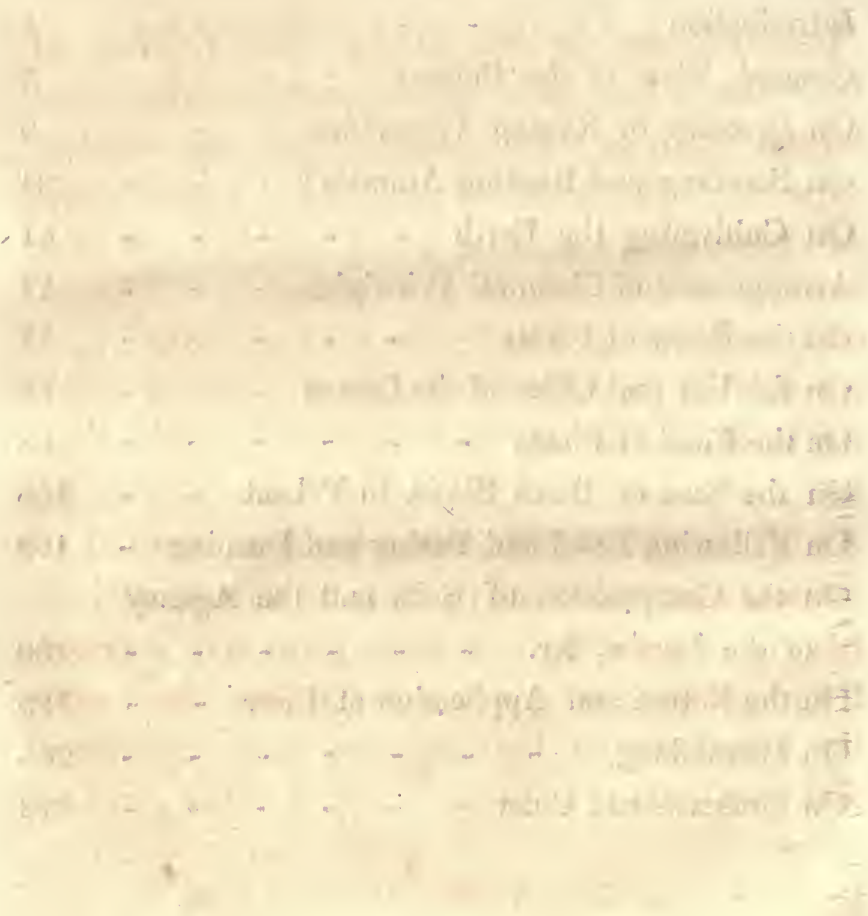




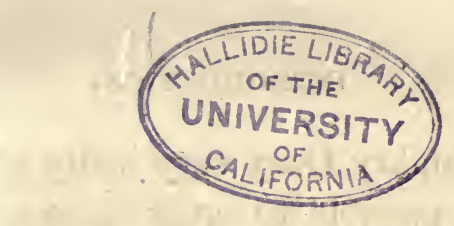

INTRODUCTION.

Agriculture is defined by Mr. Kirwan to be "the art of making the earth produce the largest crops of useful vegetables at the smallest expense;" but this conveys only a contracted and partial idea of that which must be comprehended in the science of husbandry. Vegetables, and animals which feed on vegetables; constitute that produce of the earth which is essential to the existence, and requisite to the comforts, of mankind. The art of husbandry is, no doubt, simple, if it be considered as limited to manual operations only; but the science of husbandry or agriculture is more properly, a knowledge of the laws of nature which determine the existence of both animals and vegetables, and particularly of those, which influence and govern them in their sexual intercourse and propagation, and also in their feeding, lodging, \&c. 
Sir Humphry Davy very justly observes, “ It is scarcely possible to enter upon any investigation in agriculture without finding it connected, more or less, with doctrines or elucidations derived from chemistry." And a chemical examination, shows, that the earth is but little concerned in vegetation, otherwise than as a medium or vehicle, bed or couch, in and on which, the most important operations of nature are conducted and performed.

We are commonly led to consider vegetables as the chief produce of the earth; but vegetables and animals are so completely dependent upon each other, that before we can affect in any degree the produce of the one, we must comprehend the influence they have each on the other. From a great similarity to themselves in nature, mankind were very early enabled to form a clear comprehension of the general functions of animals, in regard to their food, and as they are influenced by climate; also, of the difference in the sexes, and the natural result of their intercourse: but it was not understood until a much later period, that the general functions of vegetables are in every respect similar to those of animals, and that the operations of nature regarding both, are regulated by much the same laws; this, however, is now clearly demonstrated. 
As some portions of the earth, in the production of animals and vegetables, conduce more to the supplying the wants of mankind than others, so are some species of animals and vegetables more productive and eligible than others, and not only one species more so than another, but some varieties of the same species are more valuable than others; therefore it must be obvious, that as well as enquiring into the general nature and various qualities of the earth, we must also enquire into and ascertain, the qualities of those varieties of animals and vegetables which are the most conducive to our wants, and what causes produce those varieties, or diminish or increase their peculiar qualities. But as the qualities which give value to the different varieties of animals and vegetables must depend on peculiar circumstances, it can be of little use in a work like this, to attempt a particular description of these : and although it is obvious, that the physiology of both animals and vegetables form the fundamental principles of the science of husbandry, it does not follow that it must also comprehend a knowledge of the comparative anatomy of either animals or vegetables ; this is of trifling consequence to the husbandman. I shall therefore interfere very little with the departments of zoology or botany.

B 2 


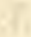

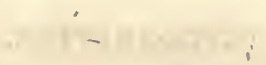

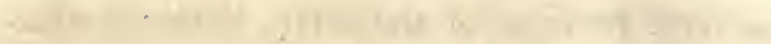

h. $-1+1$

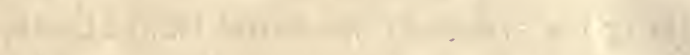

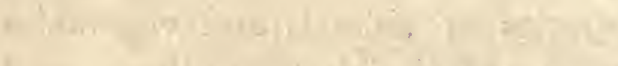

I

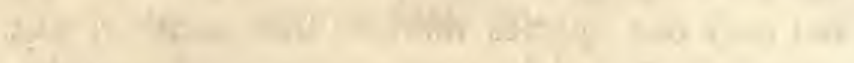

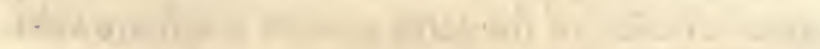

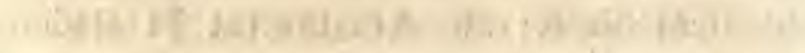

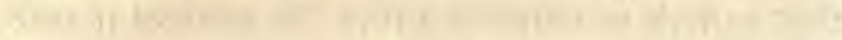

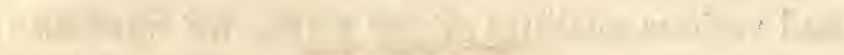

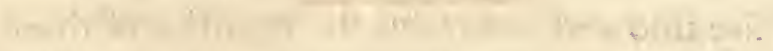

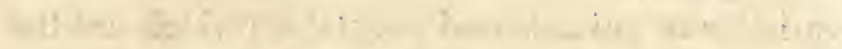

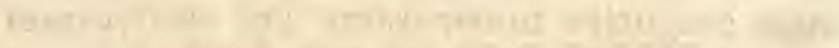

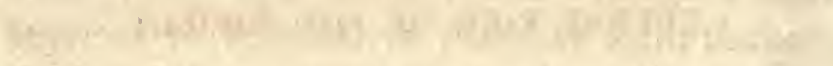

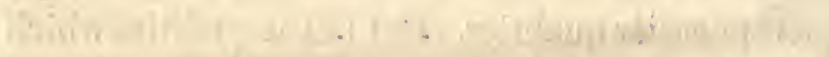

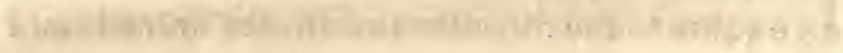

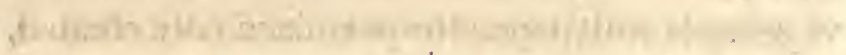
Whath

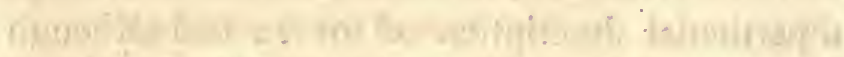

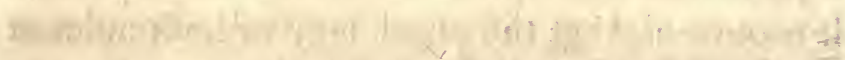

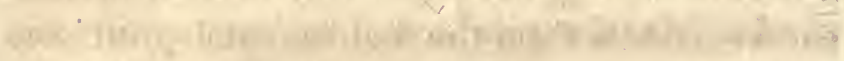

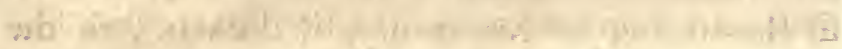

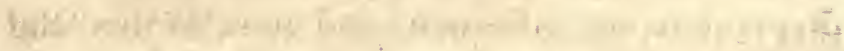

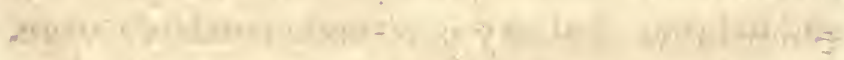

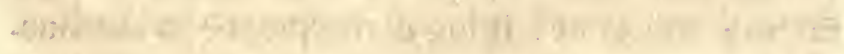

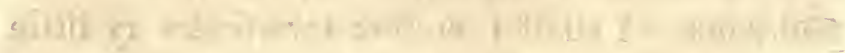
- Dy,

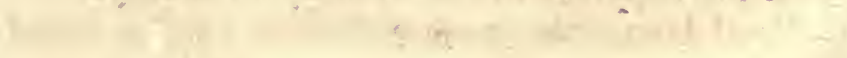


THE

\section{SCIENCE OF AGRICULTURE.}

GENERAL VIEW OF THE SUBJECT.

$I_{T}$ appears that a difference in the species only of animals and vegetables was originally created, and that the different varieties were left to be determined by the casual or accidental combinations and operations of original principles or causes. In the production of variety in animals and vegetables, no doubt climate has the preponderating influence, and next to this food and lodging; but in the general course of nature, these three grand principles operate in unison, and when all concur in one effect, the greatest distinctions are produced.

Food being the most effective and essential cause of variety in the value of animals, this has 
commanded more attention than the operation of climate and lodging in respect to animals: and climate and lodging being the more immediate, effective, and obvious cause of the variety and value of vegetables, these have commanded more attention than food in respect to vegetables. But to avail ourselves of the full advantage allowed by nature, food, climate, and lodging, both as they affect the one and the other, must be clearly understood and equally attended to.

The general progress of nature is uniform; and in the continuation of her works, as if to avoid the disorderly effect of an extreme indulgence, or the capricious negligence of individuals, the sexes were created, and it was ordained that a junction of the two should be necessary for the production of one individual; and that in their offspring, the habits and propensities of both male and female should be blended.

And further to protect her creatures from casual injury arising from a change of food, lodging, and climate, the habits of both arimals and vegetables are made subservient to such changes: thus, the continuation of a superabundance of food produces an increase in size, and a deficiency of food a decrease; a cold and a hot climate, and a wet and a dry lodging, each produces a coat or covering for the body, and a tempera- 
ment of constitution best adapted to counteract extremes : these things, therefore, form most important objects of consideration.

Animals and vegetables administer to the wants of mankind in various ways; some by their flesh, or the immediate substance of their bodies; others by their offspring and seed, or the food provided by nature for their offspring; others, again, by their exterior covering, and others by assisting man in his labour, and contributing to his pleasures : therefore, in breeding and feeding both animals and vegetables, due regard must be paid to the peculiar object desired. And as nature ever determines the end to the means, the attention of the agriculturists must be directed to the adapting their means to the end in view.

Nature is ever kind and liberal in providing for the necessities of her creatures ; and being always inclined to make an exuberant return in her productions, for extra aid, she thus gives to

- mankind an opportunity to avail themselves of such propensities: by removing obstructions, and favouring and protecting the general operations of nature, and supplying the deficiency of any needful support, they may increase their means of subsistence and enjoyment.

But although mankind are thus blessed by an allbountiful Providence, their power is prescribed, B 4 
and they are not permitted to act in opposition to the laws of nature. with impunity; whenever, therefore, they presume to interfere with the operations of nature, with a view to produce any beneficial or certain effect, they must pay all due deference to her laws; all attempts to produce sudden and abrupt changes, and wide extremes, must be avoided : by assisting nature certain objects may be obtained, but attempts to force or oppose her, generally produce disorder, and often destruction.

These preliminary observations naturally lead to the three following grand divisions of the subject :-viz.

The breeding and raising of vegetables;

The breeding and rearing of animals ;

And, as connected with both these, - The cultivation of the earth, or the producing and preparing food and lodging for both.

In this order I shall proceed to consider and arrange my observations. 
ON BREEDING AND RAISING VEGETABLES.

The nature of the sexual intercourse, in the propagation of animals, may be considered as too well understood to need a minute explanation; but of the necessity of the sexual intercourse, in the propagation of vegetables, many are still ignorant. I may therefore, perhaps, be excused for intruding some observations on this part of the subject, and for giving extracts from preceding authors.

It may be but of trifling importance, who was the first that discovered, the existence of a difference in the sexes in vegetables; but as Bradley, in a work on the improvement of planting and gardening, published in 1730, seems to have been one of the first English authors who wrote on the subject, and as his description is clear and simple, I shall give it in his own language.

He says, "I hope to be excused, if in the "explanation of this wonderful mystery of the "generation of plants, I shall be found to intro" duce such kind of plants as are not to be found " in forests; and to make some of my experi"ments in the orchard and kitchen-garden. 


\section{ON BREEDING AND RAISING VEGETABLES.}

"Moses tells us, in his account of the creation, " that plants have their seeds within themselves; " that is, every plant contains in itself, male and "female powers. The text he has given us, "seemed to be explained by this discovery, and "may lead us to consider, that plants wanting "local motion, require therefore this union of "sexes in themselves; by which means they "may generate without the neighbourhood of " other plants. But before I proceed to explain " this new system, I think myself obliged to de"clare, that the first time this secret was com" municated to me, was several years ago, by a "worthy member of the Royal Society; Robert "Yates, Esq., who has had this notion for above "thirty years, that plants had a mode of ge" nerating somewhat analogous to that of ani" mals. The light which I received from this "gentleman was afterwards further explained by " another learned member of that society, Mr. "Samuel Moreland, who in the Philosophical " Transactions, 1703, has given us to understand "how the dust of the apices of male flowers is " conveyed into the uterus, or vasculum semi" nale of a plant; by which means the seeds "therein contained are impregnated. I then " made it my business to search after this truth, " and have had the good fortune enough to bring " it to demonstration by several experiments. 
"But to come to the point: the lily being a "flower more generally known than any other, " and the generative parts being large and ex"posed, I shall from thence endeavour to explain "the method which nature makes use of, to " impregnate the seeds of that and every other "plant; and by which means the several species " of vegetables have been continued to the "world.

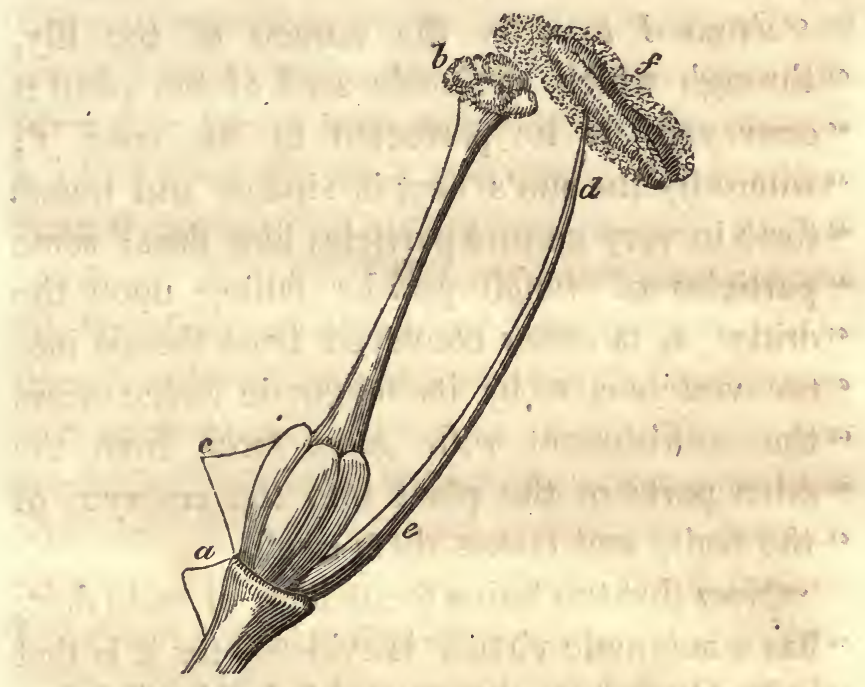

"The flower of the lily has six leaves or petals, " which are set upon the summit of the foot-stalk, " marked $a$ in the figure; they serve to guard " the parts of generation from the injury of " the weather, and as they are no other use, " that I know of, so it is not necessary that I 
"should place them in the figure. $b$ is the " mouth of the pistilium, or passage, which leads " to the uterus $c$, in which are these ovaries " filled with little eggs, or the rudiments of seeds, "such as we find in the ovaria of animals : but " these eggs will decay and come to nothing, " unless they are impregnated by the farina fe"cundans, or male seed of the same plant, or " one of the same sort.

"From $d$ to $e$ is the stamen of the lily, "through which the male seed of the plant is "conveyed, to be perfected in the apex $f$; "where by the sun's heat it ripens, and bursts " forth in very minute particles like dust; some "particles of which powder falling upon the " orifice $b$, is either conveyed from thence into " the vesicle $c$, or by its magnetic virtue draws " the nourishment with great force from the " other parts of the plant into the embryos of " the fruit, and makes them swell.

"Now that the farina fecundans, or male dust, " has a magnetic virtue, is evident, for it is that " only which bees gather and lodge in the cavi" ties of their hind legs to make their wax with; ". and it is well known, that wax when it is warm "will attract to it any light body."

Whatever may be thought of magnetic power, the wise providence of nature is here wonder- 
fully displayed, by guarding in a different and more certain manner against casual obstruction, as well as the inability of a plant to bring together the necessary parts formed for the propagation of its species. Every flower is furnished with a receptacle, called the nectarium, wherein is secreted, an odoriferous and very sweet liquid, which attracts, and serves for the food of bees, and other insects; and these vessels are always placed below the apices and the pistilium, so that the insects in their endeavours to obtain their nectar, must pass over, and between, the apices, and also the pistilium; and the farina or dust sticking about them, is thus conveyed to the mouth of the pistilium, and the process of impregnation performed; without this assistance, there are some plants which could scarcely ever be brought together, or impregnated : for instance, the cucumber and the melon, and all others of this tribe of plants, which have distinct male and female blossoms, when growing in situations where the wind has no power to disperse the farina.

As an elucidation of this, I may mention the progress and result of the following experiment: being desirous to obtain seed from a peculiar head of broccoli, and well aware that the intercourse of bees would occasion the seed to be 


\section{ON BREEDING AND RAISING VEGETABLES.}

different to the mother plant, I surrounded the sides of the plant with a frame of gauze, sufficiently open to admit a free change of air, and placed a hand glass on the top, and the consequence was, not a single seed was formed; observing the failure, I removed the covering, and gave free access to the bees, \&c., when a few remaining blossoms immediately fructified, and produced full pods of seed.

Bradley proceeds, "But again, if the parti" cles of this powder should be required by na" ture to pass into the ovaries of the plant, and " even into the several eggs or seeds there " contained, we may easily perceive, if we split " the pistilium of a flower, that nature has pro" vided a sufficient passage for it into the "uterus.

" In the first figure I have given a design of " one stamen, with its apex, to prevent mistakes " in my explanation; but the flower of every lily " has six of the same figure and use, which are "placed round about the pistilium or female " parts, so that it is almost impossible it should " escape from receiving some of the male dust, "or farina fecundans, falling upon it.

"In this and other flowers of the same nature, " the pistilium is always so placed that the apices "which surround it are equal in height with it, 
ON BREEDING AND RAISING VEGETABLES. 15

" or above it, so that their dust naturally falls " upon it; and when we observe it to be longer " than the apices, we may then conjecture that "the fruit has begun to form itself, and has no "longer occasion of the male dust. And it is " likewise observable, that as soon as the work " of generation is performed, the male parts, " together with the leaves or covering, fall off, " and the pipe leading to the uterus begins to " shrink. We may further remark, that the top "6. of the pistilium of every flower is either co" vered with a sort of velvet tunick, or emits a " gummy liquor, the better to catch the dust of " the apices.

"And now, as we find in the description I " have given of the lily, that the uterus is within " the flower, so, on the other hand, the uterus " of the rose is without the flower, at the bottom " of the petals or flower-leaves. And likewise " in fruit-trees, the cherries, plums, and some "others, have their utricles within their flowers ; " and the gooseberry, currant, apples, and pears, " on the outside or bottom of their flowers.

"But further, although nature has designed " the dust of the apices to fecundate the female " parts, contained in the flowers of plants, yet "we observe, that in some plants the male and "female parts are remote from each other; as, 


\section{ON BREEDING AND RAISING VEGETABLES.}

" for example, the gourd, pompion, melon, cu" cumber, and all of that race, have blossoms " distinctly male and female upon the same " plant : the male blossoms may be distinguished "from the others, in that they have not any " pistil or rudiment of fruit about them, but " have only a large thrum, covered with dust, " in their middle; the female blossom of these " has a pistilium within the petals or flower" leaves, and the rudiment of their fruit always " apparent at the bottom of the flower before " it opens. 'And so in like manner all nut-bear" ing and mast-bearing trees have their catkins, " or male blossoms, remote from the female " parts.

" The oak, for example, which blossoms in "May, has its male parts distant from the " acorns. We find little strings of farinaceous "flowers in great abundance, remote from the " rudiments of the acorns or fruit.

"When we view with a good microscope the " male dust of one small plant, we find every "particle of it to be of the same size and figure. "But in some cases it is of two colours, as in " the tulip, where it is yellow and blue.

"I shall proceed to demonstrate part of this " system. I made my first experiment upon the "tulip; which I chose rather than any other 
"plant, because it seldom misses to produce " seed. Several years ago I had the conveni" ency of a large garden, wherein there was a " large bed of tulips; in one part, containing " above 400 roots; in another part of it, very " remote from the former, were twelve tulips in " perfect health. At the first opening of the " twelve, which I was very careful to observe, "I cautiously took out of them all their apices, " before the farina fecundans was ripe, or any " ways appeared. These tulips, being thus cas" trated, bore no seed that summer; while, on " the other hand, every one of the 400 plants " which I had let alone produced seed.

"By this knowledge we may, perhaps, alter $\alpha$ " the property and taste of any fruit, by impreg" nating the one with the farina of another of " the same class: as, for example, a codlin with " a pearmain, which will occasion the codlin so "impregnated to last a longer time than usual, " and be of a sharper taste; or if the winter " fruits should be fecundated with the dust of " the summer kinds, they will decay before their "usual time. And it is from this accidental "coupling of the farina one with the other, that " in an orchard, where there is variety of apples, " even the fruit gathered from the same tree " differ in their flavour and times of ripening; 
" and, moreover, the seeds of those apples so " generated being changed by that means from " their natural qualities, will produce different " kinds of fruits if they are sown. It is from " the accidental coupling that proceeds the " numberless varieties of fruit and flowers which " are raised every day from seed."

The latter part of these observations, no doubt, are correct; but in his supposition, that the coupling of the farina changes the flavour or the general qualities of the immediate fruit, this author is mistaken, as it produces no such effect. The change takes place in the seed alone, and, therefore, can only be discoverable in the next generation. By this accidental coupling, there can be no doubt, but that variety in every species, is principally produced; and by taking advantage of this, and directing, and partially diverting, the usual course of nature, changes in the habits, and general properties of vegetables, and their fruits, may be produced, as well as in animals. By admixing the farina of the blossoms, and planting the seeds, varieties of potatoes are obtained; but no variety can be obtained by planting the potatoes themselves, either by varying the soil or mode of culture. And the same may be said of apples, and other fruits ; for let trees be propagated in whatever numbers, by 
engrafting or budding, and on whatever stocks, or by whatever means, it will create no variety in the fruit.

It thus appears, that mankind possess the same influence over the sexual intercourse of vegetables, as over that of animals ; and, consequently, they have it as much in their power, to raise and establish peculiar varieties in the one, as in the other, and upon the same principles, viz. that of selecting and pairing the males and females. And if it be desired to exert this influence, the process may be easily conducted, in the following manner:-a blossom being selected for a female, which has in itself the male and female organs, as soon as the bud is advanced to the state of being on the point to open or blow, the petals or flower-leaves must be opened, and the apices or anthers taken off; the blossom may then be left a day or two, until the petals have expanded themselves, and the pistilium be advanced to a state fit for impregnation; then, a blossom being selected for a male, when in full bloom, it must be taken off the parent plant, and its apices, or anthers, gently rubbed over the point, or end, of the pistilium of the prepared female blossom, so that the farina, or dust, may attach itself to it; after this, the female must be defended against the intrusion 
20 ON BREEDING OR RAISING VEGETABLES.

of bees, or such like insects, or placed out of the danger of being otherwise promiscuously impregnated. It is by a close attention to these laws of nature, that so many valuable varieties of pulse, grain, fruit, roots, and esculent vegetables, have of late been raised and obtained. It must also be observed, that by frequently propagating from seeds, carefully selected from those plants, which possess the most desirable qualities, - even though there be no intended crossing or mixing of farina to produce variety, - the most valuable habits of any species, may be improved and increased; and particularly by their being naturalised, and enabled to adapt themselves to flourish, in any peculiar soil or climate. 
ON BREEDING AND REARING ANIMALS.

Although the difference in the sexes, appears to be more strongly marked in animals, than in veget:bles; the laws of nature, as they regard the result of their connection, are much the same in both.

On the subject of breeding, Sir John Sinclair says, "The art of improved breeding consists in " making a careful selection of males and fe" males, for the purpose of breeding stock " with fewer defects, and with greater perfec" tions, than their parents, in which their mu" tual properties shall be continued, and their "6 mutual faults corrected.

"The objects of improved breeding, therefore. " are to obviate defects, and to acquire and per" petuate desirable properties; hence, when a " race of animals have possessed in a great de"gree, through several generations, the proper" ties which it is our object to obtain, their " progeny are said to be well bred, and their "stock may be relied on."

"It was upon this principle of selection that "Bakewell formed his celebrated stock of sheep, 
" having spared no pains or expense in obtain" ing the choicest individuals, from all the best " kinds of long or combing woolled sheep, " wherever they were met with: and it cannot " be doubted, that any breed may be improved in " the same manner; namely, that of putting the " best males to the finest females. After a su" perior breed, however, has been thus obtained, " it is a point that has been much disputed, " whether it is proper to raise stock; 1st, from " the same family; or, $2 \mathrm{~d}$, from the same " race, but of different families; or, $3 \mathrm{~d}$, from " races entirely different." .

This explanation of Sir John Sinclair, without doubt, is clear enough; but as he found the subject much disputed, so he seems to have left it, at any rate, but resting on very indeterminate grounds; for although he gives an ample detail of the observations, and practical results, of many of the most eminent men, on both sides the question, his own conclusions are by no means demonstrated, but calculated to confuse and mislead; for he further says, "On breeding "from the same family - this method is called, ." breeding in and in, or putting animals of the " nearest relationship together: though this "plan was for some time in fashion, under the "sanction of Bakewell's authority, yet experi- 
ON BREEDING AND REARING ANIMALS. 23

" ence has now proved, that it cannot be suc. " cessfully persevered in."

This conclusion, in a general sense, cannot be admitted, but we may, indeed, admit, that there are bounds, beyond which we cannot force nature, for having reached the point of perfection, there we must stop; we cannot proceed farther.

Sir John should also have stated, what appears to have been the fact, that Bakewell, not only selected the finest males and females, but he spared neither pains nor expense, in furnishing and adapting such climate, lodging, and food, as appeared most conducive to the forwarding his object; and then, it might have been remarked, that the pains and expense thus incurred by Bakewell, to obtain his object, was so great, that the novelty alone of his produce, could command an adequate return; and this, perhaps, may be a sufficient reason, why his plans could not be considered as eligible to be generally followed, but it does not furnish just grounds for con" demning the principle, of breeding in and in, altogether.

After a perfect stock has been obtained, how is it to be continued? This seems to be the grand question, and it only can be answered on the principles before explained, viz. by duly attend- 
24 ON BREEDING AND REARING ANIMALS.

ing to their qualities and habits, when selecting the breeders ; and again, to the means, by which those qualities and habits are sustained. If great size be the valuable quality, and the utmost nature will admit of, has been produced by an artificial climate and lodging, and a selection of food, it must be obvious, that with the same climate, lodging, and food, the same stock may be kept up, by breeding in and in; but with a less congenial climate, lodging, and food, the progeny of such animals, must decline, and become less in size; and at the same time, it might be 'observed; that under those circumstances, no crossing can keep up the size and propensities. And again, if animals or vegetables, of whatever size, bred in a certain climate, and with certain lodging and food, can be furnished with a lodging, climate; and food, more congenial and nutritive, they may be increased and improved, by breeding in and in.

Sir John proceeds, - "It may, indeed, prove " beneficial, if not carried too far, in fixing any "variety that may be thought valuable, but on " the whole it is only in appearance. Under " this system, the young animal comes into the "world on comparatively a very small scale; by " keeping it fat from the first moments of its ex$\because$ istence, it is made to attain a greater size than 
" nature intended; and its weight, in conse" quence, will be very great in proportion to the " size of its bones. Thus a generation of ani" mals of an extraordinary form, and saleable at " enormous prices, may be obtained, but that " does not prove that the practice is eligible, if "long persisted in; on the contrary, if the system " be followed up, the stock get tender and deli" cate; they become bad breeders, and though " they retain their shape and beauty, they will " decrease in vigour and activity, will become "lean and dwarfish, and ultimately incapable of "continuing the race."

If a striking instance, not only of the $a b$ sence of physiological principles, in the application of practical observation, but of the substitution of speculative opinion, was necessary, to prove a want of scientific arrangement, in Sir John Sinclair, surely this must be sufficient; and if such arguments as the following, against the attempt to produce a certain effect, are permitted to influence opinion, and such causes be assigned, as these, "it is thus made to attain a "greater size than nature intended," agriculture might; indeed, continue to be mere speculation and uncertainty.

But even were such observations, construed in the most favourable manner, they apply par= 
tially only, as they are descriptive of the effect of injudicious selection, and of artificial feeding, and do not prove the cause of defection, to be in the general principle, of breeding in and in.

It appears, that Bakewell well knew how far he could lead nature; and so far from his results proving the insufficiency, of breeding in and in to produce perfection, it completely establishes the fact, that such an object cannot be obtained, with equal facility, by any other means.

It must be admitted, that more valuable animals in themselves, never were produced, than those bred by Bakewell; but the old maxim no doubt is good, "You may purchase " gold too dear." However, as before observed, Bakewell had an object in view, and to obtain this, every advantage of artificial climate, food, and lodging, were resorted to, regardless of expense; and so long as he could furnish exuberance in food, climate, and lodging, he found an exuberance in the flesh and size of his animals returned; but when his means of increase were exhausted, nature made a standshe never went "farther than she intended." I once heard of a farmer, who, ambitious to excel, purchased a bull from Bakewell, or some such fancy breeder, and after having kept him for some time, the beast lost flesh, and became 
weak and languid; the farmer. on meeting with his former feeder, complained that the animal was fast declining, although he had plenty of grass, hay; \&c. the feeder told the farmer, that grass and hay were not sufficient ; for besides these, he had been fed on grain, and had also been indulged with a pail of milk every day, from the time of quitting his mother. This sufficiently shows the folly of carrying things to such extremes for general purposes; but it does not prove Bakewell, to have been erroneous in his judgment, nor does it detract from the principle of breeding in and in.

It is the general practice of sheep farmers to purchase their rams from professed breeders, at enormous prices, and these, which are bred under peculiar indulgencies, are always kept away from the flock, with an extra allowance of the best food, such as grain, pulse, \&c., and frequently, also, are allowed the shelter of a house ; the consequence is, that their stocks are always lean and long, and large in their bones, and unequal to sustain the hardships of the natural climate, lodging, and food, with health and vigour; and hence it is obvious, that the practice of crossing is not only attended with much useless expence, but that it obstructs what ought to be the object of every rational farmer 
to obtain, viz., the possession of a stock, in every respect adapted to the nature, and localities, of his situation and circumstances.

Sir John Sinclair also says, "Sir John Sea" bright tried many experiments, by breeding in " and in, with dogs, fowls, and pigeons, and " found the breeds uniformly degenerate." But it may be remarked, that pigeons, dogs, and fowls,

D. from their long domestication, are already as much removed from a state of nature, as nature will admit of ; and being bred and fed more to please the fancy than for any defined object, it frequently happens that the most desired qualities are the effect of disease or distortion; and, therefore, on the principles laid down; it might be expected, that weak, diseased, or defective males and females being selected and paired, would produce those that are still more so.

Sir John Sinclair again says, "A gentleman " who tried the experiment with pigs, brought " them at last into such a state, that the female " gave over breeding almost entirely, and when "they did breed, their produce was so small " and delicate, that they died as soon as they "were born." Here also an effect is mistaken for $a$ cause ; thése failures evidently arose from

$\therefore$ dae, original defect, and a peculiar selection in pair-
atficen ing having been carried to an extreme, and

$\therefore$ dae, original defect, and a peculiar selection in pair-
itaffear ing having been carried to an extreme, and 
not solely on the principle of breeding in and in; no doubt, in the pursuit of this principle, there are, as in every process, two extremes and a medium.

As for dogs, I knew a gentleman, who by crossing had lost the valuable qualities of his greyhounds, which determined him to try back, by breeding fiom the nearest blood, and he succeeded, and recovered his lost excellence. And Samuel Emley, Esq. of Salisbury, assured me, he bred in and in, with the same family, both pointers and spaniels; for thirty years, and never found them degenerate.

No opinion is more common, than that game. cocks will degenerate, when bred in and in; but having asked different breeders, in what points they have been found to degenerate, I was answered by one, that those so bred, would stand up till killed, but that they had no spirit or activity; whilst the other asserted, that they were all activity, spirit, and dash, at the onset, but gave in after a blow or two. I have also repeatedly heard the same inconsistent objections made to breeding in and in with greyhounds; one party asserting, that those so bred, have great speed, but no bottom, whilst another states, that they have no activity or speed, but will run till death. 
There can be no doubt, but that all these failures may occur, when breeding in and in, but they are clearly the effect of improper selection, and establish no grounds of objection, that will not as justly attach to the principle of cross breeding.

In breeding animals for fattening, it is the usual practice to select those for breeders, that discover the greatest propensity to fatten or grow fleshy, and such animals are generally uncertain and bad breeders, and always bad nurses; and this rests on the principle I have stated. The female being selected, as one in whom the exuberance of nature is in her flesh, end whose food is appropriated entirely to the increase of this, her powers of conception are obstructed, and her young, neither during her pregnancy, nor after their birth, can be furnished by her with the nourishment necessary to support them; and sterility in the female, and disorder and want of size and strength in her progeny, must be the result. But after their birth, the wants of nature in food and temperature, may be artificially supplied to the young, and they may thus be reared, with all the apparent qualities of their progenitors.

I obtained a sow pig, of a breed peculiar for their propensity to fatten, from Mr. Hodgson. This 
ON BREEDING AND REARING ANIMALS. 31

creature kept in high condition, even when fed on grass alone, or simple wash and grains; but she never produced more than seven young ones at a farrow, and two or three of those were generally starved to death for want of her producing milk, all her food being appropriated to the increase of her own flesh, instead of furnishing sustenance for her young ones; and whatever boar was put to her, 'made no difference in this respect, but I never obtained any young ones, that possessed in an equal degree her own propensities and shape, except when put to her own son. I also obtained another sow, of a very different breed, but of equally strong propensities to fatten, and valuable proportions, and although this animal was regularly in season for more than twelve months, and put to different boars, she never would breed. Such a sort of pigs would certainly not answer to keep as breeders of stock for a market, but to purchase for fattening, they were worth 25 per cent. more than any others I ever possessed. Such peculiarities were, no doubt, produced by breeding in and in, and could not have been by any other means, but it was also more immediately the effect of selection. Animals possessing the opposite propensities, that of breeding great numbers, with large bone, and such as 
are also with difficulty furnished with flesh, may of course be produced, by observing the same principles.

Sir John Sinclair likewise says, “ Mr. Knight's " experiments with plants have fully convinced " him, that in the vegetable as well as the ani" mal kingdom, the offspring of a male and " female, not related, will possess more strength " and vigour than when they are of the same "family, which proves how unprofitable such "connections are."

Peculiar cases may have occurred, partially to sustain such remarks, but these cannot justify such a general conclusion. The terms "s more strength and vigour," can only be understood as comparative. If a male from a plant of vigorous habits and full health, be coupled with the dowa female of languid habits and bad health, is it expected that the offspring will be more vigorous and healthy than the male parent? arely not; it would be as contrary to nature as to reason: it might be more so than the female, but this does not justify such a general conclusion.

(-And further, Sir John says, "A change of "seed is in general advantageous, in regard "both to animals and vegetables; hence many "6 farmers are induced, not only to change the 
ON BREEDING AND REARING ANIMALS. 33

" seed of the kind of grain they cultivate, but " to procure males from the flocks and herds " of those who have the same, or similar with " their own. It has been remarked that those " farmers have in general the worst flocks, who " bred from rams produced on their own farms, " and that an interchange of males is mutually " beneficial."

These observations, like many others of Sir John Sinclair, are calculated more to mislead, than to inform, the ignorant agriculturist, for instead of grounding his judgment and practice, on the established principles of science, he is here recommended to rely on blind chance, or the casual observation and imitation of others.

By crossing different varieties of vegetables, no doubt, other varieties may be obtained, and, perhaps, such as possess more valuable qualities than the parent plants; but with vegetables as with animals, food and climate, possess the greatest influence, in varying their qualities; thus the seeds of plants, transplanted from a sterile soil and uncongenial climate, to a luxuriant soil and congenial climate, will increase in the luxuriance of their produce, with every generation, until they have reached the bounds prescribed by nature, and vice versâ.

Sir Humphry Davy very justly observes, 
" As plants are capable of amelioration, by pe" culiar methods of cultivation, and of having " the natural term of their duration extended, "so in conformity to the general law of change " they are rendered unhealthy, by being ex" posed to peculiar unfavourable circumstances, " and liable to premature old àge and decay.

c "The plants of warm climates transported " into cold ones, or of cold ones transported " into warm ones, if not absolutely destroyed " by the change of situation, are uniformly ren" dered unhealthy."

A difference in opinion may always be expected to exist, as to the form and colour that constitutes the beauty of animals, as well as vegetables, but it cannot be denied that the grand object of agriculture, should be a profitable produce. The mode of attaining this object, no doubt, will be determined, in a great measure, by peculiarity of situation and circumstances; but taking it for granted that every agriculturist must be desirous of keeping up the good qualities, if not of improving his stock, the only questions that can arise, are, What is an improvement? and, What will produce profit? And let this be determined as it may, perfection can only be obtained by a selection of breeders.

If a greater or less size be required, stronger 
ON BREEDING AND REARING ANIMALS. 35

propensities, or greater and morẽ perfect health and vigour, the object must be obtained by selecting and pairing those males and females which possess in the greatest degree the requisite qualities, whether crossing be resorted to, or breeding in and in.

When left to nature it is always determined one way; those which are rendered the weakest, from whatever cause, are driven off, or down, by the strongest and most vigorous : and as all have to contend with the same climate, lodging, and food, those possessing the best habits must always prevail, and consequently the breed must be kept up to its greatest perfection. And that an adherence to those principles which are the most congenial to the laws of nature is the most profitable, is clearly established by practical demonstration.

It is well known; that there are many farms, and many large districts that never do fatten their stock, and indeed are considered and found inadequate to it; and what other cause can be assigned for this, but that the stock are bred by continual crossing with males reared under advantages of superior lodging, food, and climate, to what such farms and districts naturally produce? As Sir John Sinclair observes, animals bred from the same family, and selected 
for their peculiar propensities to fatten, have a large proportion of flesh, and but little bone; so, on the contrary, animals bred from meagre females, living in a harsh climate, and with a scanty supply of food, by crossing with males of the largest size, produced by superior food, and in a climate more congenial, have a large proportion of bone, and but little flesh, and possess withal a more delicate and precarious state of health. Any land whatever, that will furnish food enough to maintain two animals in a state for breeding, and with a climate and lodging requisite to sustain health and vigour, will be found equal to the fattening an animal that had been naturalised to it by breeding in and in for several generations. Every farm may be considered as having its peculiar advantages and disadvantages, compared with others, and a profit can only arise from a skilful observance and management of these.

There does not exist a more mistaken notion, than that the stock of one farm may be kept equal to every other, by crossing and changing the animals and seeds only. It has been well observed, that "Nature provides every creature with a "shelter from the storm." If a male and female of any species of animal or plant be bred under circumstances of a congenial climate, and a libe- 
ral supply of food, and afterwards placed in a situation where the climate is harsh, and the supply of food scanty, they must of necessity decline in flesh, and in health and vigour: but their young, bred under those circumstances of privation will acquire habits, and be reduced to a size, conformable, and these again breeding in and in, the habits of their progeny will still become better adapted, until, by degrees, they will become perfectly inured and naturalised, and capable of making the utmost return the farm is equal to, and at the least expense. But if, on the other hand, the breeder chooses to contend with, and oppose, nature; and instead of submitting to her laws, he still persists in attempting to keep up the size, by a fresh supply of males and females from the original quarter, he inevitably must be subjected to the consequences of a want of health and vigour, and incur great hazard, and extra expense.

That the above principles equally govern the vegetable, as well as the animal world, has been demonstrated by Sir Joseph Banks, who says, that by repeatedly raising plants from the seeds grown on the spot, he has so naturalised to this climate, vegetables that were natives of a warm climate, and which on their first introduction into this country, could only be kept

D 3 
(alive in conservatories, that they are now enabled to flourish in the open air without artificial protection. And in corroboration of those conclusions, I annex the following extracts: that of Mr. Mason, from Sir John Sinclair's Code of Agriculture, and Mr. Robinson's, from the Farmer's Journal, of April 15th, 1816.

Answers by C. Màson, Esq. of Chilton, Durham, to the question, whether the system of " Breeding in and in" is advisable.

To answer the question on the propriety or impropriety of adopting the system called Breeding in and in, it seems only necessary to recur to the acknowledged principles of breeding in general. It is admitted that all breeding proceeds on the presumption, that the tendency of any individual animal is to transmit to its offspring, the form, constitution, and qualities which it possesses; and as two animals are concerned in the production of one offspring, that one is expected to inherit a form and constitution compounded of the joint qualities of its parents. Thus it is found in numerous breeds of animals, as in deer, in the west Highland cattle, in the north Devon, and in the wild cattle of Chillingham Park, the offspring for an indefinite 
ON BREEDING AND REARING ANIMALS. 39

number of generations, have borne the same general characters. These are examples, where great numbers have contributed to the formation of the several breeds, and while the general character is found invariable, it is not observed to be accompanied by any general deterioration, in any essential quality: where any deterioration therefore, is observed, it is most probably ascribable to one of two causes.

1st. From some peculiarity of circumstances, few animals only may be concerned in the production of the breed, and then, any individual defect must not only be transmitted uncorrected, but will necessarily increase in the progeny; a tendency to that defect being inherited by both parents, and both being immediately descended from its original propagator. This defect may be in size, from inclination to feed at an early age, to feed fat with a comparative small consumption of vegetable food, to lay that fat on valuable points, or in constitutional health, and according to the nature of the original defect, the breed will become bad graziers, or incapable of producing any but an unhealthy offspring.

2dly. The same effects may follow in breeds formed by selection. The selector may have begun with an individual having. some radical defect in form, constitution, or quality : and if he

D. 4 
want judgment or opportunity to correct such defect, by employing other cattle of the same breed, free from such, his cattle will degenerate, as before explained. In the case of selection from a small number, it is also to be observed, that the selector too often chooses the weakest male, because such appears of the most delicate form, and nearest approaching to female symmetry; and if this be continued for a few generations, it may be easily be supposed that such a breed will dwindle, compared to one- left to the process of nature, in which the strongest males driving off the weakest; are exclusively employed for the propagation of the kind.

From these observations, strengthened as they may be by the long established practice among breeders of race-horses, \&c., the result appears to be, that any deterioration from breeding in and in, is not a necessary consequence, but a fault in the judgment of the breeder.

A Letter by Mr. Joseph Robinson, published in the Farmer's Journal, April 15th, 1816, in answer to "A Norfolk Breeder's Queries.":

Qu. 1. How were the Northamptonshire sheep treated the first summer after going to fold? 
Ans. Picked the stubbles until they went to turnips, on which they were wintered, and at spring were removed to old grass land, and never eat clover or artificial grasses. When brought to. Whitsun fair, (May 17th,) such was the glut of mutton that a price was not offered for them, and three pound ten shillings each would have purchased them. Not being sold, they were turned back upon a piece of old turf, where they remained all summer, without protection from sun and flies, and gained thirtyfive shillings each for five months' grazing. Had they been sold and slaughtered at the end of two years for three pounds ten shillings each, after being hard worked the first summer, their merit and great profit would not have been known, which undoubtedly is the case with thousands of the best animals in the nation. At the same Whitsun fair, there was a lot of the great Leicesters, six in number, brought forward by a tup man, who occupies a farm under Lord Fitzwilliam, which will feed any animal that possesses any feeding nature; and he has a father-in-law who has two of the best turnip farms in the county at command to winter sheep upon, and corn troughs generally before them. Those six Leicesters, after feeding upon the cream of two or three farms, were brought forward to beat 
the hard-worked Northamptons, which had been bred twenty-five years, sire and dam without a cross, in the same county, in the same parish, and bred and fed upon one farm only.

From the great indulgence of the Leicesters, they might at that time have been ten shillings per head more value; but the Northamptons were supposed to have cut ten shillings worth more wool at two clips than they had, which was an equivalent. The Leicesters being turned back likewise, upon the farm of Lord Fitzwilliam, and kept through the summer, were expected to come again at St. Luke's fair, and to go to the cattle show, in Sadler's yard, at Christmas. Thus, while the Northamptons were paying thirty-five shillings per head for five months' keeping, the Leicester's made a retrograde motion; the dry summer, sun, and flies, did not suit them, they went away like an owl in the desert, and their price and weight kept secret.

I do not see any good purpose answered by those honoured characters, who are ornaments to our nation, bestowing their money to encourage the bringing forward the best trained and finished animals, effected by gathering the cream off the best farms in different counties. Not one farm or one county produces them. I cannot see how, or by what means, the most profit may be made 
of an acre of poor or middling land, which composes the great majority of the soil of this kingdom. If rent was paid by the head of stock, instead of the acre, it might perhaps answer the tenants purpose to bestow the indulgence upon a few animals; but since rent is paid by the acre, the question with the occupier is, how can we make the most profit of an acre of land?

Suppose soils were classed into three or four different classes; for instance, say land under twenty shillings per acre, land above twenty and under forty shillings, above forty and under sixty shillings per acre, and premiums offered to persons who would bring animals forward making most profit of an acre of grass, cleaning up rough and smooth,-would not that answer a better purpose, as it would hold out encouragement to different classes of men and soils? There is by far the greatest proportion of poor and middling land, and on that must depend the principal supply of the market.

An attempt to improve the breed of animals for the shambles, by making choice of the largest males, is as ancient as it is fruitless; and is it not strange to see it renewed in the nineteenth century, by the professed followers of a Bakewell? They say the attempt is laudable, because difficult to be obtained. Difficult to breed a 
large good one?-A sufficient reason why I should object to it. Shall we refuse the common necessaries of life, bread and water, because easy of access, and substitute in their room what is hard to obtain? Will that do for the great national family, who are spending their strength for a bare subsistence for themselves and families? They say it is easy to breed a little good one; then is it not wisdom to accept the offered good?

"Not to know a treasure's worth

Till time has stolen away the slighted good,

Is cause of half the miseries we feel,

And makes the world the wilderness it is."

CowPER.

I cannot, for one moment, suppose that the great or small size of an animal has any thing to do with his goodness as a stock-getter.

"To find the medium, asks some share of wit, And, therefore, is a mark fools never hit."

Again let me beg those luminaries to come to the test of reason. They say we cannot combine great wool and great mutton; if we increase one, we decrease the other. Then what are they doing by enlarging the frame? Are they, by those means, diminishing or increasing the difficulty? 
As every animal is supported through the medium of the stomach, a wool-bearing animal has two demands,-to support wool and carcase; nor can either thrive further than nourishment is afforded. Then how wrong to put large animals upon a poor pasture, that produces but little herbage, and that little, less nutritious!

Again, when they say it is easy to get a little good one,-if they mean by a good one, one which will produce a son better than his sire, and a third better than a second, and a fourth better still; that is what I shall call a good one. If such a one is easily produced, do not the hungry, poor, oppressed tenantry, the great national family, in the name of all that is good, call upon them to do it? Why trifle with the sacred wants and comforts of man?

Again, they say we cannot combine heavy wool with a good carcase. I believe not with long middles and high legs, or with whimsical fanciful niceties. But to say they cannot be combined upon any principle is wrong: experience has proved we can do it with sheep that are calculated to live and thrive upon poor and middling soils.

I am convinced it would be a valuable acquisition, if males to get stock were all bred upon poor and middling soils, and treated as common 
grazing stock; then they would appear in their true light. What does pampering do, but deceive the unthinking? And passing a bad stockgetter, not only wrongs the person who uses him, but injures the public, and ultimately falls upon the poor.

The man who produces a pound of flesh, or a bushel of bread corn, where it was not produced before, gives food to the hungry, and so far promotes the works of God in his providence.

Qu. 2. Is thirty-one months the most profitable age to sell sheep, or to go to market at an earlier period?

Ans. The most proper time depends on circumstances; if sheep are hard worked at an early age, they require more time; but if indulged, will ripen sooner.

Qu. 3. What were they bred from, twentyfive years before.

Ans. They were bred from a Dishley tup, put to Northampton ewes, before the name of New Leicester was known; when Mr. Bakewell was rising out of the solitary vale where he could not meet his creditors, the vale in which he learned, by repeated experiments, of tying up different sorts of sheep, and weighing food to, 
and refuse from them. By that slow and troublesome process, he found which were the best of the different sorts he tried. When he had done this, such was the wayward prejudice of breeders in that day, they would not have them, and it was with difficulty he could prevail on any one to try them; the prevailing opinion was, too little, too little. Where they were tried, wonders were irought; they made great improvement wherever they went, and no other sheep would stand in competition with them. Then his sheep were suited to poor land, a hard common, the most so of any sheep. There are people now living who heard Mr. Bakewell say, that I, with my poor land, did him more credit than any man in the three kingdoms. But the great man mistook the effect for the cause; he knew what constituted a pleasing form, and what was a good quality, but his capacious mind was never led to consider what it was that gave the animal strength of stamina; if he had known it, surely he would have communicated it to some one, nor would he ever have departed from it. He never thought how he procured it, or how he lost it; but when he had lost it, his sheep were like Sampson when he had lost his hair and became as another man. When he had lost sterling worth, then he began to enquire after 
the trappings of fashion. Then the general question was, - What will be in fashion two years hence? And some people yet living must recollect what became the fashion: some of the worst animals that ever were introduced under the palliating name of Bakewell,-high blood. They had heads like snakes, eyes like hares, and not one feature of a natural sheep. Mr. Bakewell was a great politician, and by forming a society of nearly twenty learned men from different counties, no other sheep ever had such a weight of interest twisted, entwined, and wreathed in their support. Under these circumstances, for a lot of sheep of any other sort to be brought forward to any public exhibition, were like an individual standing against a crowd; and as they had possession of most of the best land in the kingdom, it must be something very superior to them to make any sort of stand against them. Be that as it may, Dame Truth is no gossip, if she is spoken with, it must be at home, for she will go to none, and without the old gentlewoman there is no certainty in breeding. I will appeal to any one who has been a tup man for forty years, whether he has not been frequently disappointed, and sometimes received least when he expected most, and vice versâ; which proves that without that something, which a Bakewell 
never knew, no mercenary project, no combination of interest, can go straight forward to improve the breed of sheep. Improve, did I say? I query whether there has been any improvement in the breed of sheep in Northamptonshire these last twenty or thirty years, other than what has arisen from inclosures which afford a shelter, and the introduction of turnips and clover, and the use of mercurial ointment. I am persuaded that what are called the New Leicesters, are not near so good as they were; in fact, without that something, going into this or that county, or to this or that man, for a male, is like a person afflicted with the rheumatism going to Bath for relief, and not using the waters. Bakewell's sheep, at one time, would not only improve all others, but would endure equal hardships, and make more profit of an acre of land than any other sort; would bear the inclemency of seasons, needed nothing to create desire and tempt appetite. And as he knew his sheep needed no extra indulgence, he would not let a person a tup, unless he would engage not to give the offspring corn. The professed followers of Bakewell have no objection to their customers giving their sheep corn, and every other indulgence, sparing no expense. They know that fat upon an animal, like charity, covers a multitude of faults. It is 
the prevailing fashion of some, now tacking about, to produce large fat males; and to what purpose, but to make a better hand of their corn than to take it to market : and knowledge, taking the advantage of ignorance, dupes the credulous out of their money.

Can the great quantity of fat laid.upon an animal, at such expense, produce a better stamina in the offspring, or were ever the best animals produced from the largest males? If they were, Bakewell was wrong altogether. Can it be right to call an animal from such an indulgence and put him upon poor land to work, whereby he is brought into a rapid decline, when propagating his species; and may not a sudden transition of a male from a fat to a lean state be injurious to the constitution, and is it strange that they produce a declining stock?

Various are the conjectures how or where Bakewell procured his sheep? He had them from Lincolnshire, not from the rich marshes. He there bought a score of ewes of a person who could not be prevailed upon to sell a favorite tup, and agreed to give a guinea an ewe to have them tupped by him before they came home; a great business-man, in Leicestershire, saw them on the road coming home, and heard something about the cost of tupping, and who 
told Mr. Bakewell, at Loughborough market, he would not have them at the price they cost the tupping. I think the original price was four guineas a-piece, and when he was under his misfortunes, his ewe lambs were valued at no more than eight shillings each: the best things he ever was in possession of, and from which the tups that made hundreds sprang; these were called the Dishley blood, in distinc. tion from that part of his flock. which were dashed with the Durham blood; the former possessed short legs and thick carcases; the latter higher legs, longer and larger sheep with defective fleeces; sometimes a fine large animal was produced, but not being suited to the poor soils, did not wear like the others.

Perhaps it would be thought arrogance in any person to say he knows more of sheep breeding than Bakewell did; but surely one may say some sheep are bred upon a principle different from any other sort of sheep upon the island. Whether they are better or worse, I will leave time and experiment to prove, but am persuaded that if ever that principle becomes generally acted upon, the same quantity of herbage which now produces two pounds of flesh will produce three pounds; and then what an increase of wealth to the nation, and what room for an increase of population! 
Although one sort of sheep cannot be right for all soils, if we must have two sorts of wool, one principle may be right to breed all sorts of sheep upon, viz. that which will turn a given quantity of herbage to the most advantage.

Notwithstanding all the quackery and mystery generally practised, there can be but two ways of improving animals, viz. to breed from stock of a good stamina, and train them in a proper manner when bred. Dame Nature cannot be led, but may be followed and assisted by human art.

Had Bakewell fixed a criterion, by which the public might ascertain what constituted a right animal for breeding stock, surely after thirty years' steady pursuit of the object, the best sheep would be found in more hands than they are at this time, and the tupmen in different counties not for ever destined to a dependance on the few tupmen in Leicestershire for support, and the public mind would have been at rest. I suppose the Dishley Society were formed for something like that, and to keep the best blood entire, that the public might know where to find it, but they seem as much divided in opinion as others; some say one thing is the best, and some say another; like Dr. Priestley when he offered his services to make up a creed for the Church of England, and had not made up his own. 
ON BHEEDING AND REARING ANINALS. 5S

Qu. 4. Are they in the habit of making such prices?

Ans. In the year 1812, Charles 'Tibbits, Esq. having ninety cull ewes to sell, indulged a friend with thirty of the best of them, and the remaining sixty were sold by auction, and averaged three pounds fifteen shillings each, when a nobleman in the neighbourhood sold one hundred, which averaged about forty shillings each, and a shear-hog was slaughtered, that weighed nearly sixteen stone, to win a wager; it paid one shilling and three-pence per week, for eighty-two weeks' keeping.

In 1814, ten sheep were sold in a public fair to a stranger, which paid one shilling and threepence per head per week, for one hundred and four weeks' keeping; fifty, sold in a lot, paid one shilling and four-pence per week, for one hundred and ten weeks' keeping, all grazed in a common way, without the aid of the scuttle, and have dissected a carcase, which produced thirteen and a half ounces of meat to a bare half ounce of bone.

The above sheep all produced from males, bred upon a farm that was supposed incapable of supporting a sheep through the year before I bought it. I would always choose such a situation, from conviction that the best sort of 
54 ON BREEDING AND REARING ANIMALS.

animal might be bred upon, and are best suited to, the worst soils, but not matured thereon.

Qu. 5. Are they bred by measure, height, and length, or upon what system are they bred?

Ans. As to system, they are not philosophers sufficient to know exactly how high the atmospheric air will raise sheep to make them perfect; they know how many inches it will raise quicksilver in a glass tube, but do not take that to be a measure of perfection for sheep, so as to render it necessary to take an exciseman's stick when they want to engage a male.

Qu. 6. Any thing particular in the form of the face, the length of the ear, \&c. ?

Ans. This question reminds me of what a nobleman's steward said some years ago; he went into a distant county to procure males, to improve his master's flock at some future time. Seeing some Northamptons pass the porter's lodge, he asked where they came from; and when he saw the person who bred them, he asked him where he had the breed from. The steward said, the breeders in a distant county told him if he got such features, face, eyes, \&c. he would have everything else accompanyingit; but he said, "I have the face, and you the every thing."

The above letter is written in a stile bordering on the ludicrous, yet it is evidently much to the 
purpose; and although Mr. Robinson appears more inclined to taunt than to praise Bakewell, he furnishes practical demonstration of the correctness of Bakewell's principles. By Mr. Robinson's own admission, Bakewell was in every respect equal to his task; he took up and pursued most honourably the same principles which Mr. Robinson upholds, until he found it would not produce the grand object, riches. The fact seems to be that Bakewell unfortunately experienced the fate of many men of first-rate abilities, viz. to have expended in the pursuit of science, more than he gained; and perhaps, under the depression of heavy expense and mortification, was induced to submit to the fascination of fame, and to court fortune through the medium of fancy or fashion. This line of conduct, undoubtedly, gives Mr. Robinson the advantage of accusing him of a want of true patriotism, but it by no means supports the charge of ignorance. A man of genius, who can command the fashion, will feel no difficulty in putting himself upon an equality with the plodding man; but the plodding man can never place himself upon equal terms with the man of genius, as a leader of fashion. Bakewell, in the pursuit of perfection in the way of business, became so thoroughly acquainted with the laws of nature, as to be able to lead her to her 
utmost limits, and having succeeded in attracting the attention of those that were able and willing to pay for fancy, he committed but a common fault in availing himself of such an ample resource for retrieving his fortune.

Mr. Robinson's experience in every respect sustains Bakewell's principles of breeding, but he has the merit of marking the true point where the husbandman ought to stop, and he justly describes what ought to be the object of every man who seeks to make the most of his land. The landlord often drives, and rides, a horse high-bred; but from this, it is not to be concluded that the tenant ought to breed his horses from the same stock. Strange as it may appear, it is well known, that fashion reigns as paramount among what are called, the simpleplodding farmers, in determining their choice of stock, as among the weaker sex in their dress; and the farmer looks with as much envy on the esquire's made-up ram, or bull, as his wife or daughter, does at the lady's bonnet: and thus, although from the nature of the farm, he cannot support in health and vigour a sheep of one-fourth the size of those which the esquire produces, or purchases at great prices, and sustains by artifcial means, he will do the best he can by buying his cast-off rams: and thus he produces a long, shanky race of animals, with almost as 
much bone and hair as muscle and wool; and what is still as strange, this fashion also extends to the grazier; his agent at the fair looks out for a coarse frame of bone, and persuades him it will carry more fat; and this practice is become so general, that the butchers' stalls exhibit nothing but large, coarse joints of mutton, consisting of fat sinew and bone ; and small mutton is so scarce, that the public are induced to pay one penny per pound more for lamb, from the general dislike and inconvenience of large mutton: and thus throughout, ignorance and credulity are fed by ignorance and vanity, until reason itself is obliged to give way. Mr. Robinson's, as well as Bakewell's principles, are incontrovert. ible ; and by following the plans and maxims of the former, no doubt the hills and valleys of Wiltshire, Hampshire, Somersetshire, Dorset, Sussex, \&c., may be made to breed and fatten the most delicious mutton; whereas, at present, they are wholly devoted to the rearing of animals which are little better than coarse frames of skin and bones, to be filled up with tallow and grease, by being bloated with artificial food, or in the gross unwholesome pastures of the lowlands and marshes.

How much would gentlemen, possessing hill farms in those counties, add to the pleasures and comforts afforded by their country, as we 
as increase the public stock of provisions, if they would devote their attention to the rearing of sheep, and fattening them on the same farm, as Mr. Robinson has done, than by continuing to indulge in the vanity of excelling their neighbours, in raising large, raw, bony carcases, to be crammed by others in distant districts !

In the production of wool, it is well known that the climate, and natural produce and constitution of a farm, will of itself establish a medium or proportion between the quantity and quality of wool ; thus, it is found that the wool produced on one farm in Sussex, is of superior quality to that produced on another, even at a short distance, although every means of changing and crossing had been resorted to. Indeed, what else could have established and naturalised the beautiful breed of sheep called the Southdowns, and the valuable breed of Dorsets, or the fine large long-wooled Leicesters, but that of the breeders confining themselves to the assisting nature, by selecting and pairing those animals which were best adapted, in their local situation and circumstances, to make the greatest return in wool and mutton at the least expense?

If the farmers of the South-downs had continually crossed with the Leicesters, could they have produced sheep equal to Leicestershire? or the Leicestershire farmers, by crossing with 
South-downs, have produced sheep equal to the South-downs? Certainly not; then why not? The nature of the food and the climate would not admit of it ; and this mode of reasoning will apply to every county, and almost to every farm.

It will cost very little more to breed a ram, than an ewe; and, therefore, the farmer who in a general way pays more for a ram than the extra price of breeding, added to the value of an ewe, pays so much to proclaim his own inability and comparative ignorance.

A striking instance of the indulgence of farmers in fashion or fancy, even at a considerable sacrifice, is exhibited in the black faces and legs of the South-down sheep. The great value of those sheep over any other peculiar breed, consists in the superior quality of their wool ; but by the means adopted to preserve the black faces and legs, black hairs are extended into, and sometimes dispersed through, the fleece; and as the locks containing black hairs, are unfit to make white or light-coloured cloths, these must all be thrown out, before the wool is in a fit state for the manufacturer; and the quantity and reduced quality of this is such, as to reduce the value of the whole fleece, $2 d$. per pound.

The only object in preserving this striking mark, that $I$, have ever heard explained, is, that such sheep are more hardy; but if by this is meant, 
that they are better enabled to endure cold weather, than they would if their faces and legs were white, this is, on the clearest physical principles, erroneous, and contrary to nature. Thus we find in all the most northern climates, that those animals which are of a dark colour, in the warm seasons, change to white in the winter, without which they could not endure the severe cold they are doomed to encounter. Again, we see the beneficence of our Great Creator has given the native man of the burning climate of Africa a black skin. Black absorbs and gives out heat more rapidly than white; as, in other words, any body that is white, will retain the heat which is engendered within it, much longer than that which is black. Thus the white animal in the frozen regions, is enabled to retain its heat in a due degree, to preserve its health; and the black man, by a rapid emission' of heat, is protected against those dreadful fevers, the frequent consequence of accumulated heat, by a retentive white skin. It is this principle which determines the difference in temperature of soils. $A$ black soil will, in a given time, and in the same exposure to the sun, acquire eight or ten degrees of Farenheit more than a white; and on an exclusion of the sun, the black will soon be reduced many degrees below the white. 
Although the earth appears capable of affording a spontaneous produce in vegetables and fruit, her powers of production or principles of fertility, are found to be limited, and to exist in different degrees, in different portions ; and it has also been clearly proved, that where those powers and principles abound in the greatest force, they are sooner or later decreased and exhausted by the growth of vegetables, according to the constitution, situation, and circumstances of the soil. It, therefore, is an object essential to the art of agriculture, to ascertain the causes or principles of fertility and sterility, as the only means of acquiring the power to remedy defects, remove opposing matter, make good deficiencies, and, generally, to preserve and continue the land in its most productive state. Every husbandman or agriculturist may be supposed capable of judging, what stock of animals his land is peculiarly calculated to support, in its immediate state; and this, from a knowledge of the quantity and kind of food such animals require, and the influence of lodging and climate on them. But a knowledge of the nature and application of 
food to vegetables, and the influence of lodging and climate on them, is not so-generally understood; yet it is equally necessary it should be, as it is this alone which can enable a person to follow cultivation successfully.

It has been demonstrated by direct experiment, and is admitted by all philosophers, that earth alone, in any combination of its primitive or simple principles, is incapable of maintaining plants in health; or to enable them to attain maturity; that vegetables require food to sustain them; that their food consists of animal and vegetable matter, reduced by decomposition; to a soluble state; and that such food can only be taken up. or consumed by plants, in a state of liquid, through its roots; but of what peculiar elements or principles such food is composed of; by what means prepared, or how the requisite proportion of the liquifying medium is determined; or by what peculiar powers such food is taken up by vegetables, and digested, and appropriated to their various increase and productions, are as yet subjects of discussion and uncertainty.

To establish these points, it has been found necessary to discover and investigate the elementary principles of which vegetables and animals are composed; and also to ascertain by what organic powers the process of vegetation is 
carried on; and by what means these elementary principles or substances are collected, combined, put into action, and appropriated or disposed of ; and likewise, the composition or constitution, and properties of the earth, and the manner in which it contributes to the formation and sustenance of vegetables. 'To accomplish these things, some of the most eminent chemical, philosophers of the age have given their attention, and a very comprehensive little work on the subject has been published by Mr. Kirwan.

Sir Humphry Davy was also induced by the Board of Agriculture, to give to the public a regular course of lectures on agricultural chemistry; and as those two eminent professors have in their works, given the subject a full attention, and considered it in all its various parts, and their authority being generally respected. and relied upon, I shall confine my observations and reference, on this part of my subject, chiefly to them.

Sir Humphry Davy justly observes, "It is " scarcely possible to enter upon any investiga" tion in agriculture, without finding it con" nected more or less with doctrines or elucida" tions derived from chemistry.

"If land be unproductive, and a system of " ameliorating it is to be attempted, the sure " method of obtaining the object is by deter- 
64. ON THE CULTIVATION OF THE EARTH.

" mining the cause of its sterility, which must " necessarily depend upon some def ect in the " constitution" of the soil, which may be easily " discovered by chemical analysis; some lands " of good apparent texture are yet sterile in a " high degree, and common observation and "common practice afford no means of ascer" taining the cause or removing the effect.

"The application of chemical tests in such " cases is obvious, for the soil must contain some " noxious principle, which may be easily dis"covered, and, probably, easily destroyed. Are " any of the salts of iron present? They may be " decomposed by lime. Is there any excess of " siliceous sand? The system of impravement " must depend on the application of clay and " calcareous matter. Is there a defect of cal" careous matter? The remedy is obvious. Is " an excess of vegetable matter indicąted? It " may be removed by liming, paring, and burn" ing. Is there a deficiency of vegetable.matter? "It is to be supplied by manure."

He also says, "The phenomena of vegetation " must be considered as an important branch of " the science of organized nature; but though " exalted above inorganic matter, vegetables " are yet, in a great measure, dependant for " their existence upon its laws. They receive "s their nourishment from the external elements; 
" they assimilate it by means of peculiar organs; " and it is by examining their physical and " chemical constitution, and the substances and " powers which act upon them; and the modi"fications which they undergo, that the scientific " principles of agricultural chemistry are ob"s tained.

"According to those ideas, it is evident " that the study ought to be commenced by "some general inquiries into the composition and " nature of material bodies, and the laws of their " changes. The surface of the earth, the atmo"sphere, and the water deposited from it, must, " either together or separately, afford all the " principles concerned in vegetation; and it is " only by examining the chemical nature of " these principles, that we are capable of dis" covering what is the food of plants; and the " manner in which this food is supplied and pre" pared for their nourishment; the principle of " the constitution of bodies, consequently, should. is from the first subject for our consideration. "By methods of analysis, dependent upon "chemical and electrical instruments, discovered " in late times, it has been ascertained that all " the varieties of material substances may be " resolved into a comparatively small number of " bodies, which, as they are not capable of being 
" decompounded, are considered, in the present " state of chemical knowledge, as elements.

" The bodies incapable of decomposition at " present known, are forty-seven; of these, thirty" eight are metals; six are inflammable bodies; " and three substances, which unite with metals " and inflammable bodies, and form with them " acids, alkalies, earths, or other analogous com" pounds.

"The chemical composition of plants has, " within the last ten years, been elucidated " by the experiments of a number of chemical " philosophers, both in this and other countries; " and it forms a beautiful part of general che" mistry. If the organs of plants be submit" ted to chemical analysis, it is found that their " almost infinite diversity of form, depends upon " different arrangements and combinations of a "very f'ew elements; seldom more than seven or " eight belong to them, and three constitute the " greatest part of their organised matter.

"All the varieties of substances found in plants " are produced from the sap, and the sap of plants " is derived from water, or from the fluids in the "soil, and it is altered by, or combined with, " principles derived from the atmosphere."

And again: "If any fresh vegetable matter, "which contains sugar, mucilage, starch, or " other of the vegetable compounds soluble in 
"water, be moistened and exposed to air, at a " temperature of from $50^{\circ}$ to $80^{\circ}$, oxygene will " soon be absorbed, and carbonic acid formed; " heat will be produced, and elastic fluids, prin" cipally carbonic acid, gaseous oxyde of car"bon, and hydro-carbonate will be evolved; a " dark-coloured liquor of a slightly sour, or bit" ter taste, will likewise be formed, and if the " process be suffered to continue for a time suffi" ciently long, nothing solid will remain, except " earthy and saline matter, coloured black by " charcoal.

"Animal matters are in general more liable to " decompose than vegetable substances. Oxy "gene is absorbed, and carbonic acid and am" monia formed in the process of putrefaction; "s they produced compound elastic fluids, and " likewise azote; they afford dark-coloured acid, " and oily fluids, and leave a residuum of salts " and earths mixed with a calcareous matter. The "s ammonia given off from animal compounds, in " putrefaction, may be conceived to be formed " at the time of their decomposition by the com"bination of hydrogene and azote. Except this " matter, the other products of putrefaction are " analogous to those afforded by the ferment" ation of vegetable substances; and the soluble " substances formed, abound in the elements, of

$$
\text { F } 2
$$


"which are the constituent parts of vegetables, " in carbon, hydrogene, and oxygene.

"The circumstances necessary for the putre" faction of animal substances are similar to those " required for the fermentation of vegetable sub"stances; a temperature above the freezing " point, the presence of water, and the presence " of oxygene, at least in the first stage of the "process."

He likewise says, "Soils in all cases consist of " a mixture of different finely-divided earthy mat" ters, with animal or vegetable substances, in a " state of decomposition, and certain saline ingre" dients. The earthy matters are the true basis " of the soil; the other parts, whether natural, " or artificially introduced, operate as manures. " Four earths generally abound in the soils: the " aluminous, the siliceous, the calcareous, and the " magnesian. These earths, I have discovered, " consist of highly inflammable metals united to " pure air or oxygene; and they are not, as far " as we know, decomposed or altered in vege"tation."

Mr. Kirwan says, "All plants (except the "sub-aqueous,) grow in a mixed earth, moist" ened with rain and dew, and exposed to the " atmosphere. If this earth be chemically exa" mined, it will be found to consist of siliceous, "calcareous, and argillaceous particles; often 
" also of magnesia in various proportions, a very " considerable quantity of water, and some fixed " air. The most fertile also contain a small " portion of oil, roots of decayed vegetables, a " coaly substance arising from putrefaction, " some traces of marine acid, and gypsum. On " the other hand, if vegetables be analyzed, " they will be found to contain a large portion of " water and charcoal, also of fat and essential " oils, resins, gums, and vegetable acids; all " which are reducible to water, pure air, inflam"mable air, and charcoal; a small portion of " fixed alkali is also found; some neutral salts, " most commonly Epsom, tartar vitriolate, com" mon salts, and salts of sylvius.

Thus far, we may consider all things reducible to primitive principles, or simple substances, and the opinions of these great men are accordant: our next object must be, to consider how those principles or elementary substances are again to be brought together, put into action, and combined; : and particularly for the different purposes of husbandry. Agreeably to the rules of chemistry, to demonstrate the correctness of an analysis of any body, it is required, that the same body be again produced by a recombination of the parts, discovered, and this is called a synthesis; but although it is clearly obvious to the 
most simple observer, that notwithstanding the apparent ultimate destruction of every visible substance, the same quantity of both animate and inanimate substances always exist, and it may be justly concluded, that the process of nature is carried on by a kind of transmutation, or change in the relative connection of matter, brought about by certain processes of death and decomposition, and restored again by the action and dissemination of certain principles of life and recomposition; we cannot, by artificial means alone, effect such a combination of those principles, or elementary substances, as to form either animals or vegetables, and we are therefore incapable of demonstrating by synthesis.

On this point, Sir Humphry Davy remarks, "What may be our ultimate view of the laws " of chemistry, or how far our ideas of ele" mentary principles may be simplified, it is " impossible to say; we can only reason from "facts; ye cannot imitate the powers of $\lambda$ com" position belonging to vegetable structures, but, "at least, we can understand them; and as far as " our researches have undergone, it appears, that " in vegetation, compound forms are uniformly " produced from simpler ones: and the elements " in thesel, the atmosphere, and the earth, " absorbed and made parts of beautiful and " diversified structures." 
ARRANGEMENT OF CHEMICAL PRINCIPLES, AND PRACTICAL DEDUCTIONS.

BEFone entering into a further inquiry of the principles of any particular operations of husbandry, a general view of the workings of nature in her various processes and proceedings, may materially assist in directing attention to the proper points; for this purpose, the following explanations and arrangement are offered.

All things that constitute animated nature are reducible to the same primitive or elementary principles, - viz. oxygene, hydrogene, nitrogene, carbon, and earth. The three first are permanent elastic fluids; or gases; the fourth a permanent substance; and although the earths are proved, by Sir Humphry Davy, to be compounds of highly inflammable metals and oxygene, it does not appear that they are found in any other state than as such compounds, in vegetables or animals; nor that it is necessary they should be further subdivided, either for the reproduction or sustenance of vegetables, or animals. I shall, therefore, take the liberty, in the pursuit of my

$$
\text { F } 4
$$


72 ARRANGEMENT OF CHEMICAL PRINCIPI.ES,

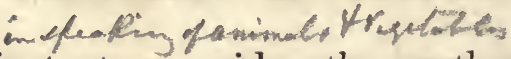

subject, to consider the earths as elementary principles.

Oxygene is the vital air of life, the principle of combustion, and the vehicle of heat,-the pure air of Kirwan.

Hydrogene is the basis of inflammable air, and is the lightest of all ponderable things, - the inflammable air of Kirwan.

Nitrogene or azote is the opposite of oxygene, and is incapable of supporting combustion, and animal life.

Carbon is the basis of common charcoal, divested of all its impurities.

Atmospheric air is compounded of the two different permanent: substances, oxygene and nitrogene, combining and uniting in certain proportions, and rendered ærial by the expansive power of heat or caloric.

Water is formed by the two permanent substances, oxygene and hydrogene, combining or uniting in certain proportions, and which, in its common state, always holds a certain portion of earth in a state of solution, and generally of carbon also.

As these elementary substances are in themselves indestructible, and, combined in different proportions, form the whole of both animals and vegetables, it clearly appears that animal and 
vegetable matter, in the general composition and continuation of the world, is divisible only, and not destructible; and that therefore, as far as we are able to comprehend, the animal and vegetable parts of the creation are continued and sustained by transmutation: or, in other words, that the process of nature in creating and constructing, is carried on by the continued operations of composition and decomposition.

Thus animals forming the superior part of the creation, are endowed with the powers of destroying, mastieating, digesting, and decomposing the substances of both animals and vegetables.

And vegetables which are more delicately formed, seem peculiarly designed by nature to aet in unisonwith animads, continuivg the animated world, by bringing the divided substances again into union and action, for their wee temffert

Animals devour both animals and vegetables to support themselves, and by this they are at the same time made instrumental in preparing the food of plants, by facilitating the decomposition of both animals and vegetables.

From the peculiar organisation of vegetables, their food can only be taken up in a state of liquid, and water is the only vehicle by which it can be administered, 


\section{ARrangement of CHeMical PRINCIPLES,}

Whatsoever, therefore, constitutes the grand invigorating or accumulating principle in the food of plants, must be reductofe to a soluble state or be placed in a state of minute divisitive

Although water in its pure state contains hy. drogene and oxygene only, as it is necessarily brought in contact with, or made to pass through animal and vegetable ${ }_{\lambda}$ substances, (which are always scattered over the surface, or contained in the soil, before it can come within reach of the roots, it dissolves, $\wedge$ combines and carries ${ }_{\alpha}$ with it the carbonaceous matter.Y Yrabines,

Plants pgssess the power of decomposing water, and the composition of their own various substances, of retaining and applying the carbon, hydrogene, and earth, and a portion of oxygene, and at the same time of emitting the superfluous oxygene as excrementitious.

Animals by respiration decompose the atmospheric air, retaining the oxygene, and emitting the nitrogene.

Animals and vegetables when deprived of life, and left to spontaneous decay, are decomposed by fermentation, and by this,process, carbon, and earth are deposited, and oxygene, which is in-

4 creased by absorption, is disposed of, by part forming ${ }_{l}$ carbonic oxyde, and part carbonic acid gas: the hydrogene and nitrogene are emitted 
as simple gases, or united as ammonia: the hydrogene also, is often combined with carbon, forming carburetted hydrogene gas.

Carbonic acid gas, or fixed air, is formed by a certain portion of carbon being dissolyed and held in solution or "combination oxygene, and is more ponderous than atmospheric air.

Carbonic oxyde is composed of carbon, and a portion of oxygene less than sufficient to produce carbonic acid.

Carburetted hydrogene gas, is carbon dissolved in hydrogene, and is much lighter than atmospheric air; it is this gas by which balloons are inflated, and which is burnt to give light, instead of oil, \&c. in lamps.

These elements being thus separated, are again combined by the various processes of nature.

By the combustion of electricity, the oxygene gas emitted by vegetables, and the hydrogene gas by putrescent animal and vegetable matter, are united and form water; and the proportions are 85 oxygene, and 15 hydrogene. By natural affinity, oxygene gas is combined with the nitrogene gas, thrown off by the respiration of animals, and atmospheric air formed; and the proportions are 22 oxygene, and 77 nitrogene.

Carbonic acid gas, from its density, is readily 
76 ARRANGEMENT OF CHEMICAL PRINCIPLES.

7 brought in contact with calcareous, carbonaceous, and metallic substances, and also with water, and by these absorbed or decomposed.

Conformably to the preceding doctrines, the cultivation of land, naturally is divided into two important gperations, ${ }^{2}$ viz sante

First, The adapting, improving, or-correeting thesurface of the earth, and the sub-soil, that it may receive and regulate a due supply of water, and afford a proper accommodation for the roots of vegetables.

Secondly, The regulating and furnishing the needful supply of food for such plants, and for such purposes as it may be desirous to cultivate $/$ h or to fumish sueh plants as the soil ${ }_{h}$ is best adapted to support.

To be enabled to form a correct judgment on these points, it will be necessary, first, to comprehend the nature and properties of the roots of plants, and also of their stalks, branches, and leaves. 
ON THE ROOTS OF PLANTS.

To give life and motion to the seeds of plants, a certain portion of water, and of oxygene or vital air, and a degree of heat of about $50^{\circ} \mathrm{Fa}$ renheit, is necessary. A seed being placed in the earth under these circumstances, it immediately absorbs moisture, and gradually swells to the extent of its shell, or skin, when the radicle, or first root, protrudes itself, and in whatever position the seed be placed, assumes a perpendicular direction, and gradually makes its way downwards into the soil; and the germen also assumes a perpendicular position, and grows upwards. A great number of experiments have been made to ascertain the peculiar principles, which influence and give direction to the first rudiments of plants, and many are recited by Sir H. Davy; but whether the first inclinations of a plant be considered as instinctive, or whether, by the influence of any peculiar principle, the root is impelled forward into the earth, is of trifling importance to the practical agriculturist: and whether it may be accounted for on the principles of gravitation, or attraction, it is 
not necessary for my present purpose to discuss. It is progressive in its growth, similar to the branches, but in an inverted direction.

As the 'branches of' a tree are formed by a very tender and succulent point, pushing upwards into the air, so the root penetrates downwards into the earth; but as it has to make its way through the pores, or between the particles composing the soil it is planted in, which is often close and tenacious, its first projecting points are wisely adapted to the purpose, by being much more minute and compliable, which enables it to advance almost as readily as water. After a root has effected a passage, it is endowed with considerable expansive and repulsive powers, and thereby enabled to make its way, by pushing off on all sides the encumbering soil. When the soil is but partially submissive, the root accommodates itself to the cavity, admitting its increase, however rugged and irregular. Roots are, notwithstanding, impatient of resistance, and at all times evince a partiality for that soil which is most accommodating, and run most evenly and luxuriantly, where they meet with the least resistance, and the greatest supply of nutriment.

The office of the root is to collect and supply the food, which forms and determines the future 
plant and its produce, and the constitution and habits of the roots determine those of the stalk, branches, and leaves; if the roots grow luxuriantly, the branches will also.

A variety of means have been resorted to by phytologists, to discover and ascertain the construction and principles of action of the roots of plants, and as various and contradictory have been their opinions and representations; but in the material point all agree; and the most minute examination, by the most powerful microscope, confirms the fact, that the food of plants can only be taken up by the roots in a state of solution in water, or suspended in a state of division, so minute as to be equal to a solution.

In a deep tenacious soil, or clay, roots can only find a free passage through fissures or clefts, which are formed by its occasional contraction, and as these openings are not very numerous, or close together, the roots do not divide much, or become fibrous, but those which strike into them range wide and deep, and getting beyond the general influence of the sun and air, collect their food, or sap, from a source ill adapted to fructification; and, consequently, plants under such circumstances are generally found to be of a cold, aqueous, unhealthy, and unprolific nature: on the contrary, 
when a soil is light, porous, and shallow; the roots meeting no obstruction, divide and form a great number of fibres, which ranging horizontally, and being more exposed to the effect of sun and air, incline a plant more to become fructiferous than to an increase of wood, or an extension of branches; and in such a situation, the greatest supply of food being appropriated to the production of fruit or seed, the plants grow less to stalk, branches, and leaf. Hence it is very truly remarked by an ingenious writer on fruit trees, that " they produce the most generous fruits when their roots spread near the surface of the earth," and whether we consider such effects to be produced by the roots being kept more within the influence of the sun and air, or by the peculiar nature of the food supplied by the soil in such a situation, it operates in support of one and the same conclusion, viz. that it is necessary the roots should be kept near the surface; for whether that which supplies the food of plants be a red, a black, or a brown loam, or sand, or clay, the proper quality of food, or habitan themplant, to induce fructification, and produce the most perfect seed and fruit, and the most abundant quantity, can only be furnished within a certain depth. 
Thus the roots having collected and abšorbed, or taken in, a supply of food or nutriment, for the sustenance of the plant, the next object for consideration is, how, or in what manner, or by what means, such food is disposed of, and appropriated to the uses of the plant, and to the formation of its various substances; and this I shall proceed to show is determined by the leaves, stalk, and branches. 
ON THE USE AND OFFICES OF THE LEAVES, \& $c$.

Upos what principles, and by what application of power, the rise of the sap from the roots, and its distribution and transformation into the different parts and produce of the plant, is conducted, is a question that has long been agitated, and which has given rise to much speculation, argument, and difference of opinion among the learned. The use and office of the leaves of plants, also, have been a subject as fully argued and discussed, and with as little practical effect; but these objects are of much more importance than is generally considered by agriculturists. The nutriment being received from the root into the stalk, becomes what is termed the sap, and this is sent forward and appropriated to the different purposes of the plant, in which process the leaves will be found to be agents of great influence in determining the produce.

Many describe the sap in vegetables as circulating, like the blood of animals, through an appropriate system of vessels; whilst others deny 
ON THE USE AND OFFICES, \&C.

the possibility of such circulation, or even the existence of such vessels.

Bradley says, "The many curious observaVinde " tions which have been made concerning the "structure of animal bodies, and what Dr. "Grew, Malpigius, and myself have remarked, " in the structure of vegetables, may ascertain " to us, that life, whether it be animal or vege "table, must be maintained by a due circula"tion and distribution of juices in the bodies " they are to support."

"The sap circulates in the vessels of plants " much after the same manner as the blood " doth in the bodies of animals." And after a variety of abstruse arguments, he says, "In "fine, a plant is like an alembic, which distils " the juices of the earth; as, for example, the " roots having sucked in the salts of the earth, " and thereby filled itself with proper juices for " the nourishment of the tree, these juices then " are set in motion by the heat, that is, they " are made to evaporate into steam, as the mat. " ter in a still will do when it begins to warm. "Now as soon as this steam, or vapour, rises "from the root, its own natural quality carries " it upwards to meet the air ; it enters then the " mouths of the several arterial vessels, arrives " at the extreme parts of them, i. e. the buds 
" of a tree, it there meets with cold enough to " condense it into a liquor, as the vapour in" a "still is known to do; in this form it returns " to the root down the vessels, which do the " office of veins, lying between the wood and " the inner bark, leaving, as it passeth by, such "parts of the juices as the texture of the bark "will receive and require for its support."

Miller says, "The notion of the circulation * was entertained by several authors much about " the same time, without any communication " one with another, particularly M. Major, a "physician at Hamburgh, M. Peracett, Mari" otte, and Malpighi : it has met, however, with " some considerable opposers, particularly the " excellent M. Doddart, who could never be " reconciled to it.

"M. Doddart, instead of the same juices " going and returning, contends for two several " juices; the one imbibed from the soil, digested " in the root, and from thence transmitted to the " extremes of the branches, for the nourishment " of the plant; the other received from the " moisture of the air, entering in at the extremes " of the branches; so that the ascending and " descending juices are not the same."

Mr. Knight is also an advocate for the doctrine of circulation, and has published a variety 
of papers reciting a number of experiments that he made, and which he considered to confirm the fact. And Sir H. Davy conforms to his opinions, and says, "In all plants there exists " a system of tubes or vessels, which, in one ex" tremity, terminates in the roots, and at the " other in leaves. It is by the capillary action " of the roots, that fluid matter is taken up from " the soil. The sap, in passing upwards, be" comes denser, and more fitted to deposit solid " matter; it is modified by exposure to heat, " light, and air, in the leaves; descends through " the bark, in its progress produces new organ" ised matter, and is thus, in its vernal and " autumnal flow, the cause of the formation of " new parts, and of the more perfect evolution " of parts already formed."

But Mrs. Ibbetson, (a lady who has studied the organism of plants, aided by a powerful solar microscope, and whose observations and descriptions are published in a series of papers in Nicholson's Philosophical Journal, ) after giving a variety of reasons which induce her to conclude that the sap does not circulate, says, " How strange, then, to alter all this beautiful " arrangement, justified, indeed taught by dis" section, in order to find a place for sap-vessels, "that cannot possibly require any. For why. 
" must they have returning vessels? Is there " not a great difference between an animal which, " after the first few years, has no increase, and " a being that increases from every joint, and is " supposed, therefore, to draw up only those juices " necessary for that increase; especially as the sap " is the liquid of the earth, not the blood of the " tree, as is easily proved by adding nurture to " the ground, when the sap fails, which soon " restores it? Besides, how is the circulation " to be effected in the eternally increasing "branches of a tree, whose every additional "twig must make a variation in the quantity of " juices wanted? Whereas, it is naturally de"creased as it mounts, by throwing out new "shoots and branches, which expend the liquor " as it rises. And I believe I may say, that I " am now so well acquainted with all the differ"ent vessels of a tree, that I can no longer fail "from ignorance: but here, except the inner " bark vessels all proceed in a different direc"tion, either round the tree, or from the centre " to the circumference, how is it possible that "such large and powerful parts should be in"visible?

"The use of dissection is to correct the use " of imagination, or those experiments which " have that effect, forcing the juices into chan- 
" nels foreign to that which nature had appointed " for them. I have before said, that I have ever "found nature disposed to such resources, in " case of any unnatural impediment. I have " myself proved it."

The effect of grafting shows that the sap does not circulate; or, at any rate, if it does circulate, that it undergoes no change by the ascending and descending motion: and this also shows the fact, that every part of a plant possesses the power of selecting and transforming the portion of fluid destined to its use as it passes up.

If the sap be passed through the body of a tree to its leaves, and there prepared and returned back, that part of the tree which is uppermost, and producing one variety of wood and fruit, must possess the power of preparing the fluids for the production of every other variety below it, unless the sap be supposed to pass up and return in the same state, which amounts to a superfluity of motion, and an excess of exertion, seldom found in nature. This subject has always excited con. troversy among phytologists, and notwithstand. ing the great variety of ingenious and elaborate experiments that have been made, they not only have not been sufficiently conclusive to produce unanimity of opinion, but the subtle and prolix arguments that have been adduced on both sides

$$
\text { G } 4
$$


of the question, have operated more to confuse than benefit the practical gardener or husbandman, and have induced a careless destruction, rather than an effectual protection, of the leaves of plants.

The leaves, however, will be found to form a most important part in the structure of a plant, and to be destined to perform an essential office in the process of vegetation.

Miller, in speaking of fruit-trees, says, “ If " the shoots have not a leading bud where it is " cut, it is certain to die down to the next "leading bud; so that what fruit may be pro" duced above that, will come to nothing, there " being always a necessity of a leading bud to " attract the nourishment; for it is not suffici" ent that they have a leaf bud, as some have " imagined, since that will attract but a small "quantity of nourishment. The great use of " the leaves being, to perspire away such crude "juices as are unfit to enter the fruit."

Again, "If we consider that the leaves are " absolutely necessary to cherish the blossom"buds, which are always formed at the foot" stalks of the leaves, so pulling them off, before " they have performed the office assigned them " by nature, is doing great injury to the trees." The Rev. Mr. Hales, in his Treatise on Vege- 
table Statics, giving an account of an experiment he instituted to prove the use of leaves in plants, says, "That boughs of trees with leaves on them, " placed in glasses containing known quantities " of water, imbibed, some twenty, some thirty " ounces in twenty hours, day, more or less, " in proportion to the quantity of leaves they " had, and when he weighed them at night they " were lighter than in the morning; while those " without leaves, imbibed but one ounce, and " were heavier in the evening than in the morn" ing, they having perspired little."

This eminent author also says, "It is plain, " from the many experiments and observations " before mentioned, that leaves are very ser" viceable in this work of vegetation, by being " instrumental in bringing nourishment from the " lowest part within the reach of the attraction " of the growing fruit; which, like young ani" mals, are furnished with proper instruments to "suck it thence. But the leaves seem also de" signed for many other noble and important " services, for nature admirably adapts her in" struments, so as to be at the same time service"6 able to many good purposes."

Mrs. Ibbetson cites a number of experiments she made, to prove that plants do not perspire: she, however, admits that plants continually give 
out oxygene while the sun shines, and in this particular all naturalists and physiologists agree. It was a maxim of the great Sir Isaac Newton, that in all scientific investigations of the operations of nature, for the purpose of ascertaining, establishing, and producing causes and effects, substances should not be unnecessarily multiplied.

If, then, in conformity with this, and as be. fore explained, we suppose the food of plants to be water, holding in solution carbonaceous mat. ter, and that the roots take up this liquid, and that plants have the power of decomposing it water being composed of oxygene and hydrogene - the hydrogene and carbon might be compounded in different proportions with a portion of oxygene, and formed into the different substances of the plant, and the remainder given out as gas; and then we have only to believe that the leaves are essential to the process, and the fact cited by Dr. Hales, that plants absorb and dispose of water, will be sustained, and many jarring opinions will be reconciled.

Admitting that a plant receives food, to sustain and extend itself, for the various purposes required by nature, and that, in this respect, it is similar to animals, may we not suppose, that as no animal is known to appropriate the whole - 
of the food it takes into the stomach, to the increase of its permanent substance, - a considerable portion being thrown off as excrement, plants also appropriate a part only, and throw off the remainder as excrementitious? And if so, what part of a plant appears so likely to be prepared for this purpose as the leaves? The food being taken up as a liquid, and duly applied to the needful purposes of the plant, the superfluous part of the oxygene might be passed off in vapour or gas, and the hydrogene, carbon, \&c. with the leaves.

A yery important question is also quoted by Miller, as put by the Rev. Mr. Hales, in addition to some queries by Sir Isaac Newton: "And " may not light also, by freely entering the ex" panded surfaces of leaves and branches, contri" bute much to enobling the principles of yege" tables?" Which must certainly be answered in the affirmative, if, by enobling vegetables, is to be understood, their being put in a proper state to produce blossoms, fruit, and seed, in maturity. It is not only obvious, that without light, vegetables will not produce blossoms or seed, but that, in proportion as plants, or any parts of plants, from being crowded together, overshadow each other, so will they be deficient in produce. The most simple appearance and habits of every plant 
clearly, demonstrate the absolute necessity of light, to stimulate and sustain the generating faculty; which is the grand object of our labour and study in that part of agriculture immediately under consideration.

It may further be observed, that it is an undeviating law of nature, that no plant shall produce blossoms, or fruit, until it be furnished with a surface of branches, stalk, and leaves, proportioned to the quantity of fluids supplied by the roots.

Thus we find, that if two plants are placed, one in a rich luxuriant soil, and the other in a poor dry soil, the suppiy of food collected by the roots of the one in the rich soil will be large, and consequently the roots, branches, and leaves, will be large. The supply furnished by that in a poor dry soil will be small, and the surface of the stem, branches, and leaves, will be small; and thus the surface of the trunk, branches, and leaves, being in each case in due proportion to the annual produce of fluids, (provided each be alike exposed to light and heat,) will each alike, in point of time, attain maturity, and produce seed or fruit.

Plants growing close together, run up tall, which is occasioned, by a natural propensity to spread and expose their surfaces to the sun and 
air, each continuing to grow more in height - than the other, until it is beyond obstruction. Hence those plants that are grown in a clump are always the shortest on the outside, for as these are sooner satiated, they stop and allow the others to overtop them.

Every artificial means resorted to by gardeners, to force plants to a fructiferous state, is determined by this law, and whether by forcing and facilitating an extension of surface by artificial heat, or shelter; or by lessening the supply of sap, by curtailing its roots, or channels of conveyance, the effect is the same.

This law, indeed, which determines the growth and produce of a plant, is very similar to that which governs the process of evaporation.

As the evaporation and inspissation of a fluid, are determined by the extent of surface, exposed to the action of heat, the preparation of the fluids in a plant for fructification appear to be governed. Thus if a vessel, presenting a certain surface, be deprived of one.half of its contents, the remaining half will be evaporated, or inspissated, in the same time that the whole would have been, if placed in a vessel exposing double the extent of surface. We may, therefore conclude, that as it is the law of nature, 
that in an open vessel, containing a liquid, the greater the surface of the liquid exposed, the greater will be the quantity evaporated in a given time, and the greater the quantity of extractive matter prepared; so it is with vegetables, the greater the surface of leaves and branches exposed to the light, and the influence of the sun and air, the greater the quantity of fluid disposed of, by being digested, appro. priated, and expelled; and the greater the quantity, and richer the quality of food and sap supplied, and raised by capillary attraction, or otherwise; the greater the quantity and richer the quality of the matter furnished, to be retained and appropriated by every part of the plant to its various purposes, either of generation, or of substantial increase.

Again, the fruit of a plant being considered, as requiring for its formation, a regularly proportioned arrangement of its organs, and a due supply of healthy sustenance, we may trace the progress of nature to this effect, on the foregoing principles, more clearly than by the doc. trines of circulation, gravitation, or any other theory that has been suggested; and we may conclude that it is with vegetables, as with ani. mals, required to sustain health, that the grand 
machinery be preserved uninjured and complete; and in conformity with this, if we wish to limit the size, or surface of plants, we must limit the food; this is the only check, or restraint, nature will admit of, without entailing future loss.

'That her great work of creation and propa gation, may not be obstructed and retarded in vegetables, by the accidental privations they are subject to, from being made subservient to the use of animals; nature, all bountiful in her pro. vision, and ever fertile in resources, has given them the power within themselves, to a great extent, of repairing and retrieving their losses; and to this end, every plant and every branch, is furnished with more buds than are required for the immediate formation of branches or blossoms, so that if one be destroyed, another may be ready to take its place, and prevent a waste of time, or surface; thus we find that the efforts of a plant, from the seed forwards, are to attain and acquire, the surface proportioned by its nature, to the supply of food, necessary to enable it, to fructify, and propagate its species ; and the juices continue to flow until it has obtained this required extent.

From the preceding observations it must be 
concluded, that although the leaves of plants, may in themselves, be of little value in contributing to the nutriment of mankind, they form an essential part in their organisation, for the production of seed and fruit, the quantity and quality of which will be in proportion to the condition, or state of health, and exposure of the stalk, leaves, \&c. : this may readily be demonstrated, by placing plants under the circumstances of both extremes; thus, if the leaves of a seedling plant of wheat, or a turnip, or a potatoe, be removed as fast as they appear, neither seeds, bulbs, or tubers, will be produced in any quantity, or quality, worthy of notice; but if the leaves of such plants are preserved, and allowed a space sufficient to expand their full extent, and be open to the influence of the sun and air, they will attain the utmost size and state of prolificacy the soil, and quantity and quality of food, is capable of producing.

The capacity of a soil, and the distance plants ought to be placed from each other, may readily be determined, by allowing a few plants a larger space than they will probably occupy; and the space they then cover by their leaves, may be taken as the distance required by each plant, to enable it to attain perfection. 
Plants that are excluded from the presence of the sun and light, and the free circulation of air, give out carbonic acid gas: thus when plants are crowded together and overshadow each other, they are, by a waste of their carbon, thrown off as carbonic acid gas, debilitated and deprived of the needful stamina; which is often followed by sterility, putrefaction, disease, and death.

An attention to these principles will enable the husbandman, with great accuracy, to judge of the difference between thick and thin sowing, and to determine the proper medium; and will show the folly of removing or destroying the leaves of plants designed to produce seed, fruit, or roots, until these are perfected. 


\section{8}

\section{ON THE FOOD OF PLANTS.}

THE food of plants has for a long time been considered an object of importance, by natural philosophers, and a great variety of experiments have been made, to ascertain what it consists of, and in what state of preparation it is most readily and effectually applied; and many conclusions have been drawn, and conjectures formed. As before explained, the earth, animals, and vegetables, have been analyzed, and their component parts minutely described, by men of the greatest talents and learning; but as yet no one has arranged and described such a system of cultivation as will enable a person to trace effects to their causes on just scientific principles. Much has been founded on conjecture, and much still remains to be determined by practical observation and demonstration.

Vegetables, like animals, vary in their nature and habits, and like them have their peculiar food; and although the food of plants may generally be composed of the same elements, it varies in the proportion of its composition, and thereby becomes adapted to different purposes : thus we find that a soil, which will furnish food 
enough to support one plant of a peculiar kind, will at the same time furnish sufficient to sustain many others of different species.

Bradley, in the work I have before noticed, says, "Land animals may be likened in general " to those plants which are called terrene, for " that they live only upon the earth, such as "oak, elm, beech, \&c.; amphibious animals, " such as otters, beavers, tortoises, frogs, \&c., "which live as well on the land as in the "waters, may be compared to the willows, " alders, minths, \&c. The fish kind, or aquatic " race, whether of the rivers, or the sea, are " analogous to the water plants, such as water " lilies, water plantains, \&c. which live only in the " fresh waters, or the fuci, \&c., which are sea " or salt water plants, and not any of these will " live out of its own element; from whence " we may conclude, how improper it would be " to plant a water lily on a dry sandy desert, " or an oak at the bottom of the sea, which "would be just as reasonable as if we propose " to feed a dog with hay, or a horse with fish: " however, this rule of nature has been so little " observed, even by some of our greatest plant" ers, that we can hardly boast of good suc" cess; in one out of five plantations that have "been made." 
He also says, "I shall beg leave to remark, " that as the several land animals have their re" spective diets, so have the terrene plants their " several soils, from whence they derive their " nourishment; as some animals feed on flesh, " others on fish, \&c., so do plants love, some " clay, others loam, sand, or gravel. Nor is this " all we ought to observe; we must consider, " likewise, how beneficial to every plant is a " right exposure; whether in a vale, the sides " or tops of hills, exposed to the south or north "winds; whether inland, or near the sea, for " it is a proper exposure that keeps a plant in " health."

Bradley, Hitt, and Miller, consider the food of plants to be salts, which every species of earth more or less contains within itself; and that according to the proportion of salts, contained in each kind of soil or manure, will its prolificacy be.

That soils, and vegetable and animal matters, may be found to produce salts, under certain circumstances and chemical processes, I have no doubt; but this does not prove it to be necessary that every substance, or any substance, containing the basis or elements of salts, should undergo this process, and be formed into salts, before it can be in a state to constitute 
food fit for the reception and nourishment of plants.

Salts are various in their nature and general effects, when placed in contact with other substances.

I have made many experiments with sea-salt, nitre, soda, barilla, alum, \&c., and have never found them operate as a proportional addition of food may be expected to do.

The opinions of Drs. Smith and Pearson on this subject appear more rational. They say, that salts; as they operate in promoting vegetation, are analogous to mustard, cinnamon, ginger, \&c., which are not of themselves at all, or necessarily nutritious, but contribute to render other things nutritious, by exciting the action of the stomach and other organs of digestion and assimilation. Salts being considered to operate in this manner, in promoting vegetation; we are naturally led to their proper application, that is, in small quantities, or in a state of weak solution.?

Notwithstanding all that has been said to establish the opinion, that sea-salt is a valuable manure, I am convinced it never can, as an article of food, contribute to the increase of any vegetable; but as a chemical agent, by destroying, and facilitating the decomposition, of animals and 
vegetables, or by its deliquiescence it may in some instances increase the fertility of the soil.

Alkaline salts, no doubt, facilitate the solution of many animal and vegetable substances; they also increase the divisibility, change the combination, and otherwise exert an influence on the soil itself, in a manner that adds much to its fertility; indeed, there are many reasons for believing that alkaline salts increase the fertility of soils, and the fertilizing powers of manures, when mixed or combined with them : the urine of cows, horses, \&c., always contain a portion of alkaline salts, and this is more fertilizing than the dung of those animals. By the reduction of vegetables by fire, alkaline salts are produced; and the action of fire on the soil generally adds to its fertility : indeed, in a great number of experiments, made with a view to ascertain the most fertilizing, and the most readily applicable and operative manure, or food for plants; $I$ have found the serum, or the watery part of blood, diluted with six or eight times its bulk of water, and given to plants in the same quantity, and in the same manner, as when supplying them with water, once or twice only in the year, to produce the most immediate, and most fertilizing effects of any thing; whilst 
the crassamentum, or clotted part of blood; left to nature, was not beneficially operative, until decomposed, and even then, was nothing equal to the serum in its effects; and the difference in the composition of those separate substances, is, that serum contains one-fortieth of alkaline salts, and the clot none. But if the clotted part of blood be broken small, and well mixed with three times its bulk of water, in which potash, in the proportion of one-fortieth part the weight of the blood, be dissolved; the blood will be reduced, and the liquid be rendered equally effective as the serous part." And if the clotted part be mixed with as much slacked lime as will form it into a thick paste, it will dissolve, and be immediately applicable; but is not so immediately efficacious as the solution by salts. It, however, must be remarked, that clotted blood, mixed with quicl lime, and left drying for a short time, will not dissolve, and is rendered useless.

Mr. Kirwan, after describing the analysis before quoted, observes, "Hence we see on the " last analysis, the only substances common to " the growing vegetables, and the soils in " which they grow, are, water, coal, different " earths and salts; these, therefore, are the true "food of vegetables: to them we should also " add fixed air, though by reason of its decompo- 
" sition, it may not be distinctly found in them, " or, at least, not distinguished from that newly "formed, during their decomposition."

He also says, "The agency of water, in the " process of vegetation, has not till of late " been distinctly perceived. Dr. Hales has "shown, that in the summer months, a sun、 "flower, weighing three pounds, avoirdupois, and " regularly watered every day, passed through " it, or perspired, twenty-two ounces each day ; " that is, half its weight.

"Dr. Woodward found that a sprig of com" mon spearmint-a plant that thrives best in " moist soils, weighing only 28.25 grs., passed " through it 3004 grs. in 77 days, between July " and October, that is, somewhat more than " its whole weight each day; he did more, for " he found that in that space of time, the plant " increased 17 grs. in weight, and yet had no " other food but pure rain water; but he also " found that it increased more in weight when it " lived on spring water, and still more when its "food was Thames water. Secondly, that the " water they thus pass, nourishes them merely " as water, without taking any foreign substance " into account; for 3000 grs. of rain water, in "Dr. Woodward's experiments, afforded an in"crease of 17 grs. : whereas, by Margraaf's ex- 
" periment, $5760 \mathrm{grs}$. of that water contain only " one-third of a grain of earth. But, thirdly, it " also follows, that water contributes still more to " the nourishment of plants, besides the service it " renders them in distributing the nutritive parts " throughout the whole structure, forming itself " a constituent part of all of them, as may be un" derstood from modern experiments. Dr. Injen" houz, and M. Senebier have shown, that the " leaves of plants exposed to the sun, produced " pure air: now water has of late been proved to " contain about 87 per cent. of pure air, the re" mainder being inflammable air. Water is then " decomposed by the assistance of light within the "vegetable; its inflammable part is employed in the "formation of oils, resins, gums, \&c. Its pure " air is partly applied to the production of vege" table acids, and partly expelled as excrement." He further says, "To M. Hazenfrez we owe " the discovery that coal is an essential ingre" dient in the food of all vegetables. Though " hitherto little attended to, it appears to be " one of the primeval principles, as ancient as " the present constitution of our globe; for it is " formed in fixed air, of which it constitutes " above one-fourth part, and fixed air exists in ". lime-stones, and other substances, which date " from the first origin of things. 
"Coal not only forms the residuum of all ves "getable substances that have undergone a slow " and smothered combustion, (that is, to which "s the free access of air has been prevented,) but " also of all putrid vegetable and animal bodies. " Hence it is found in vegetable and animal "s. manures that have undergone putrefaction, and " is the true basis of their ameliorating powers. "If the water that passes through a putrefying " dunghill be examined, it will be found of a " brown colour, and if subjected to evaporation, " the principal parts of the residuum will be " found to consist of coal. All soils steeped in "water, communicate the same colour to it in "proportion to their fertility; and this water " being evaporated, leaves also a coal, as Hazen" frez and Fourcroy attest."

And again, "Hazenfraz and Fourcroy attest, " that shavings of wood, being left in a moist "place for nine or ten months, began to receive " the fermentative motion; and being then "s spread on land, putrefied after some time, and "proved an excellent manure. Coal, however, " cannot produce its beneficial effects but inas" much as it is soluble in water. The means of " rendering it soluble are not as yet well ascer" tained : nevertheless, it is even now used as " a manure, and with good effect.". 
"In truth, the fertilizing power of putrid " animal and vegetable substances were pretty " fully known even in the remotest ages; but " most speculatists have hitherto attributed them " to the oleaginous, mucilaginous, or saline par" ticles then developed; forgetting that land is "fertilized by paring and burning, though the "oleaginous and mucilaginous particles, are " thereby consumed or reduced to a coal. And ss the quantity of mucilage, oil, or salt in fertile "land, is so small, that it could not contribute " the one-thousandth part of the weight of any "vegetable. Whereas coal is not only supplied " by the land, but also by fixed air combined "with the earths, and also by that which is con" stantly let loose by various processes, and soon " precipitates by superiority of its specific gra"vity, and is then condensed in or mechanically " absorbed by soils, or contained in dew."

Sir Humphry Davy says, "The necessity of " water to vegetation, and the luxuriancy of the "growth of plants, connected with the presence " of moisture, in the southern countries of the " old continent, led to the opinion so prevalent " in the early schools of philosophy, - that water " was the great productive element, the sub" stance from which all things were capable of " being composed, and into which they were 
" finally resolved. Van Helmont, in 1610, con" ceived that he had proved by a decisive expe" riment, that all the products of vegetables were " capable of being generated from water. His " results were shown to be fallacious by Wood"ward, in 1691. But the true use of water in " vegetation was unknown till 1785, when $\mathrm{Mr}$. " Cavendish made the grand discovery, that it " was composed of two elastic fluids or gases,' " inflammable gas or hydrogene, and vital gas " or oxygene.

" Air, like water, was regarded as a pure " element by most of the ancient philosophers. "A few of the chemical enquirers in the six" teenth and seventeenth centuries formed some " happy conjectures respecting its real nature. "Sir Kenelm Digby, in 1660, supposed that it " contained some saline matter, which was an " essential food of plants. Boyle, Hooke, and “. Mayow, between 1665 and 1680, stated that " a small part of it only was consumed in the "respiration of animals, and in the combustion " of inflammable bodies. But the true statistical "analysis of the atmosphere is comparatively a " recent labour, achieved towards the end of " the last century, by Scheele, Priestley, and "Lavoisier. These celebrated men showed that "its principal elements are two gases, oxygene 
" and azote, of which the first is essential to "flame, and to the life of animals ; and that it " likewise contains small quantities of aqueous " vapour, and of carbonic acid gas : and Lavoi" sier proved that this last body is itself a com" pound elastic fluid, consisting of charcoal dis" solved in oxygene.

"Jethro Tull, in his Treatise on Horsehoeing, "published in 1733, advanced the opinion, that " minute earthy particles supplied the whole " nourishment of the vegetable world. That " air and water were chiefly useful in producing " these particles from the land; and that ma" nures acted in no other way than in ameliorat" ing the texture of the soil : in short, that their " agency was mechanical. This ingenious au" thor of the new system of agriculture, having " observed the excellent effects produced in " farming, by a minute division of the soil, and "s the pulverization of it, by exposure to dew. " and air, was misled by carrying his principles " too far. Duhamel, in a work printed in 1754, " adopted the opinion of Tull; and stated, that " by finely dividing the soil, any number of" " crops might be raised in succession from the "same land. He attempted also to prove by " direct experiments, that vegetables of every " kind, were capable of being raised without 
" manure. This celebrated horticulturist lived, " however, sufficiently long to alter his opinion. " The results of his later and more refined ob"servations led him to the conclusion, that no "single material afforded the food of plants. " The general experience of farmers had long " before convinced the unprejudiced, of the truth " of the same opinion, and that manures were " absolutely consumed in the process of vegeta" tion. The exhaustion of soils by carrying off " corn crops from them, and the effects of feed" ing cattle on lands, and of preserving their " manures, offer familiar illustrations of the prin" ciple. And several philosophical enquirers, " particularly. Hazenfraz and Saussure, have "shown by satisfactory experiments, that ani" $\mathrm{mal}$ and vegetable matters deposited in soils " are absorbed by plants, and become a part of " their organised matter. But though neither " water, nor air, nor earth, supplies the whole of "s the food of plants, yet they all operate in the "process of vegetation. The soil is the labora"tory in which the food is prepared. No ma" nure can be taken up by the roots of plants " unless water is present; and water, or its " elements, exist in all the products of vegeta" tion. The germination of seeds does not take "place without the presence of air or oxygene 
"gas. And in the sunshine, vegetables decom" pose the carbonic acid gas of the atmosphere; " the carbon of which is absorbed, and becomes " a part of their organised matter. And the " oxygene gas, the other constituent, is given " off": and, in consequence of a variety of agen"cies, the economy of vegetation is made sub" servient to the general order of the system of " nature.

"It is shown, by various researches, that the " constitution of the atmosphere has been al"ways the same, since the time that it was " first accurately analysed : and this must, in a " great measure, depend upon the powers of " plants to absorb, or decompose, the putrefying " or decaying remains of animals and vegeta"bles, and the gaseous effuria which they are " constantly emitting. Carbonic acid gas is " formed in a variety of processes of fermenta" tion and combustion, and in the respiration " of animals, and as yet no other process is " known in nature by which it can be consumed, " except vegetation."

Thus it appears to be a general opinion; among the chemical philosophers, that carbonic acid gas forms a preponderating ingredient in the constitution of the food of plants. And the means of its formation and production are alike 
described by all, but as to the manner, or through what particular medium, it is supplied and consumed, these authors vary in their opinions; and I cannot but think, Sir Humphry Davy has taken a very mistaken view of this part of his subject. To show that there are other means in nature by which carbonic acid is consumed, than by the leaves of plants, we need only take his own description of the nature and properties of lime. On this part of the subject he says, "Slacked lime was used by the Romans "for manuring the soil in which fruit trees grew; " this we are informed by Pliny. Marle had been " employed by the Britons and the Gauls, from " the earliest times, as a top dressing for land. "But the precise period in which burnt lime first " came into general use, in the cultivation of "land, is, I believe, unknown: the origin of " the application, from the early practices, is "sufficiently obvious. A substance which had " been used with success in gardening, must " have been soon tried in farming; and in coun" tries where marle was not to be found, cal" cined lime-stone would be naturally employed " as a substitute."

"The elder writers on agriculture had no " correct notion of the nature of lime, lime"stone, and marle, or of their effects, and this 
"r was the necessary consequence of the imper"fection of the chemistry of the age. Calca"reous matter was considered, by the alche" mists, as a peculiar earth, which in the fire " became combined with inflammable acid; ; and "Evelyn and Hartlib, and still later, Lisle, in " their works on husbandry, have characterised " it merely as a hot manure, of use in cold "lands. . It is to Dr. Black of Edinburgh, that "our first distinct rudiments of knowledge on " the subject are owing. About the year 1755, $\therefore$ this celebrated professor proved, by the most " decisive experiments, that lime-stone and all " its modifications, marbles, chalks, and marles, "consist principally of a peeuliar earth united " to an aerial acid; that the acid is given out in " burning, occasioning a loss of more than forty "per cent.; and that the lime in consequence "becomes caustic.

"'These important facts, immediately applied " with equal certainty to the explanation of the " uses of lime, both as a cement, and as a " manure. As a cement, lime, applied in its " caustic state, acquires its hardness and dura" bility by absorbing the aerial (or, as it has " been since called, the carbonic,) acid, which " always exists in small quantities in the atmo"sphere; it becomes, as it were, again lime-stone." 
Now admitting that carbonic acid is a necessary part in composing the food of plants, it appears to me that Mr. Kirwan's theory is by far the most probable. He says, "That car" bonic acid soon precipitates, by superiority of " its specific gravity, and is then condensed in, " or mechanically absorbed by, soils, or con"tained in dew." He also further remarks: "That plants do not thrive, but most frequently " perish, when surrounded by an atmosphere of " fixed air, has long been observed by that "great explorer of the most hidden processes " of nature, Dr. Priestley; but that fixed air, " imbibed by the roots, is favourable to their " growth, seems well established by the expe" riments of Dr. Perceval of Manchester, and " fully confirmed by those of M. Ruskert. "This last mentioned philosopher planted two " beans in pots of equal dimensions, filled with "garden mould; the one was watered almost " daily with distilled water, the other with water " impregnated with fixed air, in the proportion " of half a cubic inch to an ounce of water; "both were exposed to all the influence of the "atmosphere, except rain; the bean treated " with aerated water, appeared overground nine " days sooner than that moistened with distil"led water, and produced twenty-five beans; 
" whereas the other pot produced only fifteen : " the same experiment was made with stock " July flowers, and other plants, with equal " success. The manner in which fixed air acts " in promoting vegetation seems well explained " by Senebier. He first discovered that fresh " leaves exposed to the sun in spring water, or " water slightly impregnated with fixed air, al" ways produced pure air, as long as this im" pregnation lasts; but as soon as it is exhausted, "or if the leaves be placed in water, out of " which this air has been expelled by boiling, " they no longer afford pure air; from whence " he infers, that fixed air is decomposed, its car" bonic principle detained by the plant, and its "pure air is expelled; it appears to me also, "by acting as a stimulant, to help the decomposi" tion of the water."

Sir Humphry Davy again says, "When a "growing plant, the roots of which are sup" plied with a proper nourishment, is exposed " in the presence of solar light, to a given " quantity of atmospheric air, containing its due "proportion of carbonic acid, the carbonic " acid, after a certain time, is destroyed, and a " certain quantity of oxygene is formed in its " place. If new quantities of carbonic acid gas "be supplied, the same result occurs, so that 
" the carbon is added to plants from the air, by " the process of vegetation in sunshine, ' and "oxygene is added to the atmosphere." $\mathrm{He}$ adds, "This circumstance is proved by a num“ ber of experiments made by Drs. Priestley, “Ingenhouz, and Woodhouse, and M. T. de "Saussure, many of which I have repeated "with similar! results. The absorption of car"bonic acid gas, and the production of oxygene, "are performed by the leaf. And leaves re"cently" separated from the tree, effect the' " change, when confined in portions of air con" taining carbonic acid, and produce oxygene, " even when immersed in water holding carbo" nic acid in solution."

From what has been before said, on the nature and properties of the leaves of plants, it is not only pretty clear, that they are not furnished with organs, necessary for the double action, but it is in no respect necessary they should possess this power. Why should a plant be endowed with the power of feeding at both ends, any more than animals, and when, like them, it is proved, that the taking in their food at one, is sufficient for all their purposes? 'The experiment cited, of carbonic acid being absorbed by leaves recently severed from the tree, is no corroboration of Sir Humphry's theory, as it 
does not appear, that the stems were sealed, and therefore they were left with the power of taking up the fluid through the usual and natural channels.

Sir Humphry Davy again says, "Vegetable " and animal substances deposited in the soil, as " shown by universal experience, are consumed " during the process of vegetation, and they can " only nourish the plant by affording solid matter " capable of being dissolved by the fluids in the "leaves of vegetables: but such parts of them " as are rendered gaseous, and that pass into the " atmosphere, must possess a comparative small " effect, for gases soon become diffused through " the mass of the surrounding air."

"The great object in the application of ma" nures, should be to make it afford as much "soluble matter as possible to the roots of the "plant, and that in a slow and gradual manner, "so that it may be entirely consumed in forming " its sap and organised parts."

And again, "No substance is more necesșary " to plants than carbonaceous matter, and if this " cannot be introduced into the organs of plants, " except in a state of solution, there is every " reason to suppose that other substances less " essential will be in the-same case. I found by "some experiments made: in 1804, that plants 
" introduced into strong solutions of sugar, mu" cilage, tanning principle, jelly, and other sub" stances, died; but that plants lived in the same "solutions, after they had fermented. At that " time I supposed that fermentation was neces"sary to prepare the food of plants, but I have " since found that the deleterious effects of the " recent vegetable solutions were owing to their " being too concentrated; in consequence of "which, the vegetable organs were wholly clog" ged with solid matter, and the transpiration of " the leaves prevented. The beginning of June in " the next year, I used solutions of the same " substances, but so much diluted, that there was " only about one two-hundredth part of solid ve"getable matter in the solutions. Plants of " mint grew luxuriantly in all these solutions, " but least so in that of astringent matter. I " watered some spots of grass in a garden, with "s the different solutions of jelly, sugar, and mu" cilage, which grew most vigourously, and that " watered with the solution of tanning principle, " grew better than that watered with common " water.

Again, "Mucilaginous, gelatinous, saccharine, "oily, and extractive fluids, and solutions of " carbonic acid in water, are substances that in " their unchanged states contain almost all the 
" principles necessary for the life of plants; but " there are few cases in which they can be ap"plied as manures in their pure forms, and "vegetable manures in general contain a great " excess of fibrous and insoluble matter, which " must undergo chemical changes before they "become the food of plants."

I must confess I do not see the utility of Sir H. Davy's expressing such an opinion. To say the best of it, it appears, as Mr. Kirwan observes, to be but a speculation; and as he does not state the few cases, it is worse than useless, inasmuch as it is calculated to mislead, bewilder, and confuse, and to shake the confidence of mere practical husbandmen in the general doctrines of chemistry.

I cannot but think it by far the most probable, that Sir Humphry Davy's first idea was the correct one; and that such substances must be reduced by fermentation before they can be taken up by the roots. At any rate, under those circumstances, the effect of such an application as he describes, to the roots of the plants, must have been the same, that is, death : but another cause of death much more probable may be assigned, than that of the vessels being clogged with solid matter; viz. the oxygenization, or acidifying of those solutions, which most likely 
destroyed the roots. At any rate, whenever I have found a plant wholly killed by the application of fermenting substances, I have observed the roots were first destroyed. I have no doubt of the correctness of Mr. Kirwan's observation, that "vegetables not only require food, but " that food be duly administered to them, a sur"feit being as fatal to them as absolute privation." But the effect of surfeit in plants, is generally the same as with animals, and discovers itself by disease affecting different parts, in the manner of sores and putrefying wounds, which also, as with animals, are often followed by mortification and death.

If, as Mr. Kirwan states, the more solid part of vegetables be submitted to dry distillation, or burnt in a close vessel, it will be reduced to charcoal; and which will continue to occupy almost as much space, as the vegetable itself did previous to the change, and to retain the same figure and the same organic disposition. It is therefore very evident, that the basis of charcoal, which is termed carbon, not only forms the grand stamina of plants, but that it enters into the composition of every part and produce of vegetables : it may hence be justly inferred, that if the plant be formed by the required elements, taken in at the root, (and of which there 
can be no doubt,) the basis of charcoal must, in that part of the food of plants which is supplied by artificial means, form almost an integral; and how to prepare, co coct, and apply this substance, is the grand desideratum.

As Sir Humphry Davy says, mucilaginous, gelatinous, saccharine, oily, and extractive fluids, and solutions of carbonic acid in water, are substances that in their unchanged states contain almost all the principles necessary for the life of plants; and all that is contained in these substances, except the basis of charcoal, is contained in water; viz. oxygene, nitrogene, and earth. In the preparation of food for plants, therefore, the principal object must be to produce and apply carbon, and the manner of effecting this is still an object of doubt, difficulty, and uncertainty, which is evinced by the opinions even of those great philosophers which I have quoted.

What Mr. Kirwan says respecting coal, is true enough; but as to coal in itself, being made to form any part of the food of plants, I have never seen it proved ; that it has been applied as manure with good effect, may be, but its operation must have been as an alterative in the soil, and a preventative of putrefaction, and not as affording carbonaceous matter to the plant. The shavings of wood, no doubt, might have been reduced 
to charcoal, by the operation of fire, but would they in this state have afforded as much of the basis of charcoal in a soluble state, as by the result of oxydizement or fermtrntation? Certainly not: then it may be inferred, that to furnish charcoal, or a substance capable of being converted into charcoal, is not enough. Carbon must be presented in that state which admits of its perfect solution and combination with water. And even after this is produced, it clearly appears that some co-operating agent is necessary, either to release it from the natural attachment of some other principle or substance, which is obnoxious to plants, or to stimulate the plant to receive it; for it is found that the black residuum of vegetables, spontaneously decomposed by putrefaction, will not of itself sustain such plants as are objects of cultivation in agriculture; nor will simple calcareous earths; but these two substances blended in due proportions, constitute the most fertile soils. Hence, as is well known, black soils, which are constituted wholly of vegetable matter, are sterile, and that by the simple combination of lime they are rendered fertile. Then what is this principle of fertility? this is an important question.

The most complete solution of carbon, or that state which admits of the most perfect union 
with water, appears to be carbonic acid; but as it has not been proved, that in this state it is, by any application, capable of producing anything like the quantity of carbonaceous matter required to sustain a plant in health and vigour, it may justly be concluded that carbonic acid, like coal, is, by its constitution, restricted in its operation. That process of decomposition, therefore, which can be conducted so as to produce the required state of solution and separation, without its running into the excess of carbonic acid or charcoal, must be the most efficient; and the chemical terms which best express this state, appear to me to be vegetable and animal oxydes; and my opinion as to the best mode of producing and applying this, I shall hereafter explain.

Sir Humphry Davy says, "There is no ques" tion on which more difference of opinion has " existed, than that of the state in which ma" nure ought to be ploughed into the land; " whether recent, or when it has gone through " the process of fermentation. And this ques" tion is still a subject of discussion; but whoever " will refer to the simplest principles of che" mistry, cannot entertain a doubt on the subject. "As soon as dung begins to decompose, it " throws off its volatile parts, which are the 
" most valuable and most efficient. Dung " which has fermented, so as to become a mere " soft cohesive mass, has generally lost from one" third to one-half of its most useful constituent " elements. It evidently should be applied as " soon as fermentation begins, that it may exert " its full action upon the plant, and lose none " of its nutritive powers."

Again, "All green succulent plants con" tain saccharine or mucilaginous matter, with " woody fibre, and readily ferment. They can" not, therefore, if intended for manure, be used " too soon after their death."

A reference to the principles of chemistry, most certainly induces me to form conclusions very different to Sir Humphry: in his explanations of chemical principles, and their combinations, no doubt he is clear and correct; but many of his applications of those principles, and his inferences, appear to me to be superficial, hypothetical; and fallacious : and this most probably arises from a want of practical knowledge and observation. His opinions seem to be grounded on the belief, that in the production and application of food for plants, quantity is the grand desideratum. He appears to have no notion that the health and condition of plants, determine 
their value; or that vegetables are as much affected by both the quality and the quantity of food, as animals are, but such is the case.

That the state and condition of food when ad. ministered to animals, determine its effects, is generally understood: and it is precisely the case with vegetables. Thus, whenever the nutritive part of food is blended with a large portion of filthy and impure matter, vegetables, like animals, become gross, bloated, and diseased.

Although, (as I have before observed when speaking of the leaves of plants,) a rapid growth and large surface may be produced, this is of little value as food for animals; it is aqueous, vapid, obnoxious, and of little solid value; and plants in such a state, are, in another point of view, like animals, - they are sterile, and seldom produce their seed or fruit in perfection. And, therefore, notwithstanding a great part of that which constitutes vegetable and animal matter, may be thrown off in the process of fermentation, it is important to consider, what those parts are, before we attempt to appreciate their value. May it not be necessary to the health of vegetables, that a certain part should be expelled? And, although a portion of the more valuable part may be wasted in the process of fermentation: 
may not the process render the remainder of more avail and value, and thus create a profit instead of a loss?

It must be remembered, that the authority of chemistry rests upon this axiom, - that whatever constitutes a body, or operates as an agent in its construction, must be demonstrable on a chemical examination, both by analysis and synthesis. Now it does not appear, by the different analysis before explained, that any vegetable substance contains nitrogene, except gum, which is the produce of disease; but, that all animal substances, in an undecomposed state, do contain nitrogene. Therefore, - with all due deference to Sir Humphry Davy, - as in a demonstration by synthesis, or in the composition of vegetable, from animal substances, nitrogene cannot be considered as necessary, ought it not to be disengaged and expelled from such substances as are prepared for the food of plants? And if so, - as nitrogene cannot be separated, by any other means than fermentation, - is it not necessary that such decomposition should be effected previous to its application?-or that the substances be so placed, that the obnoxious gases be passed freely off, and that the action of decomposition may not affect the roots? It does not appear 
that plants throw off anything as excrementitious but oxygene ; and consequently, if nitrogene is taken in, it must be appropriated. This remark also applies to the consumption of hydrogene. If a plant be induced to consume an extra quantity of hydrogene, or carburetted hydrogene, it must form a surface sufficiently large to employ or appropriate it, or it must be passed off as diseased excresence; it cannot be expelled in a healthy manner, like oxygene.

Sir Humphry says, "In the writings of scien" tific agriculturists, a great mass of facts may " be found in favour of the application of farm" yard dung in a recent state. Mr. Young, in " an Essay on Manures, which I have already "quoted, adduces a number of excellent autho" rities in support of the plan. Many who " doubted have been lately convinced: and, " perhaps, there is no subject of investigation, " in which there is such a union of theoretical " and practical evidence. I have myself, within " the last ten years, witnessed a number of dis" tinct proofs on the subject. I shall content " myself with quoting that which ought to have, " and which I am sure will have, the greatest "weight among agriculturists. Within the last " seven years, Mr. Coke has entirely given up 
" the system formerly adopted on his farm, of " applying fermented dung: and he informs me, " that his crops have been since as good as they " ever were, and that his manure goes nearly " twice as far."

This doctrine, in a general sense, and compared with the old practice, agrees perfectly with my observation and experience; but Sir Humphry does not state, whether the dung is immediately ploughed in, by Mr. Coke, or suffered to lie on the surface; and the difference between those two modes of application, will be found to be very important, by every person who will try them.

I shall hereafter state my reasons why it is improper, as a general practice, to manure lands that are intended for immediate seed crops; but there may be cases where the state of the soil, rom extreme poverty and other circumstances, require it; and in those cases, I am convinced that the best time and manner of supplying dung for such crops is, by spreading it over the surface after the seeds are sown : at first sight, and according to Sir Humphry's notions, this may appear to be a wasteful practice; but it is far otherwise : for, as Sir Humphry says, " Or" "ganic substances, as soon as they are deprived 
" of vitality, begin to pass through a series of " changes, which ends in their complete destruc" tion, in the entire separation and dissipation " of the parts. Animal matters are the soonest " destroyed by the operation of air, heat, and " Light. Vegetable substances yield more slow" ly, but finally obey the same laws. The periods " of the application of manures, from decom" posing animal and vegetable substances, de"pend upon the knowledge of these principles." Now, notwithstanding the manner of applying dung which I recommend, -that of spreading it over the surface, and there permitting it to remain, before it be ploughed in, twelve months or more, is directly opposite to that recommended by Sir Humphry, it will be found more completely accordant with the above principles, as well as with those of Mr. Kirwan : for, by leaving dung openly spread on the surface, it is evident, that the influence of the air, the heat of the sun, and light, will be the least controlled or obstructed; and, consequently, the decomposition will be more rapid, regular, and conformable to the wants of the plants. Under such circumstances, more carbonic acid may be generated; but as this elastic fluid is heavier than the atmospheric air, it will fall on and penetrate the open surface of the soil, and thus accord in 
effect with the experiments, cited by Mr. Kirwan, of Dr. Priestley and M. Ruckett. And as to any loss arising by the evolution of any other gases, they are less likely to occur from dung in this situation than when buried; for carburetted hydrogene gas is formed in the greatest quantity during the putrefactive fermentation, and when the substances are immersed in, or glutted with, water, and excluded from the air and light; and in this state they most generally are when buried: and this gas, possessing an opposite quality to the carbonic acid gas, in being much lighter than the atmospheric air, will, as it is formed, operate in a reverse manner to the carbonic acid; it will immediately, on being liberated, penetrate the surface of the soil, mount rapidly into the atmosphere, and pass off with the wind, and be thus lost. And further, it is well known that animal and vegetable substances decomposed by the cold putrefactive fermentation ander the earth, or at the bottoms of stagnant ponds, are inert and inefficient; at least, until they are made to undergo some other chemical change, by calcination, oxydation, \&c.; this is evinced by peats, bogs, \&c.

We may likewise instance the effect of the accumulated animal substances decomposed under the earth in burial grounds, which never exhibit 
any comparatively extraordinary luxuriance of vegetation. And, as a practical demonstration that dung, when laid on or near the surface, and repeatedly turned over and exposed to the action of the atmosphere, is not very rapidly or very effectually exhausted, I shall state a course of operations which were carried on in a field of about six acres, within my immediate observation.

The soil of this field was a fine friable loam, and of a black colour, but the surrounding land, although of the same texture, was of a foxy brown; this difference in the colour, no doubt, was occasioned by the difference in cultivation and manuring. The surrounding lands had been treated in a careless, slovenly manner, as a common farm; whilst the field in question was cultivated as a market-garden, cropped with esculent vegetables, and manured at least once in the year, for many years. At the period it came under my notice the market-gardener had died, and it fell into the hands of another person, who having but seven years to run of a lease, determined, as he said, to work it out; he therefore sowed it with white wheat for five years following, without giving any manure. The first year, it produced forty-eight bushels per acre, and every year after, the crops declined three or four bushels per acre. The sixth 
year, it was planted with potatoes without manure, and the crop averaged fourteen tons per acre. The seventh year, it was sown again with wheat, without manure, and it produced upwards of thirty-two bushels per acre.

And to show the beneficial effects of topdressing, I shall also state that about this time, I took possession of a field of pasture land of about twenty acres, a strong yellow or foxy clay; it lay on the side of a hill, and was very wet and poachy, particularly during winter; had been generally cut for hay, although it seldom produced more than three-fourths of a load per acre, and this not until the end of July. I drained it by cutting a ditch at the upper side, deep enough to get below the stratum of clay, which in some places was upwards of five feet, turning the water down the sides, and gave it a top dressing of scavenger's manure, the cleaning of the town streets; and the year after, it produced me a load and a half per acre, in the middle of June; and a second crop, of three-fourths of a load, the beginning of September; and this it continued to do, varying a little, more or less, according only as the seasons were wet or dry.

And to shew the effect of dung buried deep; the following instance may be sufficiently strong. I had noticed a field at Wickham in Kent, 
which was laid down for a cherry orchard, and planted with fine young healthy standard trees, that for two years made a beautiful and luxuriant growth, and the third year, in the spring, they threw out their shoots with equal luxuriance; but before summer, I observed to my astonishment, they were all withered and dead. Not being able to assign a cause for such an unusual failure, I called on the proprietor, to enquire how it happened; he seemed perfectly resigned to what he called his ill luck, in having them struck with a blight; however, perceiving no reason why his trees should be blighted, whilst his neighbours all around, should escape uninjured, I enquired farther as to the nature of the subsoil, \&c., when he told me he had been at great expense and trouble to prepare the soil, by giving it a thick covering of rich stable dung, and trenching it. in, a spit and a half deep with the spade. I observed the trees had thrown out a profuse discharge of gum, and have no doubt, that during the two first years, the roots had not penetrated the dung, but on reaching it the third year, they were poisoned; or so glutted with such impure food, as to be thus diseased and destroyed.

Whatever devastation may be committed by the insect or fungus tribe, to trees or plants, 
I am convinced that by far the greatest extent of injury, from what is placed to the account of canker, mildew, \&c. if correctly investigated, will prove to originate in the unwholesome supply, or impurity, of the food.

As to the objection, that by leaving dung on the surface, a too rapid decomposition of the manure, will be followed by a too rapid consumption of food; it may be said, " a man cannot eat his cake and have it too." Let the crop be suited to the manure, or the manure to the crop, and as long as he gets its full value, lie will have little reason to complain of its coming into his pocket too quick; the sooner he gets a profitable return for one dressing of dung, the sooner he can afford another; and if a proper course of crops be taken, he may go on a long time, without feeling cause to complain that his lands are too prolific, or too rich.

To be consistent, we must either stick to chemical principles, or give them up. The difference in the effect of the method I-recommend, of applying manure on the surface, and there to suffer it to remain the longest period convenient; and that, by Sir H. Davy, of burying it immediately; may be determined by the comparative formation and effect of the two gases, carbonic acid, ànd carburetted hydrogen. If the former be, as stated, a principal 
ingredient in the food of plants, and that by its gravity it will penetrate into the soil, no method more favorable for its generation and equal distribution can be devised, than by my mode of application; and if carburetted hydrogen be either an unwholesome food, or by its rapid escape, the occasion of a great waste of carbon; and nitrogene gas be poisonous, or obnoxious, when in contact with the food; no mode can be more favorable to, or productive of, both those effects, than burying the dung in an un. fermented state.

If we were to suppose, that a difference in the quality of the food supplied to plants, produced no difference in its effects; or that the roots possessed the power of selecting the exact quantity and proportion of each principle, required for its particular purpose, from any composition that may be presented to it; we should be driven far off from accounting for the diseases of plants, or for the difference in the size, substance, state, and condition of plants of the same species, when growing in the same situations: and, although we are justified in believing, that a plant having taken in its food in a compound state, possesses the power of dividing and appropriating the different parts to its different purposes, it must be obvious, that any unnatural obstruction to the due 
exertion of those powers; or any improper substance being taken into the system with the food; must be followed by disorder, disease, and destruction.

One great power which plants are allowed to possess, and which seems absolutely necessary; is the decomposition of water, and the emission of oxygene; for, from the proportion of oxygene in water, being so much greater than in any of the vegetable products, the plant must take up more than it can need; and the great power and activity of oxygen is such, that unless plants had the means of expelling the superfluous quantity, they could not exist, nor could the different products be formed. But plants do not appear to possess the power of expelling hydrogene; therefore, whatever quantity of this substance be taken into the system, it must remain and be appropriated. With these ideas, the following analysis will be found generally to accord :-

Water contains,

Oil contains,

Sugar contains,
85 parts oxygene, 15 - hydrogene.

79 parts carbon, 21 - hydrogene.

- 28 parts carbon, 8 - hydrogene, 64 - oxygene. 
Gum contains,

23 parts carbon,

11 - hydrogene,

65 - oxygene,

1 . nitrogene.

Starch contains, - 43 parts carbon,

7 - hydrogene,

50 - oxygene.

Most people are aware, that the quality of the food consumed by animals, is equally as determined in its effects, as the quantity, and such is the case with vegetables. When an animal is constrained to live on meagre, impure food, or that, wherein a small quantity of nutriment is diffused or blended with a large insipid mass, it is induced to consume a greater quantity, to make up for the want of a more concentrated quality ; and the consequence is, an extension of the stomach and bowels. But although the animal in this condition, appears large in bulk, it possesses little solid value, and less strength to bear up under the additional weight; and such is the case with vegetables; their stalks, branches, and leaves, are the organs for the reception and digestion of the food; and whenever they are glutted with meagre food, a large extension of the leaf and branches follows, but in this state these possess little substance or value.

That some plants are more voracious than 
others, and that they sometimes, like some animals, feed on gross impurities; is distinctly proved by the flavor of esculents, and particularly the cabbage tribe: thus we find that sea-kale, growing in rank manured beds, is so gross and bitter in flavour, as scarcely to be eatable; whilst that which is grown in a pure natural soil, is sweet and delicious.

Certainly, we cannot pretend to the powers of determining and measuring out the exact proportions of the required elements; but we may, by a little attention, be able to counteract and avoid extremes.

It appears throughout nature, that the efforts of a plant, from its first establishment, is directed to acquire the proper state and condition to propagate its species; and that in its seeds and fruit is comprised its concentrated essence. We may therefore estimate its powers and efforts to be in proportion to its wants; and hence we may suppose, that as starch, and sugar, contain a large portion of oxygene, and a small portion of hydrogene; that those plants whose desired products consist of such substances, should be supplied with food containing a large portion of carbon and oxygene; and as oil contains a large proportion of hydrogene, and no oxygene; that to those vegetables, whose seeds produce oil, a 
supply of food should be given, containing a large portion of hydrogene and carbon.

On these grounds, admitting carbonic acid and carburetted hydrogene to form the food of plants, we come to the following conclusions. Those substances, and that mode of preparation, which produce carbonic acid, and carbonaceous oxydes, constitute the best food, and the best state, for all plants producing grain and pulse ; and surpass also, the best adapted for clovers, grasses, \&c., for feed and for hay; as the quantity of saccharine matter they contain, determines their value, and not the bulk, which alone would be increased by carburetted hydrogene. For thóse plants whose seeds produce oil, such as hemp, flax, rape, and all the cabbage tribe, car. buretted hydrogene may be well adapted. We find those ideas cortoborated by natural and practical results : thus, seed-crops of grain and pulse are always most healthy and prolific, on lands that have been treated in that manner, and left in that state, in which the roots are the most completely freed from those substances which produce carburetted hydrogene gas; and hemp, rape, turnips, cabbages, \&c., from their peculiar form of growth, are enabled to sustain a large and extended surface, and can therefore 
appropriate a large portion of carburetted hydrogene without injury.

A due attention to these particulars will explain the want of accordance in the opinions of Sir Humphry Davy, with many of the operations that are most successfully practised by many eminent farmers. Indeed, if the food of plants was wasted, by exposure to the atmosphere; ploughing and stirring up the soil must occasion waste and sterility; and the same must be the case with turning over, and exposing masses of dung; but, observing practitioners well know that those processes are followed by additional prolificacy.

That class, among the cultivators of plants, who, of all others, pay the most attention to their health, and proper condition for fructification, is, perhaps, the florists; and the most eminent amongst those, make it their practice to mix and turn over their compost at short intervals, so that every part may be exposed to the influence of the sun, air, and light, for at least twelve months before they use it.

The fact is, I believe, that whether carbon and oxygene combined, as carbonic acid, be the best state of preparation for the consumption of plants, or not; carbon and oxygene form the 


$$
\text { ON THE FOOD OF PLANTS. }
$$

grand essentials for making them prolific; and when vegetable aud animal substances are laid on the surface of the soil they are intended to enrich, they are in a situation best calculated for decomposition, by oxydizement; for then, as they are reduced to a soluble state, they are dissolved by water, and carried to the roots; and when there is not moisture enough to carry down the soluble part, it lies dry on the surface; and whilst dry,-as Sir H. Davy observes,no fermentation can take place; and thus circumstanced, under the alternate state of wet and dry, the decomposition is gradual, complete, and rapid. This may be observed by a stake of wood, that has been some time fixed into the earth ; for that part which is under the earth, and that which is in the air, will remain sound, long after that part which is between both, or on a level with the surface of the earth, is completely decomposed.

Besides, there is a natural operation constantly working, to assist in the decomposition of vegetable substances which are laid on the surface, and to facilitate their conveyance to the roots of plants; which, although little thought of, is of great importance, and this is conducted by the earth worms. Whoever will notice the surface of the earth, will find those creatures not only.con- 
stantly boring holes, and drawing the light substances around them, but that by their slime they very much quicken the decomposition; this is readily proved by leaving a piece of twine on the surface of the earth a short time; and within a few days after it has been laid hold of by the worms, it will be found quite rotten; their holes also afford ready channels of convey. ance for the decomposed matter.

And further, these little creatures perform another important operation; they devour and cast upon the surface, the more finely divided earthy substances and undecomposed matter; and thus that part of the soil best adapted to sustain vegetation, is collected and accumulated on the surface, and within the healthful range of the roots of plants. The soil is also by such means, rendered more conducive to an equal percolation and evaporation of water; and it may be observed, that placing dung on the surface, favours both the existence and the working of these useful cultivators; the surface of the earth, thus continually opened, also affords a free ingress to the carbonic acid gas, and egress to the carburetted hydrogene.

Again, Sir Humphiy says, "All green suc" culent plants contain saccharine, or mucilagi" nous matter, with woody fibre, and readily 
"ferment; they cannot, therefore, if intended "for manure, be used too soon after their "death."

"W. When green crops are to be employed for " enriching a soil, they should be ploughed in, " if possible, when in flower, or at the time the "flower is beginning to appear; for it is at this " period that they contain the largest quantity " of easily soluble matter, and that their leaves " are most active in forming nutritive matter; " green crops, pond weeds, the paring of hedges " or ditches, or any kind of fresh vegetable " matter, requires no preparation to fit them for " manure; the decomposition slowly proceeds "beneath the soil; the soluble matters are gra" dually dissolved, and the slight fermentation " that goes on, checked by the want of a free " communication of air, tends to render the woody "fibre soluble, without occasioning the rapid " dissipation of elastic matter."

This doctrine is evidently founded on the notion, that plants consume vegetable substances in their compound state; but having admitted that carbon, oxygene, and hydrogene, with a portion of earth, are all the elements that are necessary to compose a vegetable; and also, that water contains all those elements in itself, except carbon, and that carbon, produced by the 
fermentation of vegetables, is readily dissolved and taken up by water; and that plants possess the power of decomposing water, and of dividing and appropriating its principles, in combination with carbon, to all its various uses; why are those principles abandoned, and a process recommended, grounded upon supposition only, in preference? Such a deviation from the wise rule of Sir Isaac Newton is surely worse than trifling; it is injurious to the character of science. Vegetables exposed to the sun and air, and dried, are found to possess more or less of sugar, according to their nature ; and sugar is a vegetable oxyde, almost immediately soluble and convertible into food; and it is most readily convertible and productive of carbonic acid; let any person take a bundle of hay, and a bundle of green grass, and submit each to infusion, and compare the extract, both in appearance and effect; the difference will be considerable:

What says Sir Humphry of malt dust? That it " consists chiefly of the infant radical, se" parated from the grain." And he says, "I " have never made any experiment upon this " manure, but there is great reason to suppose " it must contain saccharine matter, and this will " account for ITS POWERful effects." Now if these infant radicals had been separated and 
búried in their green state, what powerful effects could they have been expected to have produced in fertilising the soil, more than the severed ra-: dicals of other plants, of which the earth is always full? Surely none. Then what created the difference? Most evidently the exposure? to heat and air on the kiln, which, by oxydise-: ment, created the sugar.

Vegetable substances and dung, in drying, undoubtedly are reduced in weight, by the evaporation of its water; but this is a loss of no importance, for water is again readily supplied, and by the operation they absorb oxygene, and are thus brought to a state much more efficient; that of soluble oxydes. From all the observations I have made, and which I have endea-. voured to explain, I am convinced, that every: addition of food to plants, and every operation of agriculture, wherein the cultivation of vegetables is concerned; will be found more or less: efficacious as it favours the free access, or in-s gress and egress, and the general influence, of the oxygene of the atmosphere and water, to the whole structure of the plant, and the ingredients of its food during preparation.

And as to the mechanical effect of dung, in pulverising the soil ; that which is placed on the surface, must ultimately be equal to that which 
is immediately buried; for, as has been stated, that by burning, the solid part of the earth cannot be reduced; no more can the solid part of dung be reduced by evaporation; and the effects of dung thus placed, in increasing the disposition of a soil to absorb moisture from the atmosphere, cannot be less, than when immediately buried : and what is more essential, it will be less retentive of water.

Sir Humphry Davy has fully and minutely described the nature and properties of all the different substances used as manures, and such who wish for particular information on these divided subjects, I must refer to his work. My object being to establish general principles, it would be superfluous to attempt following him further. On the preservation of manure he says, "When dung is to be preserved for any "time, the situation in which it is kept is of " importance; it should, if possible, be defended " from the sun; to preserve it under sheds "would be of great use, or to make the site of " a dunghill on the north side of a wall. The "floor on which the dung is heaped should, if " possible, be paved with flat stones, and there "should be a little inclination from each side " towards the centre, in which there should be "drains comnected with a small well, furnished 
.8 with a pump, by which any fluid matter may "be collected for the use of the land. It too si often happens that a dense mucilaginous and " extractive fluid is suffered to drain away from " the dunghill, so as to be entirely lost to the "farm."

My previous objections to the application of Sir Humphry's ideas, must be equally strong against the mode here recommended.

Those who are in the habit of making hotbeds for vegetables, know that fresh dung from the stable, packed together without a sufficient degree of moisture, to modify its fermentation; will very speedily acquire a high degree of heat, and throw off a quantity of elastic vapour; either carburetted hydrogene, or ammonia, and that as the moisture declines, the heat will also: and the dung will then be overrun with mouldiness, or fungii, and thus during such fermentation, the exclusion of moisture or rain, by a shed being placed over it, must facilitate and increase the loss by such evaporation, and by the evolution of the gases; and the earth covering dung in this state, will not afterwards support vegetation. As the chief supply of manure is derived from the stable and farm yard, the arrangement and management of these is a matter of no trivial importance. 
In the general mode, I have always thought. sufficient care and attention are not given to the preservation and application of the urine of the animals; and that this is more valuable in the composition of the food of plants, than is generally calculated: urine not only in itself contains greater fertilising powers than the excrement, or dung; but added to this, it considerably accelerates and moderates the fermentation, and particularly when diluted with water in a due degree. The effects of the urine, also, when thus divided and diluted, by mixing with the dung, are much increased and beneficially extended: and a much better mode, in my opinion, for conducting this process, than that recommended by Sir Humphry, is described by, Sir John Sinclair, as adopted in the Netherlands.

He says, "The more opulent pave and line. "with brick the receptacles for their dung, " which is thus constantly kept plunged in a " mass of liquid matter; the fibrous parts of " the vegetables are thus completely decom"posed, and four tons of this manure go as far. " as five kept with less precaution."

But this liquid should consist of urine not too much diluted, or with no more water added, than is sufficient to keep the fermenting heat below the power of generating steam. 
Drains should be carefully inade from the stables and cattle-sheds; to cisterns or wells protected from the rains; and from these, the urine should be taken and thrown over the dung-heap, which should be open to the air : there is little danger of too much water added by the rains, if not under the dripping of a shed.

I am convinced that stable and yard dung, saturated with urine, and preserved in this manner, would go twice as far as such dung prepared in the usual manner, that is, by being thrown into the open yard, and where the urine of the stables and sheds is not only suffered to run away, but the yard laid in such a manner that the dung is washed by the rains, and the drainings wasted.

It is a little singular that landlords, well aware that on the supply of manure depends the value of the farm; are in many instances so jealous of having all the produce of the farm spent on its land, that they will not permit their tenants to sell a load of straw; and yet they not only will not be at the expense of properly constructed receptacles for preserving the manure, themselves; but will not regard the careless ignorance and neglect of the tenant, of these objects.

The superior effect of putting the manure on I 3 
the land as it is produced, as stated by $\mathrm{Sir} \mathbf{H}_{\text {。 }}$ Davy to be the case with Mr. Coke, may be accounted for, as arising from the urine absorbed by the litter, which, if left in the usual way, spread in an open yard, would have been wasted and lost.*

* Whilst recommending the careful and effectual draining of stables, for the preservation of the urine, as the most valuable part of animal manure, I will also state a circumstance, which cannot be thought unworthy of notice to agriculturists, which occurred to me, to show how necessary this is also to the health of animals.

I took possession of some stables, with the horses that had been some time kept in them, and, to my misfortune, in a very short time I found that the horses kept in those stables had been subject to that dreadful disease, called the mad staggers; for several years. Some horses had died, and the horses then there, and which had been for some time kept in the stables, were in wretched condition. Two fine fresh horses which were put into them, were within a few months seized with the mad staggers, and one of them literally killed himself by knocking his head about against the manger and stall; the other was saved by copious bleeding, and removal into a fresh stable, but was so reduced as to be lessened in value onehalf. My neighbours advised the pulling down the stables, considering the disease infectious; but having, on going into the stables early in the morning, been almost suffocated and blinded by obnoxious gas; I examined the floor and drains, when I found the former to consist of large burr stones, laid on a stiff clay; and the floor sunk so low below the drain, as not to admit of the draining away of the urine. This struck me to be a sufficient eause to affect the brain of 
To show the fertilising effects of urine, Sir John Sinclair says, "Every sort of urine con" tains the essential elements of vegetables in a "state of solution. The urine of a horse, being "so much lighter, would be more valuable than " its dung, if both must be conveyed to any dis" tance. The urine of six cows, or horses, will "enrich a quantity of earth, sufficient to top"dress one English acre of grass land; and as " it would require four pounds worth of dung " to perform the same operation, the urine of a " cow, or horse, is worth about twelve shil" lings per annum, allowing eight shillings "per acre as the expense of preparing the " compost. The advantages of irrigating grass "lands with cow urine almost exceeds belief. "Mr. Harley, of Glasgow, (who keeps a large " dairy in that town,) by using cow urine, cuts " some small fields of grass six times; and the " average of each cutting is fifteen inches in "length."

In concluding this part of my subject, I shall shortly recapitulate my observations.

any animal confined in it, the same as it had the horses. I therefore had the floor taken up, relaid, and properly drained; and the walls and ceiling, manger, cribs, \&c, washed with quick lime; and from that time for ten years, I never had a discased horse. 
It seems to be generally admitted, that animal and vegetable matter must be reduced to a perfectly soluble state, before it can be appropriated as food for plants; and to effect this, it is considered necessary, that a perfect decomposition should take place, of the substances provided for this purpose, and many processes are noticed, by which a decomposition is effected; but that which is most generally considered as the indispensable one, is the putrefactive fermentation. There are, however, five distinct stages of fermentation described by chemists; namely, the saccharine, or that which changes coagulated mucus, or starch, into sugar; the vinous, or that which forms alcohol, or spirit, from sugar, and at the same time generates carbonic acid; the acetous, or that which forms vinegar from sugar; the colouring, or that which converts the substance of the green indigo plant into blue; and the putrefactive, which effects the last and complete disunion of all the component parts of a body; leaving all at liberty to form other combinations.

Now all the different authors appear to concur in the opinion, that the putrefactive fermentation is a necessary process for the reduction of animal and vegetable substances, to the requisite state of food for plants; the other different stages 
being either overlooked, or considered unimportant: but in this, I think, they egregiously, err.

. It is certain, that when animal and vegetable substances are left to spontaneous decay, the putrefactive fermentation must be the ultimate result; but it is demonstrative, that the residuum, or the matter left by completely putrefied animal and vegetable substances; will not support the vegetables cultivated by man, in a healthful progress to prolificacy, any more than either of the simple earths: and that when reduced to this state, its action is merely mechanical, or operative only, as it serves to temper, or constitute, the compost or soil. And further, that when in too great a proportion, in this state, it is injurious, as it retains water until it becomes in a state of stagnation; whilst, on the contrary, every process that checks the putrefactive fermentation, and every operation that retards and dispels its effects, in and on the soil ; and the addition of many substances that are decidedly anti-putrescent, such as charcoal, alkaline salts, lime, \&c. and which facilitate the dispersion of water : add to the fertility of the soil, and increase its prolificacy.

Thus we find that the spreading of dung thinly over, and near, the surface of the earth; 
the repeatedly stirring and turning it up, and exposing it to the action of the sun, light, and air ; paring and burning; the addition of lime; and the calcareous and saline substances; and, above all, the production, presence, and retention of carbonic acid; all corroborate my principles.

And if all physiologists do not agree, that carbonic acid forms the productive food of plants; all accord in the doctrine, that those substances which either contain, or are capable of producing carbonic acid : are conducive to the fertility of the soil, and congenial to the health and fructification of plants. I therefore cannot but think the following are the true inferences; that in the decomposition of vegetables and animals, or the preparation of the food of plants; (so far from hastening, ) every means should be adopted that anticipate, or precede, the putrefactive fermentation, in the reduction of those substances to a soluble state; - that vegetable substances should be managed and disposed, so as to effect and encourage the saccharine fermentation to the utmost; before they are exposed to the putrefactive, which is done by effectually drying them in the sun and air; - and that animal substances should, as much as possible, be placed under those circumstances which favour the formation and 
diffusion of nitrous salts, and that prevent the formation of carburetted hydrogen; and this is done by mixing them with vegetable substances and calcareous earths, lime, \&c. and exposing them, as much as possible, to the action of the air and light. And, above all, that every means be adopted to remove every tendency in the soil, or the manure, to retain water in a state of stagnation; for those plants which are the grand objects of cultivation in husbandry, will never grow healthy and prolific in stagnant water; whatever food they may be supplied with; nor will the residuum of animal or vegetable matter, decomposed by putrefaction in stagnant water, either invigorate or sustain such vegetables. 
ON THE RUST OR BLACK BLIGHT IN WHEAT.

According to our understanding of the principles, which regulate and determine the preparation and application of the food of plants; must be our notions of the diseases of plants, and our ideas of the best mode or course of cultivating them.

A wide difference undoubtedly exists in the formation, functions, and peculiar nature of animals and vegetables; but yet they may, in many respects, be assimilated; and thus, by comparison, the proper treatment of plants be simplified, and rendered more easy of explanation and comprehension. I shall take leave to state, that the observation and experience of many years have convinced me, that the opinions of the great reformer of the medical profession, Mr. Abernethy - that the most afflicting diseases to which the human species are subjected, are generated in the stomach, and consequently are to be remedied by the stomach -are perfectly just and well founded : and I am also convinced, that most of the diseases of animals and of plants, may be accounted for and remedied, on the same principles. From what has been said, it is clear, that vegetables cannot 
be supported without a due supply of food; and that with those, as with animals, the quality and quantity of food must possess an equal influence.

Every man is aware, that the quality of the food he consumes, is equally as determined in its effects, as the quantity; and such, no doubt, is the case with plants, as before observed. When an animal is constrained to live on meagre, impurefood, it is induced to consume a greater quantity, to make up as much as possible for the deficiency of quality; and the consequence is, a distension of the stomach and bowels. And this is often followed by a poverty and corruption of the fluids, which produces disease and debility; and the body is wasted by eruptions, and becomes a prey to vermin. And when an animal (more particularly during parturition) is glutted with gross and rich food, a surfeit is the consequence; and it is subjected to a stagnation of the fluids, inflammations, and eruptions; which often end in mortification and death : and plants, under the same circumstances, are subject to the same consequences.

These observations will be found correctly to apply to, and to afford a clear exemplification of, the rust,' or black blight, in wheat.

On this subject, Sir John Sinclair says, "It " appears, from an able paper written by a dis- 
" tinguished naturalist (Sir Jos. Banks), that this " disease is occasioned by the growth of minute "parasitical fungus, or mushrooms, on the leaves, "stems, and glumes, or chaff, of the living " plants; and that the roots of the fungus, inter" cepting the sap intended by nature for the " nutriment of the grain, render the grain lean " and shrivelled, and, in some cases, rob it com"pletely of its flour. Nor is that all; the straw " becomes black and rotten, unfit for fodder, or " little better than a caput mortuum, possessing " neither strength or substance."

Again, - "Several of the accidents, above " enumerated, may contribute to the production " of rust; but there are two additional circum"stances which likewise tend to promote it. "First, - Having the land in too rich a state for " corn crops ; and, Secondly, - When too fre" quent a repetition of crops of wheat takes "place."

"It has been well observed, that when crops, " intended to ripen their seed, are objects of " sulture, there is not only wanted a degree of "vigour and luxuriance in the plants sufficient " for the purpose; but if the fertility of the soil " be raised to a higher pitch than is necessary or " consistent with that object, injurious rather .6 than beneficial consequences may be the result. 
"Land may be too rich for corn crops; and it is " better to keep it in a well-balanced condition, " or in a medium state of productiveness, than "s in too fertile a state. The greater quantity of " sap and juices in vegetables, growing on highly " cultivated lands, it is evident, must necessarily " render them more susceptible of the effects of "sudden and extreme changes, and, conse" quently, more liable to disease. Besides, as " mushrooms are produced on beds of dung, "great quantities of manure must promote the " growth of fungi, or parasitical plants, on the " crops of wheat, if they are once infected. The " wheat produced on the site of a dunghill is " always rusted, even in the most favourable " seasons; and if the whole field is a species of " dunghill, how can it escape ?" "A too frequent repetition of crops of wheat, " more especially when accompanied by great " quantities of manure to force a crop, will often " have the same effect. The rust was but little " known in the western or the northern parts of " England, or the southern counties of Scotland, " until of late years, when every exertion has " been made to increase the quantity of that "grain."

Sir John Sinclair also says, "Among the reme" dies likely to diminish the effects of this fatal 
" malady, the following have been particularly" " recommended: 1. Cultivating hardy sorts of "wheat; 2. Early sowing; 3. Raising early "varieties; 4. Thick sowing; 5. Changes of" "seed; 6 . Consolidating the soil after sowing; “7. Using saline manures; 8. Improving the " course of crops ; 9. Extirpating all plants that " are receptacles of rust; and, 10. Protecting " the ears and roots of wheat, by rye, tares, and " other' crops."

And again, hesays, "It is likewisestated on the " respectable authority of an eminent naturalist " (T. A. Knight, Esq.), that by crossing different "varieties of wheat, a new sort maY be produced, " which will completely escape being : rusted, " though the crops in the neighbourhood, and in " almost every district in the kingdom, may suffer "from it in the same year. These circumstances " tend to prove, that the rust does not depend " solely on atmospheric influence, otherwise it " could not be prevented by changes of seed, or " by the crossing of different varieties."

This theory of Mr. Knight's is like many, others of his, grounded on a superficial view of things, and is a mere fallacious hypothesis.

Indeed all these great naturalists appear to. have bewildered themselves in specious theory; and from not having traced the operations of 
nature to its source, have throughout mistaken the effect for the cause.

Suppose a farmer was to find a sheep, unhappily reduced, and preyed upon by maggots, or the larva of the flesh-fly, he may very justly suppose that the maggots reduced the sheep; and as justly expect, that whatever sheep were subjected to the maggots, would be reduced in the same manner. Then what would be the best and pro. per remedy? Knowing the maggots to be produced from eggs deposited by flies, would he try to cover his sheep from the flies; or attempt to drive them where there were no flies? Where is the farmer or shepherd that does not know, that flesh. flies will not deposit their eggs on a healthy part of a sheep ; or if they do, that they will not produce maggots? They know full well, that if a sheep be diseased by eruptions, or wounded; the flies will find out these places, and there deposit their eggs; and, therefore, the remedy is simple: cure and prevent the disease, or protect the wounds, and the evil is avoided - "Remove "the cause and the effect ceases."

Very similar will be found the diseases in wheat, called the rust, or black blight, and its cause.

The fungus undoubtedly preys upon that which is intended to nourish and sustain the 
wheat; but what afforded an attraction and lodgement for the fungus? This is the grand question.

It is stated, that the fungus is a parasitical plant, like the misletoe, but this is not the fact; the fungus has no power to attach itself to, or penetrate, the healthy stalks of the wheat, any more than the larva of the flesh-fly have, the healthy skin of the sheep.

Any one who will examine the stalks of wheat growing on a luxuriant, rank soil, at short.intervals, about the time of its first showing the swelling of the ear; will perceive the vessels to become ruptured, either from the luxuriant flow of the sap up the tender tops of the plants, being checked by cold winds, or an unhealthy overfulness, or some other casual obstruction ; and the sap being thus suddenly checked, will rupture the vessels, and ooze out through little slits, or longitudinal fissures; the discharged matter will soon assume the appearance of a white jelly; as it dries, it will become yellow, and then brown, and of a hard texture: and in proportion as the sap-vessels are injured and destroyed, and this exudation takes place, the plant must of course, more or less, fail in its supply of nourishment to the grain In some : cases, the strongest stalks will not be able to push the ear beyond the leaf, and the corn 
consequently will be starved. Whilst the season continues dry and cold, the exuded sap will remain like dry gum; but as it advances, and the weather becomes warm and moist, the gun becomes moist, soft, and putrefying; and then forms, and affords a nutritive bed for the mould or fungus; which grows and increases until it is deprived of moisture, or is so reduced as to be insufficient to sustain it, when it dies ; and according as the season is favourable or unfavourable to its growth, it produces a brown, or black powdery substance, in a proportional quantity. Thus then, the foundation or cause of the rust or fungus, is the putrefying matter discharged from the ruptured sap-vessels of the plant: and although the ruptures may be occasioned by a contraction or obstruction of the vessels by atmospheric influence; the overfulness, or overluxuriance of the plant, produced by surfeit ; or the being glutted with rank and unwholsome food; and its incapacity of digestion, and unhealthy obstructions; renders it more liable to such injuries : and may therefore be considered as the general cause of the disease, blight, or rust.

I have planted wheat in a rank compost of dung, which from its first appearance in the autumn, during its growth in the winter, and 
in the spring; maintained excessive luxuriance, but which was ultimately so reduced by rust, as to be rendered weak and incapable of bringing its seed to perfection: at the same time, and close alongside; I also planted wheat in a pure and sweet sand, and supplied it with a solution or infusion of rotten dung, by way of food; this never appeared half so luxuriant as the other; but the stalks or straw grew perfectly healthy, and free from disease, and the grain was of good quality.

The following statement by Sir John Sinclair, as well as what has been already quoted, will in every respect be found to corroborate and sustain my observations and opinions.

He says, "As land in too rich a state is apt to " produce rust, it is found to be an effectual "remedy, if previous to a crop of wheat the "d dung is applied to a smothering crop, as tares, " hemp. \&c, Indeed after cole seed, wheat is "s scarcely ever known to be rusted. The gene" ral culture of that article, and the use of Dutch " ashes impregnated with saline matter, as a "6 manure, tends greatly to the exemption from " rust, by which, wheat in Flanders is distin" guished.

"Potatoes, when the crop is large, have the "same effect; in Flanders, where the wheat is 
" never materially injured by rust, potatoes are "s considered in its best cultivated district (the " Pays de Waes) as the best preparation for that "s crop. If too much dung occasion the pro"pagation of fungi, which there is reason to "believe is the case, smothering crops, by " exhausting and diminishing the strength of "s the dung, may take away that tendency."

Undoubtedly the tares, cole-seed, potatoes, \&c. growing on the manured soil, must reduce, if not wholly consume, its gross and over-luxuriant qualities, and time and exposure, effect a more complete decomposition and evolution of its vitiating effluvia, and thus the great cause being removed, the effect must cease.

- Sir John further says, "Mr. Knight is de. " cidedly of opinion that the disease is taken up "by the root, every experiment to communi" cate it from infected straw to others proving " abortive, and indeed if it were introduced into " the ear of the plant how could it descend, and " infect solely the stem, which is the case, un. "less when the disease is inveterate?"

As to the fungus passing into plants by the roots, or being prevented from propagating, by any of the means here pointed out, it appears almost too preposterous to be seriously thought of: How difficult do our housewives find it, to ex: 
clude the seeds, or prevent the fungus, growing on their pickles and preserves, even by tied down bladders and tight corks? And if horsedung in a mass be placed in certain situations, it is well known that even the large edible mushrooms will rise and grow where they never were seen before.

Thus, then, if the cause of the rust or black blight be as I have stated, - and the observations both of Sir John Sinclair and Mr. Knight confirm my opinions, and the observations of. Sir Joseph Banks do not controvert them, - the remedy is simple and obvious: viz. for the production of seed crops; let manuring follow, and not immediately precede them; or at any rate, dung should not be ploughed in, on such lands, immediately before sowing the seeds.

And it is equally obvious, that the ploughing in, green crops, must be conducive to the production of rust. And the feeding off turnips with sheep, or folding them on the land, immediately before sowing, must have a strong tendency to the same effect.

- If, when lands are manured, two or three succulent or green crops be taken off, before it is sown for seed-crops, although the leaf and plant, or straw or haulm, of such crops may not appear. so luxuriant: in consequence, the seed will be 
larger in quantity, and finer in quality. And if, in the general course of cultivation, dung be applied or given to the green crops, which precede the white or seed-crops, the luxuriance of leaf, stalk; \&c. will be produced in that form which is most valuable, either as green food, turnips, \&c. or hay; and the succeeding graincrops would, in no respect, be diminished; and the straw, from being free from disease, would be much increased in value.

From what I have stated, if two crops of wheat be desired in four years, the better mode of manuring for them is, to lay on the dung the two first years for green crops, and take the two wheat-crops following, in the last two years. There never was a more widely mistaken notion, than that a supply of dung given one year, can be exhausted either in that or the following year, by cropping with any thing, but by burying it below reach of the roots, or so low that it becomes inert or poisonous; the manure may be worse than lost.

Sir John Sinclair again very justly observes, "By the improvements which may be effected " by the observations of ingenious naturalists, and " the experience of intelligent farmers, there is " every reason to hope that the diseases of wheat " may, in a great measure, be so mitigated in their" 
"effects, that they will not in future be felt as " a national calamity. For that purpose, how" ever, it is necessary that the diligent farmer " should seize every opportunity of improving " his knowledge in the diseases of wheat; should " note down all the circumstances connected " with the subject as they occur, and should " compare his observations with those of others ; " that whether the causes of rust are general or "local, they may as much as possible be ob. " viated."

To this I will beg leave to add, that however repeatedly, the diligent farmer may have been misled by theory, he cannot be justified in wholly opposing or neglecting science. The opinions I have here endeavoured to explain, are grounded on demonstrative practical experiment. And as it is in the power of every farmer to make the same demonstration, I trust every one will consider it, in justice, due from all, to do so, before they indulge in speaking. lightly of them, or in treating them with neglect. 


\section{ON FALLOWING.}

THE concurring action of the principles $I$ have laid down, will be found correctly to apply to the operation of fallowing, and clearly shew the real value of this process.

In a general point of view it is obvious, that both the advocates for, and opponents of, the system of fallowing, have indulged in extremes; the former attributing effects which, under common circumstances, it cannot produce; and the latter denying those which are clearly evident. I shall however hope to show; that a little giving way on both sides, will tend most to the public, as well as private benefit.

Sir John Sinclair observes, "Over the greater " part of Europe, it was formerly considered to " be a most advantageous practice, periodically " to dedicate an entire season to the cultivation " of arable land, without raising from it any " crop. It was supposed that the expense would " be amply compensated by the texture of the "soil being ameliorated, by the destruction of " weeds, which would be thus effected, and by " the increased produce of the succeeding crops. 
"But when the expenses of cultivation were " augmented, when new crops, as turnips, were " introduced, (which were favourable to the " process of cleaning the ground by their later " period of sowing, and the hoeings they re"quired,) and when the productions of the soil "became more valuable; it was natural for the " farmer to consider whether such great sacri" fices were really necessary, and whether fallows " might not, in many cases, be diminished, and " in others, totally given up. On this subject, " a controversy has arisen between two sects, " the fallowists and anti-fallowists, which has " been conducted with much keenness and " energy.

"Of late years the question at issue has been " much narrowed. It is now admitted, that " on all light soils, where the turnip-culture can " be practised, fallows are unnecessary; and " that on strong lands, under a judicious system, " they are not essentially necessary more than " once in the course of a rotation. The subject "under discussion, therefore, is reduced to this " short question:-Is it for the interest of a " farmer who cultivates cold, strong, clayey, "adhesive, and wet-bottomed lands, periodi" cally to fallow them?".

This is certainly reducing the eligibility of the 
practice, to a matter of calculation of profit. And as, after all, this must depend entirely on the means of the farmer, it may not be an unjust view of the subject, although a very contracted one.

But does the operation of fallowing increase or diminish the fertility of the soil? This is the question undetermined, and is the most important one, and to solve it, it will be necessary to trace the operation of chemical principles to practical results.

Sir H. Davy says, "The chemical theory of "fallowing is very simple. Fallowing affords " no new source of riches to the soil. It merely " tends to produce an accumulation of decom" posing matter, which, in the common course " of crops, would be employed as it is formed. "And it is scarcely possible to imagine a single " instance of a cultivated soil which can be sup" posed to remain fallow for a year with advan"tage to the farmer. The only cases where " this practice is beneficial, seems to be in the " destruction of weeds, and for cleaning foul " soils."

Again, "The most important processes for " improving land, are those which have been " already discussed, and that are founded upon " the circumstance of removing certain consti- 
" tuents from the soil, or adding others, or " changing their nature. But there is an opera"tion of very ancient practice still much em"ployed, in which the soil is exposed to the "air, and submitted to processes WHICH ARE " PUREL MECHANICAL, namely, fallowing. "The benefits arising from fallowing have "been much overrated; a summer fallow, or a " clean fallow, may be sometimes necessary in "lands overgrown with weeds, particularly if " they are lands which cannot be pared and burnt "with advantage, but is certainly unprofitable " as part of a general system of husbandry. "It has been supposed by some writers, that " certain principles necessary to fertility are de" rived from the atmosphere, which are ex" hausted by a succession of crops, and that these " are again supplied during the repose of theland, " and the exposure of the pulverised soil to the " influence of the air ; but this in truth is not the " case. The earths commonly found in soils " cannot be combined with more oxygene; some " of them unite to azote, and such of them as " are capable of attracting carbonic acid, are " always saturated with it on those soils in which " the practice offallowing is adopted. The vague " ancient opinion of the use of nitre, and of " nitrous salts, in vegetation, seems to have been 
" one of the principal speculative reasons for the "defence of summer fallows.

" Nitrous salts are produced during the expo"sure of soils containing vegetable and animal "remains, and in greatest abundance in hot " weather; but it is probably by the combination " of azote from these remains, with oxygene in " the atmosphere, that the acid is formed, and " at the expense of an element which otherwise " would have formed ammonia, the compounds " of which, as is evident from what was stated in " the last lecture, are much more efficacious " than the nitrous compounds in assisting vege" tation.

" "When weeds are buried in the soil, by their " gradual decomposition they furnish a certain "quantity of soluble matter; but it may be " doubted whether there is as much useful ma" nure in the land at the end of a clean fallow, " as at the time the vegetables clothing the sur" face were first ploughed in. Carbonic acid gas " is formed during the whole time by the action " of the vegetable matter upon the oxygene of "the air, and the greater part of it is lost to the "soil in which it is formed, and dissipated in the "6 atmosphere."

The reasoning here offered by Sir Humphry Davy, affords further proof of the possibility of 
staggering even truth itself; by a plausible theory, when practical observation is not brought to aid the judgment.

To show the fallacy of the objections above stated, and to prove that by the operation of chemical principles, fallowing must add to the fertility of the soil, we need only refer to what has already been said on the nature of the food of plants : however, the more clearly to establish those principles which are most important, I shall endeavour further to elucidate their applicability. Admitting what Sir Humphry states to be fact, "That the earths commonly found " in soils cannot becombined with more oxygene, " and none of them unite with azote;" yet the remains of vegetables which are always in the soil may; superfluous or stagnant water may also be dispersed; and the formation of carburetted hydrogen gas prevented : for as he further says, "In " the production of a plant from seed, some reser" voir of nourishment is needed before the roots "can supply sap, and this reservoir is the cotyle" don, in which it is stored up in an insoluble form, " and protected if necessary during the winter, " and rendered soluble by agents which are con" stantly present on the surface. The change of " starch and coagulated mucilage into sugar, con" nected with the absorption of oxygene, may be 
"rather compared to a process by fermentation, "than to that of respiration; it is a change ef$\because$ fected upon unorganised matter, and can be ar" tificially imitated; and in most of the chemical " changes that occur, when vegetable compounds " are exposed to air, oxygene is absorbed, and " carbonic acid formed or evolved."

Then why deny the presence or action of such agents, to change and prepare both organised and inert vegetable matter, and rendering them soluble; and reducing them to a proper state as food for plants; when thrown up and exposed to the surface by fallowing?

The very idea of fallowing, presupposes the land intended to be submitted to the operation, to be charged with vegetable matter, both organised and inert, by long exclusion from the action of the sun, air, and light; and the earth being turned up to the depth of the fibrous roots of the plants, and the plants themselves being severed and turned upside down, and exposed to the effects of a drying sun \&c., the vitality of the whole is (as far as can be done by a simple operation) destroyed, and their substance, with that of the before, inert matter, is exposed in the manner best adapted for oxydisement, or the production of sugar; which in all cases is proved to be not only the most soluble, but the state most productive of carbonic acid, 
that vegetable matter can be placed in; or the best adapted as food for plants; and particularly of those which are desired to be prolific in fruits, seeds, bulbs, and tubers. And as to such an exposure to the atmosphere, producing either nitre or ammonia ; it certainly cannot be likely, that lands submitted to common cultivation, can be sufficiently pregnant with animal and vegetable matter to produce either; but if it does so, nitre is the most probable; and this is constituted to be the most profitable ; for nitre being composed of oxygene and nitrogene, it contains one of the vital principles of plants, and of which they cannot take up too much, as they possess the power of expelling any superfluous quantity. But ammonia contains nothing that a plant can need, it being composed of hydrogene; and nitrogene. By a due supply of water, plants obtain a due supply of hydrogene; and nitrogene is worse than useless, as it produces disease ; and indeed, the wise providence of nature seems here distinctly displayed, by making ammoniacal gas so much lighter than the atmospheric air, that it may as speedily fly off as it is formed.

But whether the additional fertility obtained by fallowing, can be equal to that produced by other operations, is another question; and is, indeed, one more of expediency than of scientific 
demonstration; but in determining this, we must take into consideration an axiom, that (as has been before observed) seems not to have occurred to Sir Humphry Davy; viz. that plants may be overfed, and diseased by unwholesome food. We will therefore suppose that part of a foul field, even of a middle quality, were laid up in fallow; and part manured, or laid down to turnips, and fed off with sheep; and both ploughed without any further manuring to either part, and cropped with wheat,-Query, would not the quality of the grain and straw of the fallow land make up for the difference in bulk on the other; taking into consideration the casualties of rust, and the being lodged or blown down? and whether the clean state of the land after fallowing would not more than compensate the difference of profit arising from the turnips?

This is the simple question at issue, and which cannot be fairly answered, without reference to the state of the land which is to be submitted to the operation. If the land be foul, or full of vegetable matter, both organised and inert, and withal stiff and wet; on the principles already explained, fallowing must certainly be a beneficial operation; but if the land be free from vegetable matter; the idea of increasing the fertility of the soil, by a year's exposure to the atimosphere, can- 
not be supported by any chemical principle: nor can I believe it could ever have proved good in practice.

It is admitted on all sides, that a vegetable being destroyed and decomposed, and again deposited on the spot where it grew, adds much to the capacity of the soil; and, after what has been said, a doubt can scarcely exist whether, if it be exposed in such a manner, during the decomposition, to the influence of the sun, air, and light, as to become duly oxydized; it will add more to the fertility of the soil, than if it were decomposed in a situation immersed in water, or obscured from the light, heat, and oxygene.

The consumption of vegetables by animals, effects much the same change; as exposure to the sun and air ; that is, by favoring oxydizement or by rendering the substance not only more solublé, but reducing it to a state more readily to absorb oxygene; and particularly when the dung and urine are united: and these changes, aided by the continual turning of the soil by the plough, universally constitute the most effective operations in cultivating the earth.

As to the loss of a season, and a crop of vegetables, as food for animals, or as manure to the land; the object of fallowing, on the principles I have explained, may be fully sustained and acted 
up to, without incurring such loss; as the requisite alteration in the vegetable matter contained in the soil, may be as effectually produced during one dry summer month as in twelve.

Any green crop, that will admit of being removed in the months of June or July, may be raised without detriment ; thus, grass, clover, or tares, may be removed, either as hay, or green food for cattle; or if these or other greens be intended as manure, they should be cut and dried before they are buried or ploughed in; for, as before observed, the operation of making grass into hay, is the conversion of mucus into sugar; and, therefore, hay, as a manure, will be found very. superior in its effects, to green grass. And when land is manured for turnips or rape, for feeding, as a preparation for a wheat crop; if rust or laying down of the corn be an object, the feed (for the reasons stated) may be carted off and eaten on other lands.

Conformable to his general notions, Sir $\mathbf{H}$. Davy again expresses his dissent to the operation of fallowing. He says, "When weeds are buried " in the soil, by their gradual decomposition " they furnish a certain quantity of soluble mat-" " ter; but it may be doubted whether there is as" " much useful manure in the land, at the end of " a clean fallow, as at the time the vegetables 
"clothing the surface were first ploughed in ;" but how does this accord with his ideas on the effects of paring and burning? - on the subject of which, he very justly observes - "Many ob" scure causes have been referred to for the pur" pose of explaining the effects of paring and " burning; but, I believe, they may be referred " entirely to the diminution of the coherence and "tenacity of clays, and to the destruction of "inert and useless vegetable matter, and its con"version into manure."

If, then, the fertilizing effects of fire be wholly comprised in its acting thus, as an alterative; how can it be denied, that the same effects, though in a more moderate degree, are produced by a summer fallow? Fire is undoubtedly a powerful agent in fertilizing the land, and more particularly when applied to stiff wet clays.

In a general point of view, I agree with Sir H. Davy, as to the effects of paring and burning, and in many of his ideas as to the peculiar principles of its operation, and particularly when he says,-

"When clay or tenacious soils are burnt, the " effect is of the same kind; they are brought " nearer to a state analogous to that of sands." "In the manufacture of bricks, the general "principle is well illustrated; if a piece of dry 
" brick earth be applied to the tongue, it will ad" here to it very strongly, in consequence of its " power to absorb water; but after it has been " burnt, there will scarcely be a sensible ad" hesion."

"The process of burning renders the soil less " compact, less tenacious, and retentive of moist" ure; and when properly applied, may con" vert a matter that was stiff; damp, and, in " consequence, cold, into one powdery, dry, and " warm, and much more proper as a bed for " vegetable life."

"The great objections made by speculative " chemists to paring and burning is, that it de"stroys vegetable and animal matter, or the " manure in the soil; but in cases in which the " texture of its earthy ingredients is permanently. " improved, there is more than a compensation: "for this temporary disadvantage. And in some "soils, where there is an excess of INERT VEGETA" BLE MATTER, the destruction of it must be " beneficial, and the carbonaceous matter re" maining in the ashes may be more useful to " the crop than the vegetable fibre from which “ it was produced."

As Sir Humphry very justly observes, whether the operation of burning increases or diminishes the soluble carbonaceous matter, is of 
little importance, as these effects are comparatively transient; but what is termed the mechanical change in the texture of the soil, is of the greatest importance, as in this respect the land may not only be considered as permanently improved, and altered from that state in which it is at all times uncertain in its produce;-capable of being worked only at particular and short intervals; difficult and expensive in its preparation for seed-crops; and, in general, ill appropriated for feeding cattle; - to a state free from all those casual defects; - but it is rendered less capable of forming and retaining that enemy to healthy vegetation, STAGNANT WATER, and much more capable of receiving and applying, the source of all vitality and prolificacy in vegetables, FRESH WATER. These are the great and most valuable effects of fire, when applied as an agent in cultivation : and fallowing approaches the nearest to fire, in its effects, of any operation in agriculture.

It is well known, that animals require a constant supply of fresh air, to sustain a healthy existence; and the constant supply of fresh water, is no less essential to the healthy existence of vegetables.

The soil and subsoil that is constituted and situated the best to sustain these principles, is always the most valuable; and every operation in 
husbandry that is known to produce fertility in the soil, acts in umison with them ; indeed, underdraining proves, comparatively, that agricultural plants do better without water, than when immersed in stagnant water; and irrigation shews, that when rapidly changing, a plant can scarcely have too much water. Digging and ploughing, and hoeing, stirring, and turning up the soil; not only loosens the texture, and thereby admits a more perfect percolation of water; but spongy vegetable matter, that, whilst under the earth, retains water in a state of stagnation, is brought upon the surface; the unwholesome moisture evaporated, and the substance reduced to a state more absorbent, but less retentive.

When the earth is in a proper state, or the soil and subsoil properly constituted, and under proper circumstances; a constant circulation or motion of the water up and down among the roots of vegetables, is going on;-thus, when rain falls in sufficient quantity; by its gravity, it percolates and sinks through the soil. And again, as soon as the surface of the earth is sufficiently rarefied to pass off what it retains in vapour, the motion is reversed, and by the capillary attraction of the soil the water is again raised, and brought to the surface, and in its passage upwards again comes in contact with the roots of vegetables; and 
in this manner a continued change of water and fresh supplies of the vital principle are produced.

It is evidently this principle which establishes the greatest value of the operation of hoeing. And although not recognised by Jethro Tull, was what gave effect to his favourite process of horse-hoeing. It is this also which produced the increased fertility so much and so justly extolled by Mr. Curwen, in his mode of culture, that of repeatedly stirring the surface between the growing vegetables; and not, as he supposed, the absorption of the volatile gas thus extricated, by the leaves of plants. Had Mr. Curwen's conception been just, the plants at a considerable distance from the loosened soil, must have been benefited by the floating of the vapour, or gas, by the wind, but which I take for granted was not the case. The fact is, clay, as soon as saturated with water, retains it in a state of stagnation, to the exclusion of fresh supplies: and thus, plants growing in it, are exposed to poisoning and starvation. And when the surface is operated upon by a drying sun, it contracts and opens, in large clefts or fissures, through which the vapour escapes; whilst the roots are closely grasped in a dry mass, and thus by the other extreme, the regetable is placed in a state of starvation. By repeatedly hoeing and stirring the 14 
surface, the adhesion is counteracted, and the rain-water, with the soluble manure, more perfectly distributed among the roots; and the contraction of the surface in drying, being prevented, or the fissures and clefts being closed or filled up, the water raised by evaporation is more equally diverted among the roots. A proper attention to, and comprehension of, those principles, can alone enable a person to judge of the eligibility of paring and burning, and to estimate its probable value when applied to particular soils.

It is evident, that the most important and permanent effects of fire consists in its imparting calcareous quality to the earth; it must therefore be as evident that soils which naturally contain a due proportion of calcareous earth, such as chalk, limestone, marle, \&c. cannot be so much improved by burning. The effect of dressing lands with lime and marle, is to : certain degree the same as fire; and therefore those lands only, which are deficient in calcareous matter can be permanently benefited by the addition of those substances. Calcareous earths also anticipate the effects of putrefaction, by reducing vegetable and animal substances to soluble oxydes, and thus they prevent a loss of carbon in the formation of carbonated hydrogen gas. 
And from the effect of these operations, other important conclusions may be drawn, viz. that the working of the plough, the hoe, the harrow, and the roller, cannot well be overdone, during the dry weather of spring, summer, and autumn ; and that it cannot be too seldom done in wet weather and in winter; as these operations, when the surface is dry, open the pores: and, when wet, close them.

In all cases, where the soil is so tenacious and retentive of water, as to render it necessary to lay the land in narrow ridges for the purpose of getting rid of it; fire may be applied in the manner before explained, so as to effect such an improvement as would amply repay both the landlord and the tenant any expense that may be incurred by the operation.

When lands are laid in narrow ridges, the best and most effective manure, or that which is laid on the surface, is washed away, and the spaces occupied by the furrows are wasted, and so much land lost. The surface-soil of such lands being made friable, and open in its texture, sufficiently to admit of a free percolation of water to a proper depth, and well under-drained, would not only be rendered more productive, but like fine sandy loams, it would admit of working at all times and seasons. 
I once saw a very large field, of a stiff foxy clay, laid down to turnips; one half had been reduced by burning, and the other not: the part that was burnt, was clothed with as fine a crop of roots, as could be wished for; whilst on the other, the seed, although the same in both cases, and sown at the same time, appeared to have failed, there being only a few thin patches of plants; and the cause was obvious. The surface of the unburnt clay was closed, and rendered impervious, immediately after sowing, by rain; but the calcination of the soil in the other, kept it open, and made it accessible to the air, which is positively necessary for the germination of seeds.

The reducing of clay by fire, may be considered as the best mode of rendering surface draining unnecessary.

Sir John Sinclair, after a very comprehensive and minute detail of all the different modes and effects of draining, very properly says in conclusion, "So sensible have landed proprietors " become of the deep interests they have in ex" ecuting this most important species of improve" ment, on a liberal and extended scale, that it " is a practice with many, to have a general plan " for the drainage and regular division of the s different farms, when their estates are newly 
"let; and the work is thus likely to be completed " in a methodical, substantial, and permanent " manner, under professed drainers, and labour" ers solely employed on this essential work. "On this great scale of drainage, the connection " of one farm, or part of an estate, with another, " renders the effect more complete, and the " ultimate charges much less. Indeed, the te. " nants are so sensible of the advantages of this "system, that they give it a preference to " having the work done at their own expense, " and in their own manner."

And on the effects of draining, he further very justly observes: "On the whole, there is no " means by which the value of land can be ad" vanced, or from which, when usefully applied, " so many advantages can be derived, at a mo. " derate expense, as that of draining. The " owner is benefited by an increase of rent; the " occupier by that of produce; and the public, " by being thus supplied with greater quantities " of the most essential commodities, and by hav" ing a source of useful employment furnished " to the labouring classes of the community." 
ON THE COMPOSITION OF SOILS, AND THE AGENCY OF THE EARTHS IN VEGETATION.

THE surface of the earth is a variable compound, but as it respects vegetation, it is not necessary to pursue its analysis beyond the following simple divisions, viz. calx, or the calcareous; silex, or the siliceous; clay, or the argillaceous; magnesia, or the magnesian; and carbon, or the carbonaceous, or, as this is commonly called, mould.

The first four substances, are what Miller properly calls the containing part, or body, bed, or couch; and the fifth substance or mould, (which is the result of decayed animal and vegetable matter,) the part contained.

It is clearly proved that neither of the four substances, calx, clay, magnesia, or silex, in a simple state, whether separate or combined, will support a plant; and that the vegetative power of every part of the earth, is determined by the quantity of mould, or animal and vegetable matter it contains.

On the earths, as forming a component part of plants, Mr. Kirwan says, "The next most 
190 on țHe composhtion of solls, \&c.

" important ingredient to the nourishment of " plants, is earth: and of the different earths, the " calcareous seems the most necessary, as it is " contained in rain water; and absolutely speak“ ing, many plants may grow without imbibing " any other; M. Ruckert is persuaded that " earth and water in proper portions, forms the "sole nutriment of plants : but M. Giobert has " clearly shown the contrary, for having mixed " pure earth of alum, silex, calcareous earth, and " magnesia, in various proportions, and moist" ened them with water, he found that no grain "would grow in them; but when moistened " with water from a dung-hill, corn grew in " them prosperously; hence the necessity of the " carbonaceous principle is apparent."

$\mathrm{He}$ also says, "Earths cannot enter into " plants, but in a state of solution; or at least " only when suspended with water in a state of " division, as minute as if they really had been " dissolved; that siliceous earths may be sus" pended in such a state of division, appears " from various experiments, particularly those " of Bergman, who found it thus diffused in the " purest waters of Upsal ; and it is equally cer" tain that it enters copiously into vegetables: " both his experiments, especially those of Macci, " establish this point beyond contradiction. Ar- 
on THE COMPOSITION of solls, \&c. 191

" gillaceous earth may also be finely diffused, so " as to pass through the best of filtres; so may. " also calx, as appears from the quantity Mar" graaf found in the purest rain water."

On this part of the subject, after reciting a great number of experiments, Sir Humphry: Davy observes, "The general results of this " experiment, are very much opposed to the " idea of the composition of the earths by plants, "from any of the elements found in the atmo"sphere or the water."

$\mathrm{He}$ also says, "As the evidence on the sub" ject now stands, it seems fair to conclude, " that the different earths and saline substances, " found in the organs of plants, are supplied. " by the soils in which they grow, and in no. " cases composed by new arrangements of the " elements in air or water."

Here again is a great difference in the opinion of those great chemists, and on a most important point; it being admitted that earths are a necessary ingredient in the composition of plants, the question naturally arises, how, and, in what proportions, and in what state, is it required by vegetables? If Sir Humphry Davy's conclusions are just, a minute examination or analysis of soils, would be requisite to form a correct judgment of its capacity; and to these 
192 ON THE COMPOSITION OF SOILS, \&C.

lengths he has gone, and given the ingredients and proportions of several fertile soils; he has also described the method of analyzing soils; but the quantity of earth required by plants, for their various compounds, is so small, as beyond all doubt to sustain Mr. Kirwan's opinion, that it is supplied by water.

That the clearest spring water contains a quantity of earth, every person may obtain ocular demonstration of, by examining the inside of a tea kettle, in which water has been boiled for some time; the earth that will be found adhering to it, must have been deposited from water.

Thus then, as far as the earths are concerned as an article of consumption, or a necessary component in the food of plants, we may rest satisfied with the natural composition of most soils, and direct our attention only to its constitution, as it influences the absorption, retention, and distribution of water; and to its chemical powers, in regulating and determining the extent and effect of the different fermentations, combinations, and decompositions, which are requisite for the reduction and preparation of the various substances which constitute the food of plants.

If the earth was left solely to the action ofthe natural and chemical principles of affinity, 
ON THE COMPOSITION OF SOILS, \&c. 193

attraction, repulsion, \&c. the accumulation, or concentration, of the separate primitive substances; or of vegetable and animal matter or mould; may be too great to raise and sustain plants in a healthy and fruitful state, and such may be the case with other bodies, either simple or combined; we therefore find that nature has provided the means of averting those extremes, by reducing and blending, or mixing them, and this by the operation of insects and reptiles; as has been before observed, the earth worms seem peculiarly formed for this purpose; by their means the different substrata of clay, calx; sand, \&c. are covered with a stratum, compounded of the finely divided matter of its composition, forming what is called loam, or the soil ; these little creatures, in making their passages or inroads, have no other means of clearing their way, than by eating the opposing matter, carrying it to the surface and there throwing it up : hence we find, that every part of the globe that supports vegetables is furnished, or covered, with an admixture of the different earths, forming the soil, of greater or less depth; and the depth of this stratum or covering, the degree of concentration, and proportion of the different substances, the nature of the substrata, as it regards the percolation and retention of water; 
194 ON THE COMPOSITION OF SOILS, \&c.

the quantity of water supplied; and the exposure to the sun, air, and light, determine the natural produce of the general substance or soil.

From what is here said, so far from earth worms being an enemy to the farmer, they are his best friends; without them his lands would soon become impenetrable to air or water, and hence sterile and unproductive; and it is certain earth worms never wound, or prey upon the sound or living parts of seeds, roots, or plants.

As Mr. Kirwan observes, the calcareous earths seem to be the most necessary as a component part of the food of plants; from its peculiar chemical powers, it is also most necessary as an operative agent in the preparation and reduction of animal and vegetable substances, and in due proportion, it is also well adapted to render the other more tenacious substances permeable to water and air, all which have been before explained.

But that state, in which the operation of the calcareous earths have been found to be the most powerful, is lime. This singular substance is never found in a native state; but from the simplicity of its formation, and very extraordinary powers, its uses and application in the arts is most extensive, and perhaps no produc'tion, from its universal adaptation, ever obtained 
or deserved more attention from the chemists ; but I very much doubt whether any person has yet been able to give a demonstrative definition of the principles of its various action.

'The application of lime in agriculture has' been justly described to have rendered sterile lands fertile, and fertile lands sterile. To speak of it, therefore, as a manure, is evidently absurd and calculated to mislead. The meaning of the term alterative, as it is used in medicine, is generally understood, and this appears to me to be the proper denomination for lime, when applied. to the cultivation of land.

Sir Humphry Davy, has given a clear and minute detail of the component parts of the basis of lime, or lime-stone, and of the chemical principles of its formation and action; but either from a want of a more marked distinction between the effects of quick lime and slacked lime, or from some other cause, his observations, by no means accord with mine.

He' says, "Lime forms a kind of insoluble "soap with oily matters, and then gradually "decomposes them by separating from them " oxygene and carbon; it tends to diminish, " likewise, the nutritive powers of albumen from " the same causes, and always destroys, to a "certain extent, the efficacy of animal manures, 
196 ON THE GOMPOSITION OF SOILs, \&c.

" either by combining with certain of their ele" ments, or by giving to them new arrange" ments." Lime should never be applied with " animal manures, unless they are too rich, or " for the purposes of preventing noxious efflu" via; as in certain cases mentioned in the last "lecture, it is injurious when mixed with any " common dung, and tends to render the extrac" tive 'matter insoluble."

Now, as I have before observed, I have mixed the crassamentum, or clotted part of blood, with quick lime, which formed a kind of insoluble soap, and was therefore inapplicable as food for plants; but mixed with slacked lime it formed a perfectly soluble soap, and thus rendered the albumen immediately applicable and inodorous, which left to itself could not have become so, until it had undergone the putrefactive fermentation, and have thus generated and diffused a most noxious effluvia.

He again says, "In those cases in which fer" mentation is useful to produce nutriment from "vegetable substances, lime is always effica" cious." Now in the experiment I have just explained, it prevented the fermentation, and I have always found this to be its peculiar property.

Parkes says, "It appears from several late " experiments carefully made, that sugar is com- 
" posed entirely of hydrogene, oxygen, and car"bon. Mr. Cruikshank made many experi" ments on fermentation, and invariably found " that whenever he added a fourth substance to " the three which compose saccharine matter, no "fermentation took place; he tried lime, and at " another time a small quantity of potash, and "the addition of either prevented fermentation." Sir Humphry Davy also says," "Quick lime " in its pure state, whether in powder or dis" solved in water, is injurious to plants."

I have found slacked lime, when sown or spread over plants of all kinds and stages of growth, to destroy slugs, effectually perform this, and without in the least injuring the plants.

As it must appear from these observations, that I cannot practically and beneficially, further apply the inferences of Sir Humphry Davy, regarding the uses of lime in agriculture; I shall not obtrude any further remarks on his ideas on the subject; but shall give an extract from the Encyclopædia Britannica, which appears to me, to be more clearly, if not correctly, explanatory of the uses and effects of lime in agriculture: but even this author, seems either not to have understood the principles of the action of lime, or to have erroneously described them. He speaks of lime as a septic, and of its assisting o 3 
198 ON THE COMPOSITION OF SOILS, \&C.

and hastening putrefaction; but as before shown, lime possesses a directly opposite quality; it not only prevents, but arrests putrefaction, and is therefore in fact, antiseptic ; and it is the action of this principle which renders soils prolific. Lime is, certainly, a most powerful agent in the decomposition of animal and vegetable matter, but it is on a principle more analogous to that of fire; as in the instances before stated, it not only prevents the effects of putrefaction, which are obnoxious to vegetables, but it accelerates the formation of those compounds which are essential to fertility.

It is stated in the Encyclopædia Britannica, "Where the ground has been suffered to remain " uncultivated for many ages, producing all " that time succulent plants, which are easily " putrefied, and trees, the leaves of which, like* wise contribute to enrich the ground, by their " falling off and mixing with it, the soil will in a " manner be totally made up of pure vegetable " earth, and be the richest when cultivated, that " can be imagined. This was the case with the " lands of America; they had remained unculti"s vated perhaps since the-creation, and were " endowed with an extraordinary degree of feros tility; nevertheless, we are assured by one sc who went to America, in order to purchase 
"lands there, that such grounds as had been "long cultivated, were so much exhausted, as " to be worse than the generality of ground in " this country. Here then we have an example " of one species of poor soil, namely, one that " has been formerly very rich, but has been " deprived by repeated cropping, of the greatest "part of vegetable food it contained. The "farmer who is in possession of such ground, "would no doubt willingly restore it to its "former state; the present question is, what " must be done in order to obtain this 'end? "We have mentioned several kinds of manures, "s which long practice has recommended as ser" viceable for improving ground. We shall sup"pose the farmer tries lime or chalk; for, as has "been seen, their operations upon the soil must "be precisely the same. This substance being " of a septic nature, will act upon such parts of " the soil as are not putrefied or but imperfectly " so; in consequence of which, the farmer will " reap a better crop than formerly. The sep" tic nature of the lime is not altered by any " length of time. In ploughing the ground the "lime is more and more perfectly mixed with " it, and gradually exerts its power on every "putrescible matter it touches. As long as " any matter of this kind remains, the farmer 
200 ON THE COMPOSITION OF SOILS, \&c.

"will reap good crops; but when the putres"cible matter is all exhausted, the ground then "becomes perfectly barren, and the caustic "qualities of the lime are most unjustly blamed "for burning the ground, and reducing it to a "caput mortuum; while it is plain, the lime has " only done its office, and made the soil yield "all that it was capable of yielding.

"When ground has been long uncultivated, " producing all the time plants not succulent, " but such as are very difficultly dissolved, and " in a manner incapable of putrefaction, there " the soil will be excessively barren, and yield "very scanty crops, though cultivated with the "greatest care. Of this kind are those lands " covered with heath, which are found to be " the most barren of any, and the most difficultly "brought to yield good crops In this case " lime will be as serviceable as it was detri" mental in the other; for by its septic qualities, " it will continually reduce more and more of " the soil to a putrid state, and thus there will " be a constant succession of better and better" crops, by the continual use of lime, when the " quantity first laid on has exerted all its force. "By a continued use of this manure, the ground " will be gradually brought nearer and nearer " to the nature of garden mould, and no doubt, 
ON THE COMPOSITION OF sOILS, \&c.

201

" by proper care, might be made as good as "s any : but it will be as great a mistake to ima" gine, that by the use of lime this kind of "soil may be rendered perpetually fertile, as to s think that the other was naturally so; for " though lime enriches the soil, it does so, not " by adding vegetable food to it, but by pre" paring what it already contains; and when all " is properly prepared, it must as certainly be " exhausted as in the other case.

" Here then we have examples of two kinds of " poor soils; one of which is totally destroyed, " the other greatly improved by lime; and " which therefore require very different manures: " lime being more proper for the last than dung, "while dung being more proper to restore an " exhausted soil than lime, ought only to be " used for the first. Beside dunging land which " has been exhausted by long cropping, it is of "great service to let it lie fallow for some time; " for to this it owed its original fertility, and " what gave the fertility originally cannot fail $"$ to restore it in some degree.

"By attending to the distinctions between " the reasons for the poverty of the two soils " just now mentioned, we shall always be able " to judge with certainty, in what cases lime is s' to be used, and when dung is proper. The 
202 ON THE COMPOSITION OF SOILS, \&c.

" mere poverty of a soil is not a criterion where" by we can judge; we must consider what hath " made it poor. If it is naturally so, we may " almost infallibly conclude that it will become " better by being manured with lime. If it is "artificially poor, or exhausted by continual " cropping, we may conclude that lime will en" tirely destroy it. We apprehend that it is this " natural kind of poverty only, which Mr. An" derson says in his Essays on Agriculture, may " be remedied by lime; for we can scarce think " that experience would direct any person to " put lime upon land already exhausted. His " words are, "Calcareous matters act as power" fully upon land that is naturally poor, as upon "land that is more richly impregnated with " those substances that tend to produce a "luxuriant vegetation. Writers on agriculture " have long been in the custom of dividing ma" nures into two classes; viz. enriching manures, "or those that tended directly to render the "soil more prolific, however sterile it may be; " among the foremost of which was dung: "exciting manures, or those that were supposed " to have a tendency to render the soil more " prolific, merely by acting upon those enriching " manures that had been formerly in the soil. "and giving them a new stimulus, so as to en- 
" able them to operate anew upon that soil which " they had formerly fertilised, in which class of " "stimulating manures, lime was always allowed " to hold the foremost place.

" In consequence of this theory, it would " follow that lime could only be of use as a ma"nure when applied to rich soils, and when " applied to poor soils would produce hardly "any, or even perhaps doubtful effects.

"I will frankly acknowledge, that I myself " was so far imposed upon by the beauty of this " theory, as to be hurried along with the general " current of mankind, in the firm persuasion of the " truth of this observation, and for many years " did not sufficiently advert to those facts that " were daily occurring to contradict this theory. "I am now, however, firmly convinced from re" peated observations, that lime and other cal" careous manures produce a much greater "proportional improvement upon poor soils, " than such as are richer: And that lime alone " upon a poor soil, will, in many cases, produce " a much greater and more lasting degree of " fertility than dung alone.'

"Thus far Mr. Anderson's theory is exactly " conformable to the theory we have laid down, " and what ought to happen according to our "principles. He mentions, however," some 
204 ON THE COMPOSITION OF SOILs, \&c.

"facts which seem very strongly to militate " against it, and, indeed, he himself seems to " proceed upon a theory altogether different.

"Calcareous matters alone (says he) is not " capable of rearing plants to perfection : " mould is necessary to mix with it in certain " proportions, before it can form a proper soil. "It remains, however, to be determined what is " the due proportion of these ingredients for " forming a proper soil.

"We know that neither chalk, nor marl, nor " lime, can be made to nourish plants alone; " and soils are sometimes found that abound with " the two first of these to a faulty degree, but " the proportion of calcareous matter in these " is so much larger than could ever be produced " by art, where the soil is naturally destitute of " these substances, that there seems to be no " danger of erring on that side. Probably it " would be much easier to correct the defects of " those soils in which calcareous matters super" abound, by driving earth upon them as manure, " than is generally imagined; as a very small " proportion of it sometimes affords a very per" fect soil. I shall illustrate my meaning by a " few examples.

"Near Sandside, in the county of Caithness, " there is a pretty extensive plain on the sea- 
" coast, endowed with a most singular degree " of fertility. In all seasons it produces a most " luxuriant herbage, although it never got any " manure since the creation, and has been for " time immemorial subjected to the following " course of crops.

“ 1. Bear after once ploughing, from grass, " usually a good crop.

"2. Bear, after once ploughing, a better " crop than the first.

"3. Bear, after once ploughing, a crop " equal to the first.

"4. 5. and 6. Natural grass, as close and " rich as could be imagined, might be cut if " the possessor so inclined, and would yield an " extraordinary crop of hay each year: after " this the same course of cropping is renewed.

"The soil that admits of this singular mode " of farming, appears to be a pure incoherent "sand, destitute of the smallest particle of ve" getable mould; but upon examination it is "found to consist almost entirely of broken " shells; the fine mould here bears such a small " proportion to the calcareous matter, as to be "scarcely perceptible, and yet it forms the " most fertile soil that ever I yet met with."

The writer of this article in the Encyclopædia accounts for this fertility, by supposing that 
206 on THE COMPosition of soILs, \&c.

from its vicinity to the sea, it derives its prolific powers from the salt water; but by adverting to the principles I have laid down, a much more probable arrangement and combination may be suggested. In the first place, we may suppose that the mechanical texture of the soil and subsoil is such, and so situated, as not only to obtain a supply of fresh water, but to admit of, and facilitate, a constantly ascending and descending motion of such water; and that its chemical constitution is such, as to facilitate the decomposition and reduction of the roots, leaves, and stalks of the vegetables, regularly deprived of life, to a soluble state, without the process of putrefaction, and its consequent loss in carburetted hydrogene gas, \&c.

All calcareous earths may alike possess antiseptic powers, but all do not possess the capacity of operating so effectually as that here described, to supply the requisite motion, change, and quantity of water, by percolation and capillary attraction, and consequently no other can be equal in its fertility.

Sir H. Davy has given a minute analysis and description of almost every kind of soil, and explained the means of chemical investigation. But as, I think, what has been said will be suffi. cient to enable every person to form a pretty 
ON THE COMPOSITION OF soILs, \&c, 207

correct judgment of the capacity and constitution of soils, as adapted to the general purposes of husbandry; I shall not enter more particularly on this part of the subject, but must refer those who wish for such information, to his work on agricultural chemistry. 
208

\section{ON HAYMAKING.}

Having observed that in a season when there was no rain whatever, and the hay had been made with rapidity, and carted within a short time after it had been cut, that a greater quantity was destroyed and injured, by being overheated and burnt, than in a catching irregular season; that when hay had not heated in the stack it was frequently mouldy; that as hay lost its native green colour and approached a brown, it lost its nutritive qualities; and that altogether, the making of hay, as usually conducted, was a very precarious and teasing operation: I determined on trying to arrange a system on some more regular and certain principles, in which I succeeded; and by adopting a certain and regular course of operations, was enabled to make my hay of a uniform good quality; and, let the weather be as it might, at a regular expense of labour. And considering such a process not only of importance, as it ensures a more perfect quality; but as it affords a more certain protection against the injuries usually consequent on the uncertainty of the weather, 
and overheating in the stack; and that it thus removes two great causes of anxiety, it may be well worth the public attention.

In the first place, as to the state of the weather, it generally happens at this season of the year, that there are three or four days rain and three or four days dry; therefore, on beginning to cut the grass, as it is well known that during wet weather grass may be cut, and suffered to remain in the swarth for several days without injury; and it being desirable, where hands are plenty, to have a good quantity, or as much as will complete a stack in a day, in the same state of forwardness; I should prefer beginning to cut during the rainy weather: however, be this as it may, the swarths should not be opened but on a certain fine day; and when this is done, the grass should be well shaken apart and equally spread over the ground. As soon as the upper surface is dry, turn it well over; and in this operation, great care should be taken to open and spread any cocks that may not have been divided in the first opening. This being done, commence raking into wind-rows in time, that the whole may be made into small cocks before night. The second day these cocks must remain untouched, let the weather be wet or dry: the third day, if the weather be certain and 
fine, throw the cocks open; but if the weather be wet or threatening, they may remain another day, or until the weather is certain to be fine for the day. The cocks should then be thrown, according to the crop, into beds of two or three rows; and after three or four hours' exposure, turned over; and taking time to gather the whole into wind-rows and cocks before night, let this operation commence accordingly, and none be left open : the day after this, which in fine weather will be the fourth; the cocks must again remain untouched, or not be opened, whether the weather be wet or dry. On the fifth, or the next dry day, these cocks will only require to be opened for an hour or two, when they will be fit for the stack. The novelty of this mode consists only in suffering the hay to remain in cock the second and third, or alternate days; and at first sight it may appear that so much time in fine weather must be lost, but this is not the case. Whilst the hay remains in cocks, a slight fermentation, or what is termed sweating, will take place; and in consequence, after it has been opened on the third and fifth days, it will prove to be just as forward as if it had been worked every day. And the advantages resulting from this, are obviously the following:-by shortening the time of open exposure, the co- 
lour of the hay is more perfectly preserved, and consequently the quality; and the fermentations, or sweating, which take place in the cocks, prove so much to have diminished that principle, or inclination, as to prevent its heating injuriously in the stack; and the whole operation of making, whether it takes four days or eight, requires three days' labour only; and the hay being left in that state every night, in which it is the least possibly exposed to the injuries of the weather, and in which it may remain for a day or two in uncertain weather, without injurious exposure; much painful anxiety, and useless attendance of labourers, are obviated. 
By introducing the subject of cider, my object is not to enter into the history of the apple, nor to discuss the' merits of the different modes of making cider, nor to describe the vast variety of cider fruit; but knowing that certain prejudices and erroneous opinions exist, that much depreciate the value of that, which, when well made, is a wholesome and delicious liquor; and that such prejudices and opinions absolutely deprive many districts of the profit and pleasure, resulting from the growing and making good cider; I entertain the hope of being able to state such observations and facts, as will assist in removing those obstacles.

In the first place, it is a general opinion that the soil of those districts that are famous for good cider, such as Devonshire, Herefordshire, Somersetshire, \&c. is the grand cause of the superiority of their productions; but this is an egregious error; it is by no means the case: the soil has little effect on the quality of the cider; as it is well known that in those counties, celebrated for good cider, the prime ciders are 
produced on soils of directly opposite qualities. However, to convince my neighbours of Wiltshire, that the cause of their inferiority was in their bad assortment of apples, and not in their soil or climate; I, many years since, selected some apples of the sort there called the cadberry, which grew in a very poor; shallow, black, gravelly soil, resting on a chalk subsoil; and made cider from them: and this cider proved, and was allowed by many good judges who tasted it, to be as rich, strong, and fullbodied, as any that grew on the richest lands, or most famous districts. I also gathered from one tree of the sort called the golden ducat, growing on a soil of the same description, forty bushels of apples, and these were made into cider, which, like the apple itself, proved to be a brilliant, sparkling, delicious, vinous liquor. In the same orchard the greater part of the apples were of the worst sorts, green, thin and sour; and when mixed, made a thin sour cider. I also, by way of demonstration, made cider from various other fruits separately, and among the rest, of a green hard apple, called the stone pippin, which being well known to keep well, and after long keeping, to ameliorate and become palatable; I wished to prove if the cider also would improve by keeping: which it did 
not, but was always like the apple, thin and sour. Hence it must be obvious, that as far as the soil is concerned, the same sorts of apples grown in any part of the kingdom, will produce cider of equally good quality; indeed, every person knows that a nonpareil is a nonpareil, and a golden pippin, a golden pippin, in all places alike; the only difference that can arise in the soil, is in the supply of moisture and manure; the greater the supply of these the greater may be the quantity; but the quality will be more aqueous, and of course less valuable. The quality will be chiefly influenced by the climate and exposure, as it may affect the ripening, for the riper and diyer the fruit, the richer and more spirituous the cider; and these things vary in their effect on apples, as much in one county as another.

Another very prevailing opinion is, that a good eating apple cannot be a good cider appie; and that a good cider apple is not to be selected by its taste, or effect on the palate; but this is equally erroneous. A person may not be able to ascertain the exact specific gravity of the juice of an apple by his palate; but the general character of an apple may be correctly ascertained; and the character or qualities of the cider, will always be found to prove very nearly 
the same as the apple. Thus, a rough sweet apple will give a rough sweet cider; a thin sweet apple, a thin sweet cider; and an acid and sour apple, an acid and sour cider; but generally, the rough asperity of an apple and the aromatic flavor will remain in the pulp, or pass off in fermentation. Another erroneous opinion is also very generally prevalent, that a mixture of apples makes the best cider; but as a general proposition, a simple view of the thing must show its absurdity. If there be a good cider apple, and a bad cider apple; how can an union of the bad, make the good better? The fact is, fermentation possesses the greatest influence in determining the quality of the cider; and it is a law of nature, that without a perfect vinous fermentation, there cannot be a perfect vinous liquor. Now it is well known, that two sorts of apples may be selected, the juice of one of which will commence fermenting in two or three days, and that of the other, not in less than eight or ten days. It must then be obvious, that as the early fermentation of the one, will force the backwardness of the other, and the late fermenting will check and retard the early, there can be no perfect fermentation with either; and consequently no perfect vinous liquor: and this principle will undoubtedly operate, with 
the fruit from the same tree, as some must unavoidably be better ripened than others; and therefore, in this case, if the ripest were selected and separately made into cider, the quality would prove superior to that made of those that were less ripe, or if made together. After cider is made, indeed, it may, by mixing, be made more suitable for peculiar, or general purposes, and thus be said to be better for mixing; but mixing the apples must be a pernicious and unprofitable practice.

The science of fermentation is most important to all who make cider, or wine, or beer; and those who wish for information on this subject, may find it in a valuable little book, by Maccullock on wines.

The health, duration, and prolificacy of appletrees, as well as all other fruit-trees, are more dependent upon the subsoil than the surfacesoil; in planting trees, therefore, this requires more attention than is generally given to it. Healthy and prolific apple-trees will seldom be found where the subsoil is of a cold, tenacious, wet, and stagnating quality; and whatever may be the nature of the surface-soil during very dry summers, the roots in search of water will delve deep into the subsoil, and having penetrated, however low, there they must remain; they 
cannot get back again, In all cases, food selected deep in the soil, is aqueous and unwholesome; and if the water be stagnant, the roots canker and rot in the winter, which vitiates the sap, and thus the tree becomes cankered and diseased; and a tree thus situated, although it máy for the few first years produce fine fruit, and afterwards, generally produce strong fine shoots in the summer, these will become diseased, and often die in the winter or spring. The fruit, also, when a tree is in this state, is generally vapid and imperfect, and a crop very uncertain.

In planting orchards, therefore, it will be necessary, to ensure success, or permanent and progressive prolificacy; to guard against those casualties, by underdraining and supplying water on the surface, during very dry weather. But the most effectual mode will be, in improper subsoils, to form an artificial rock, as a foundation on which to plant the trees, about a foot or a foot and a half underneath the surface of the soil, which may be easily done by removing the soil to the required depth, and laying a kind of floor of stones, bricks, tiles, or slates, taking care that the joints be well closed or stopped with cement, that the roots may not penetrate, as a tree extends its roots, even farther than its 
branches. To make the foundation quite perfect may be expensive, but it must be considered, that the work thus done is for ever done; it will not require repairing: and the additional prolificacy of the trees, their healthy duration, and the superior quality of the fruit, will make an ample return. However, where the expense of paving to a full extent cannot be afforded, even three or four feet square immediately under the tree, will be a great protection : it will, at any rate, give a right direction to the roots in their first outset, and prevent the formation of taproots, which are bad things in fruit-trees.

As the figure of a tree, or its shape and form, determines its powers of sustaining weights on its branches, and of resisting the wind; and its prolificacy, in a great measure, depends on the due and regular expansion and exposure of its branches equally to the influence of the sun and air, this should be attended to on its first formation or grafting. And if the following particulars in the mode of managing it are attended to, they will be found to produce a tree of that shape and strength, that will be equal, in every respect, to its wants.

Whether the tree be intended to be raised by inserting the graft near the ground, or at a sufficient height to form a head; only one graft 
should be permitted to remain; and this should be trained up, with a single stem, to the utmost height of its growth, and never stop'd or cut back. The horizontal branches or head will then be found to form itself, by pushing out shoots immediately around the point of the year's perpendicular shoot or stem; and as this will be long or short, according to the soil and situation, the horizontal tiers of branches will be at proportional and proper distances; and thus the tree will assume the shape and growth of the fir or the wild cherry-tree. If any irregular shoots should push out on the sides of the stem, or too many horizontals, they may be removed. And if the perpendicular stem or leading shoot should be destroyed, one of the horizontals may be fixed up perpendicularly to fill its place, which it will soon do, and the knife will not be required to be used for any other purpose. A tree formed in this manner, will apply all the sap furnished by the roots to a profitable purpose; and as it will never be headed, or cut back, its progressive or annual increase will be effective. And, as I have before observed, it being a law of nature, that no tree shall bear fruit until it has obtained a surface of stalk, branches, and leaves, proportioned to the food it takes up, this law will be fully supported; and the tree will attain the 




\section{DAY USE \\ RETURN TO DESK FROM WHICH BORROWED \\ LOAN DEPT.}

This book is due on the last date stamped below, or on the date to which renewed.

Renewed books are subject to immediate recall.

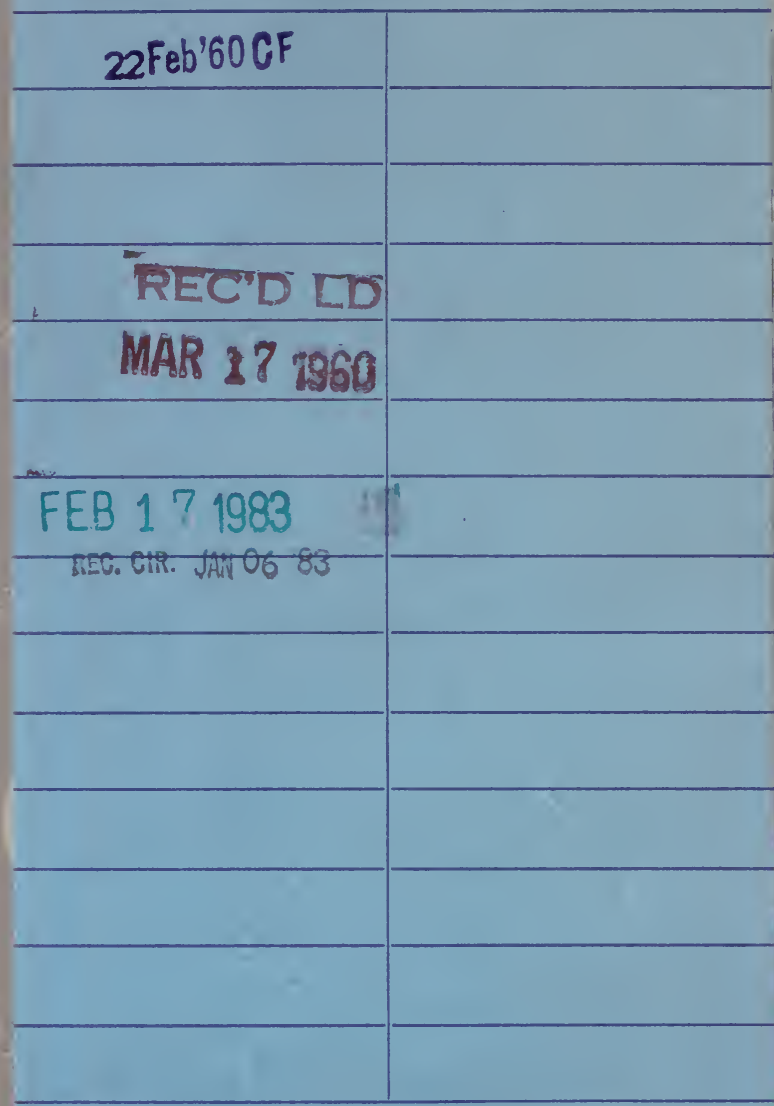

LD $21 \mathrm{~A}-50 m-4, ' 59$

(A1724s10)476B

General Library

University of California Berkeley 


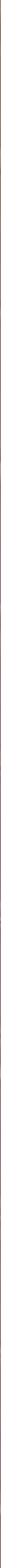


$3)^{3}$

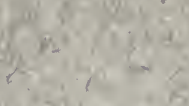

$$
\begin{aligned}
& \text { A }
\end{aligned}
$$

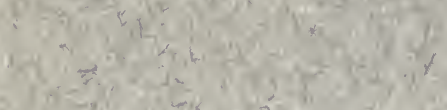

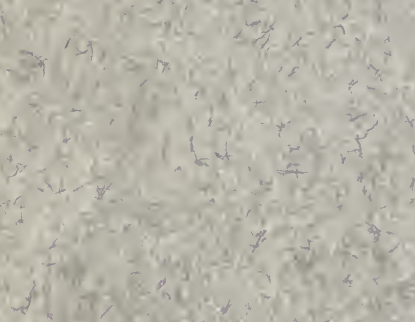

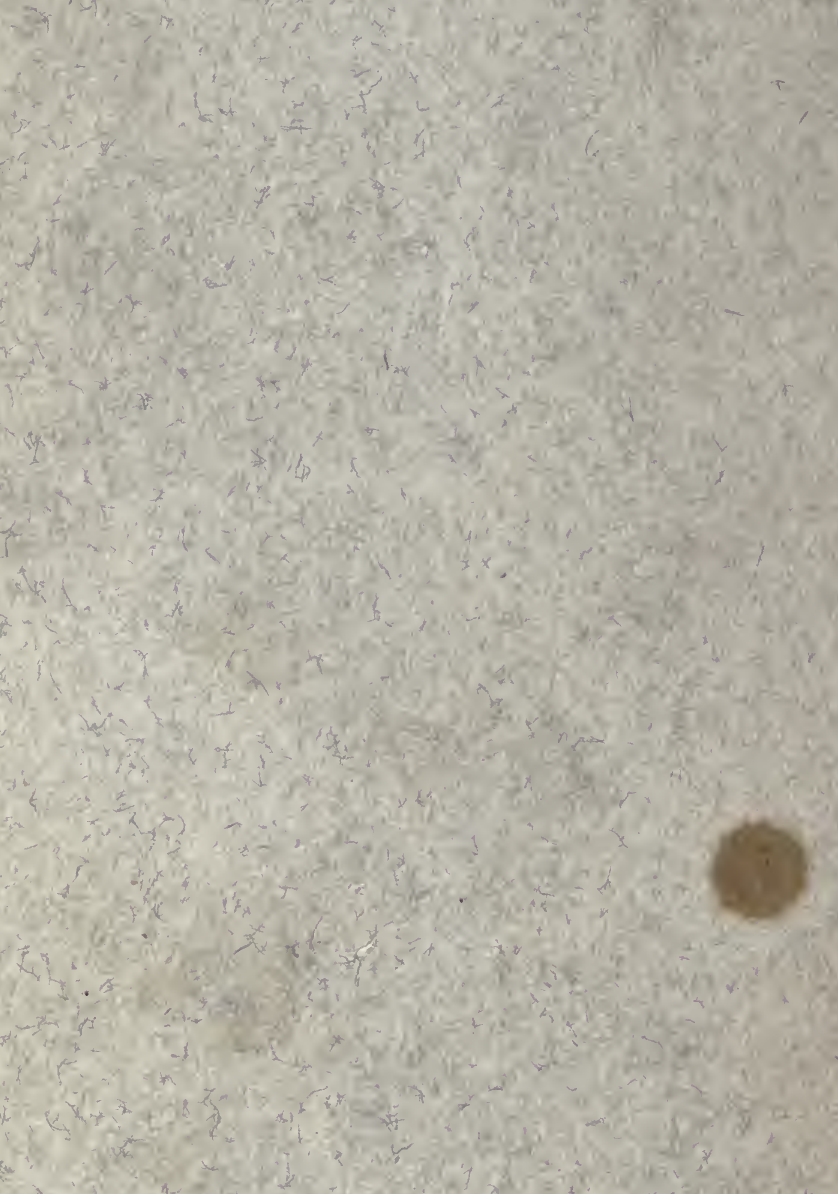

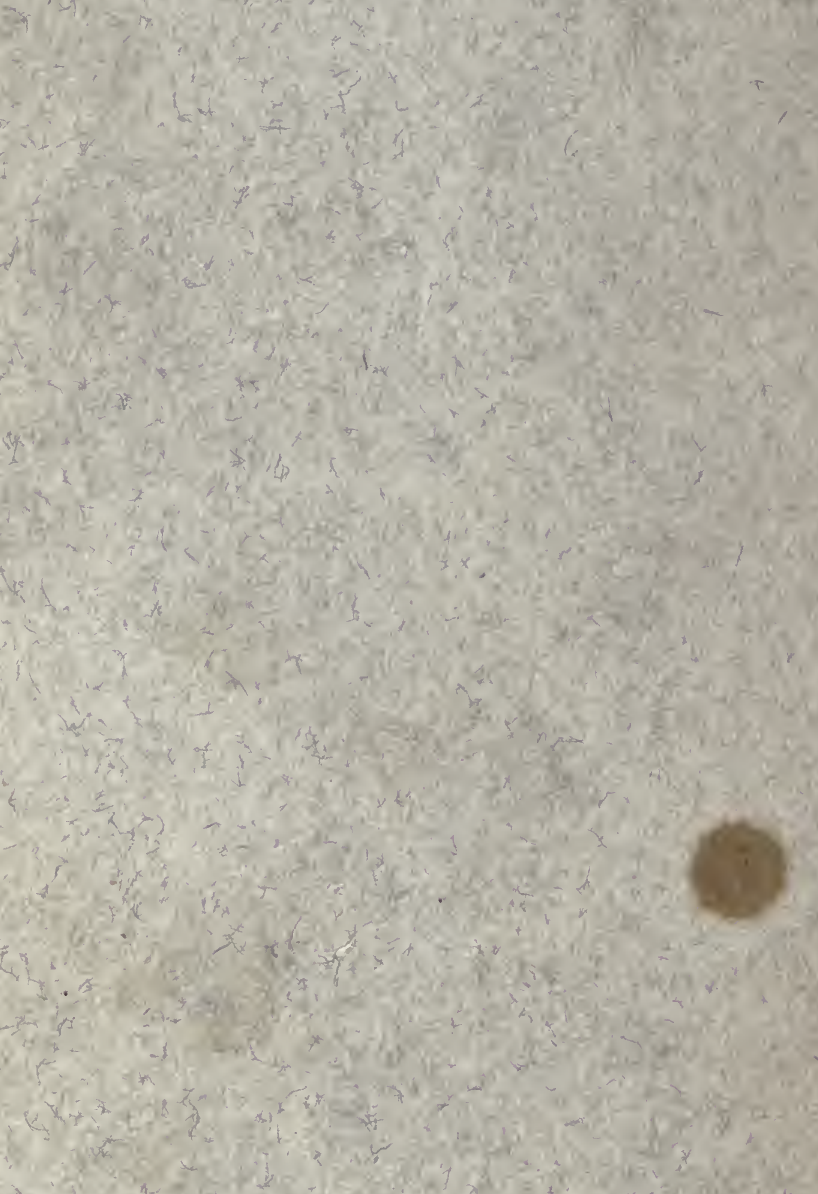

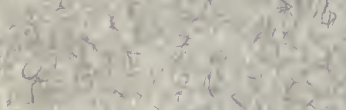

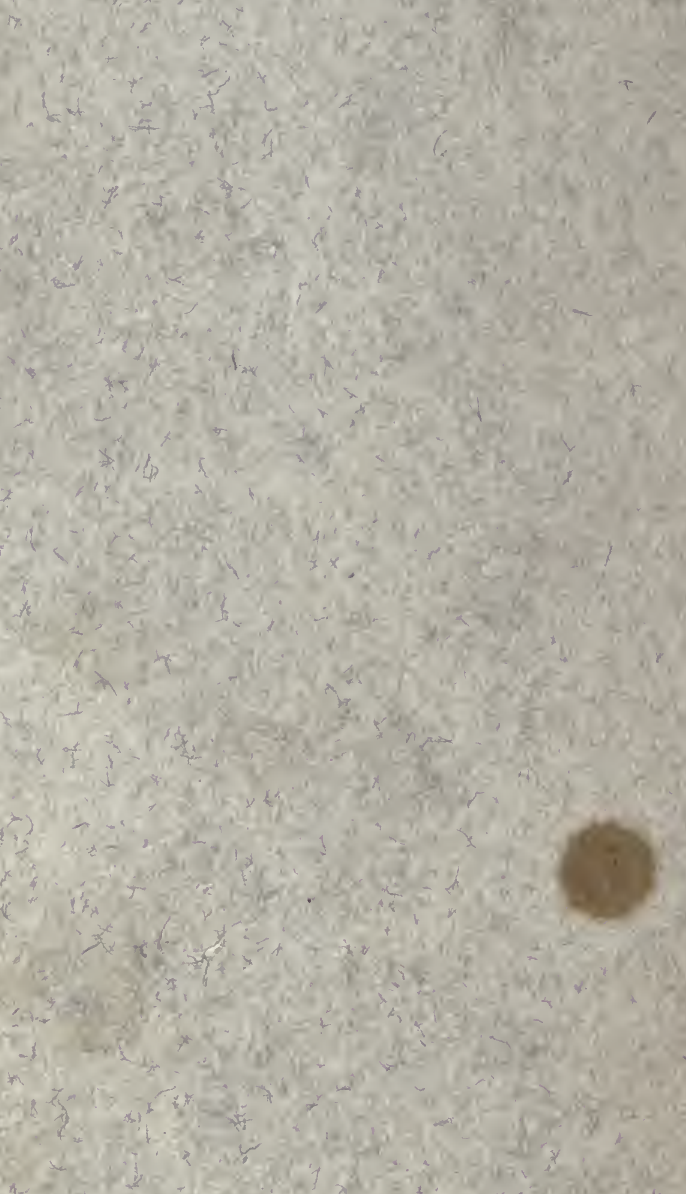

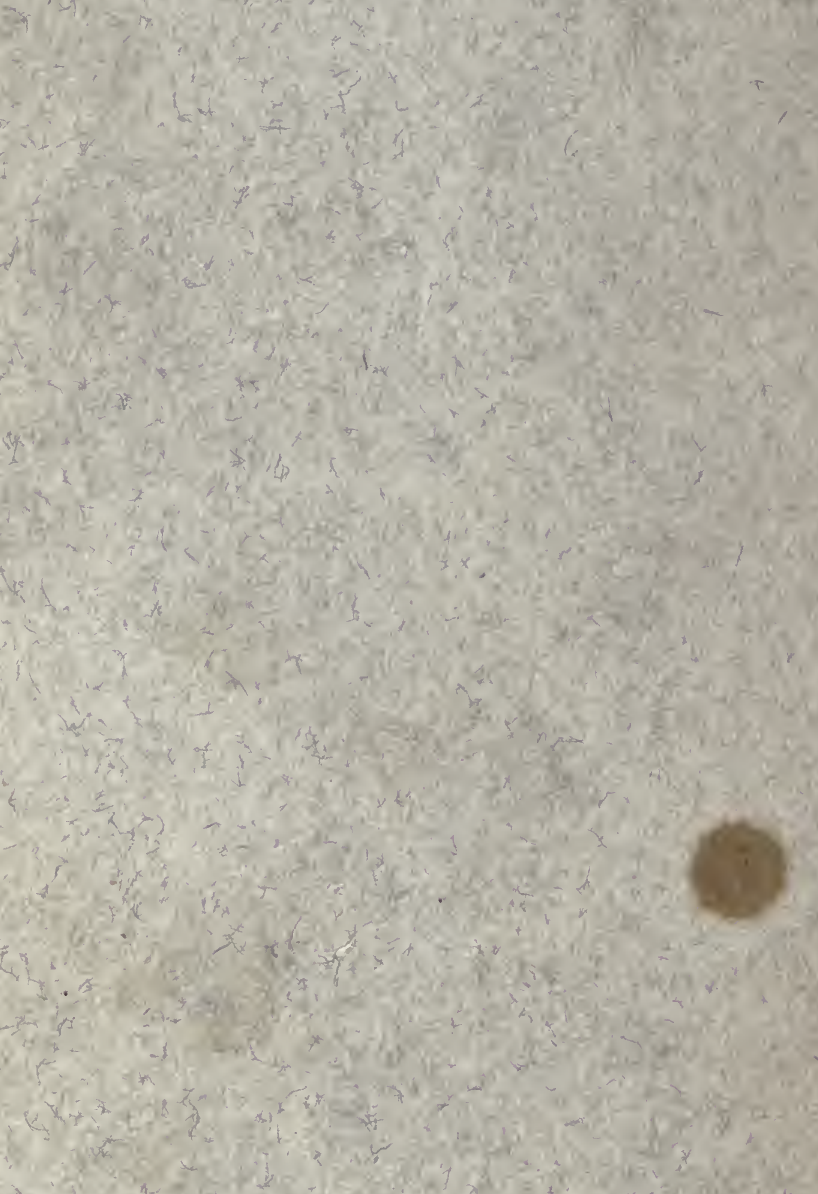

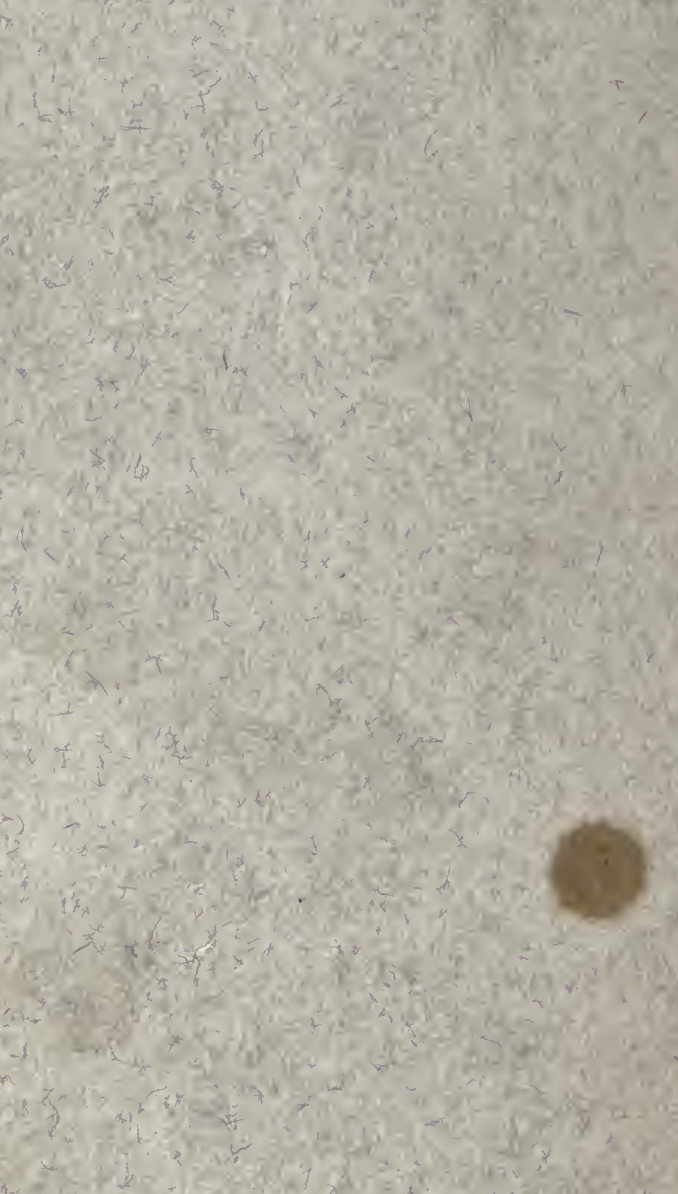

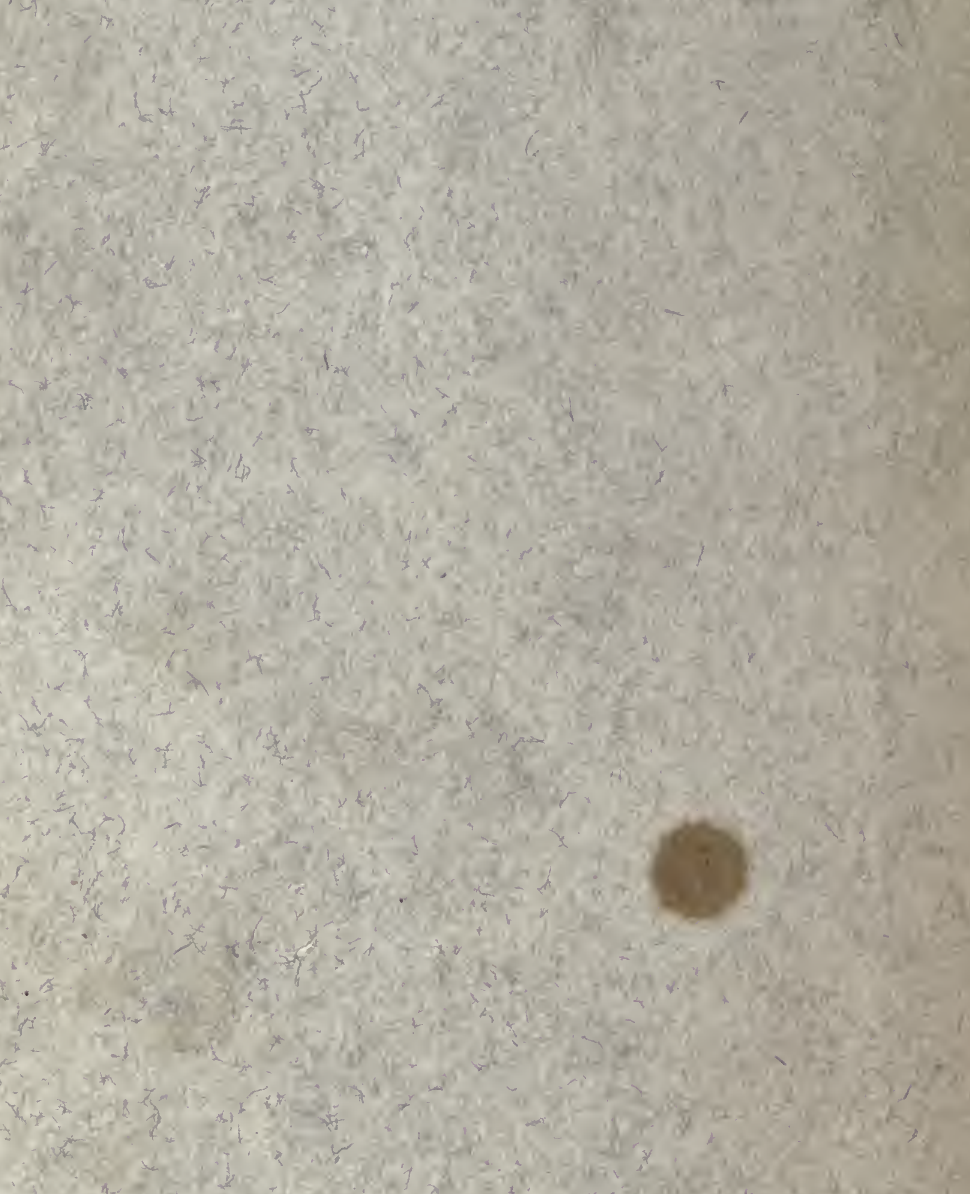

